Aus dem Institut für Medizinische Mikrobiologie

(Prof. Dr. med. U. Groß)

im Zentrum Hygiene und Humangenetik

der Medizinischen Fakultät der Universität Göttingen

\title{
Epidemiology and prevalence of oral candidiasis in HIV patients from Chad
}

\author{
INAUGURAL-DISSERTATION \\ zur Erlangung des Doktorgrades \\ der Medizinischen Fakultät der \\ Georg-August-Universität zu Göttingen
}

vorgelegt von

LILIANE TAVERNE-GHADWAL

aus

Böblingen

Göttingen 2015 
Dekan:

I. Berichterstatter: Prof. Dr. med. U. Gro $\beta$

II. Berichterstatter/-in: Prof. Dr. med. H. Schwörer

III. Berichterstatter/-in:

Tag der mündlichen Prüfung: 03.03.2016 


\section{TABLE OF CONTENTS}

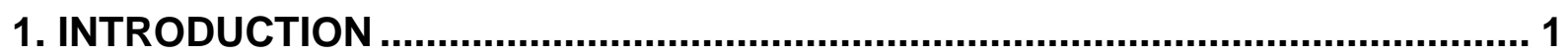

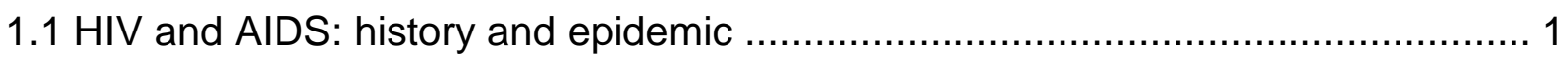

1.2 HIV transmission pathway and pathogenesis .............................................. 1

1.3 HIV/AIDS epidemic in Sub-Saharan Africa .................................................. 2

1.4 The importance of oral lesions in people living in Sub-Saharan Africa ................ 3

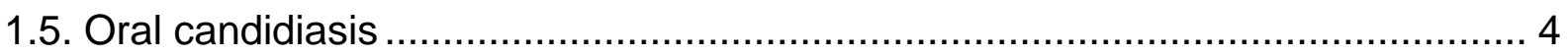

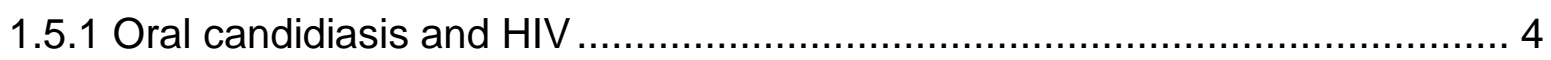

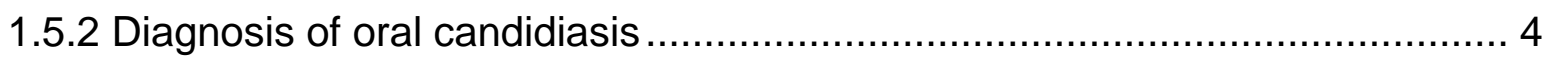

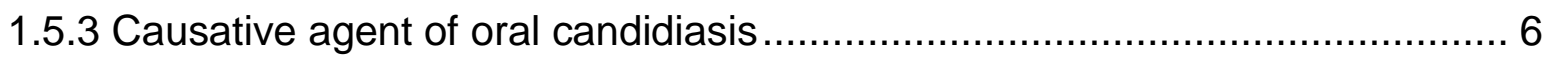

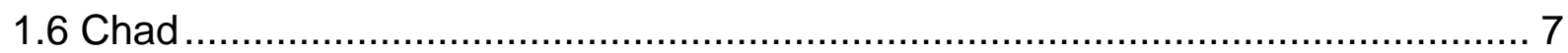

1.6.1 The country's geography, climate and population ...................................... 7

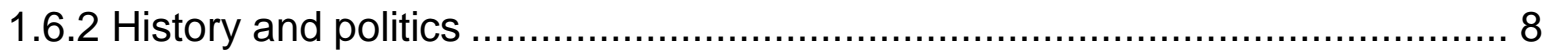

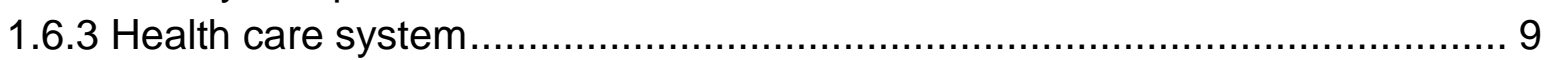

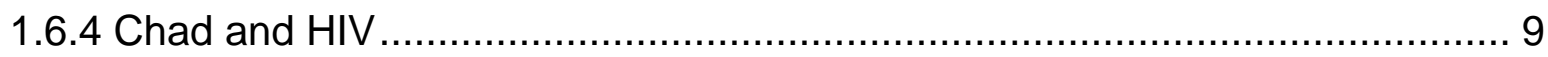

1.6.5 The clinic of Maingara in Sarh ............................................................ 10

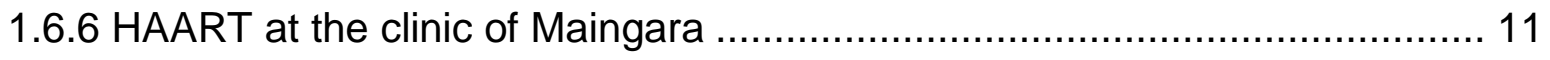

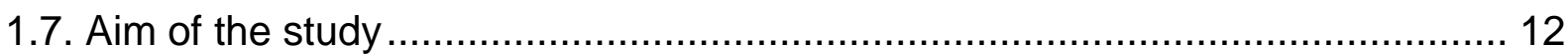

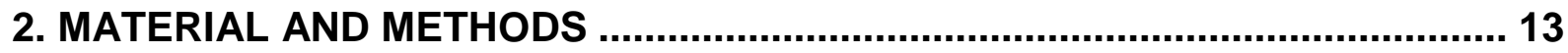

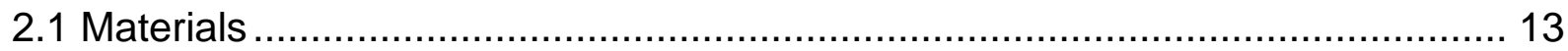

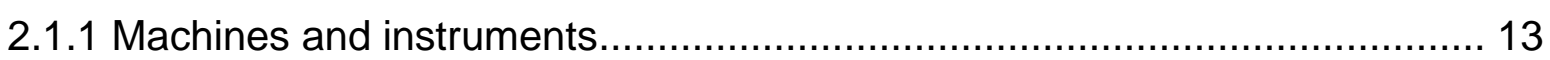

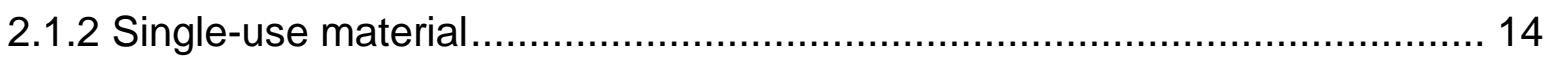

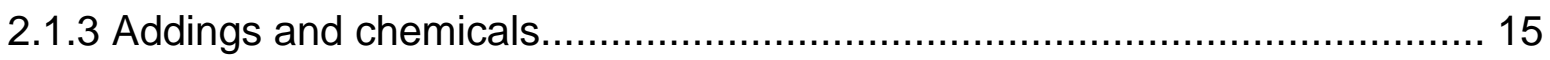

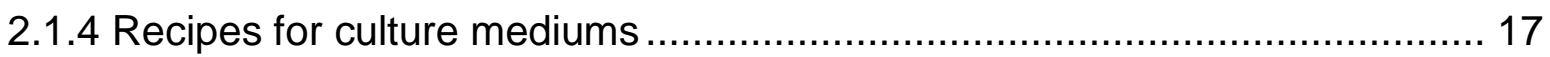

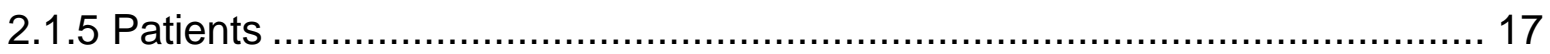

2.2 Methods and study procedure ……........................................................ 18

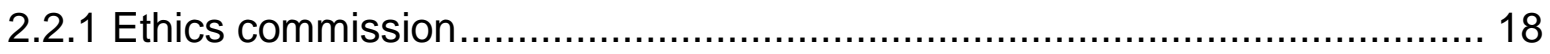

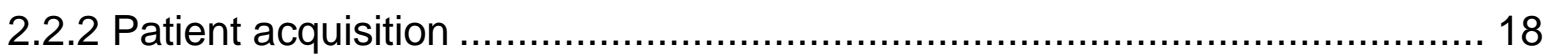

2.2.3 History taking and clinical inspection/examination..................................... 18

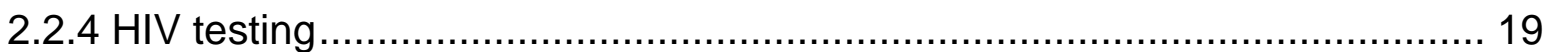

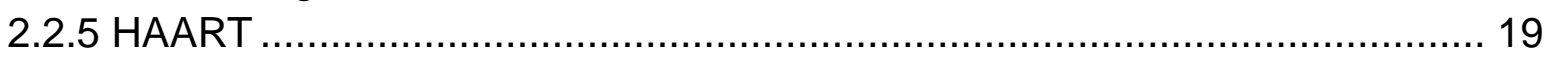

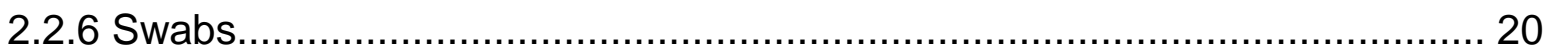

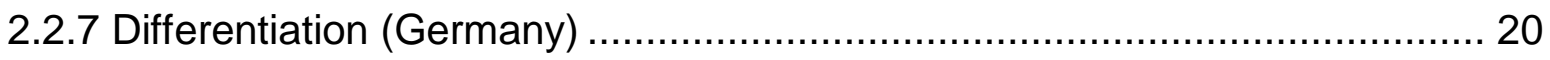


2.2.7.1 Microbiological and biochemical differentiation ................................. 21

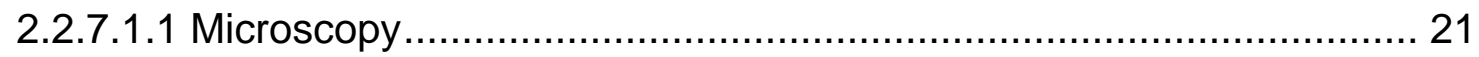

2.2.7.1.2 Rice agar, Staib agar and API ............................................. 21

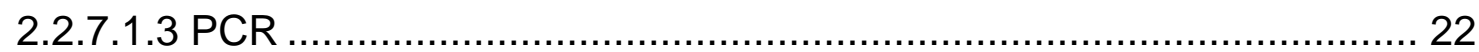

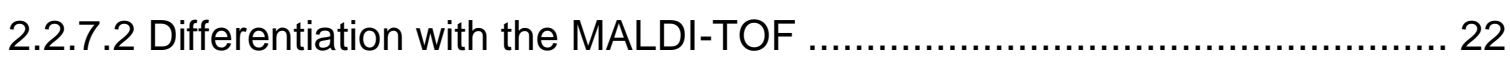

2.2.7.2.1 Bruker MALDI Biotyper 2.0 system ............................................ 22

2.2.7.2.2 AnagnosTec Saramis system ................................................ 23

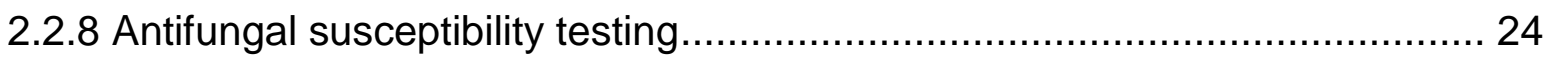

2.2.8.1 Broth mediums and preparation of the microdilution plates ................. 24

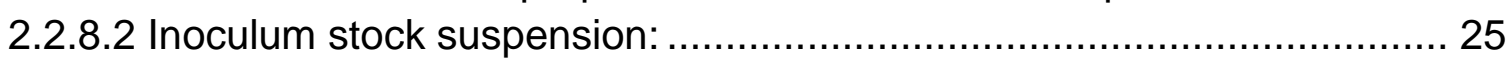

2.2.8.3 Working suspension and dispersion onto the plates: ........................... 25

2.2.8.4 Incubation and reading of the results ................................................ 25

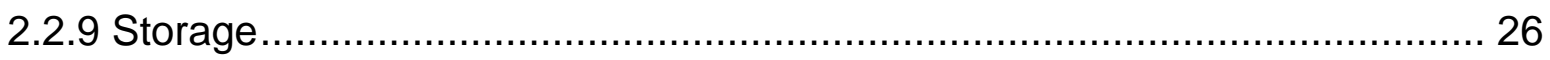

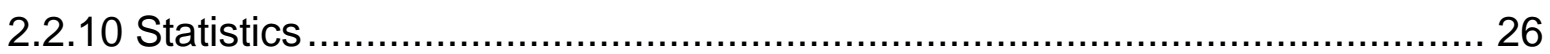

3. RESULTS

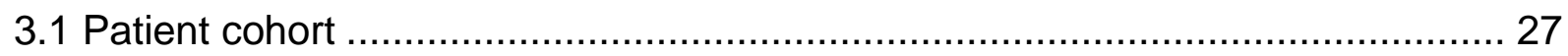

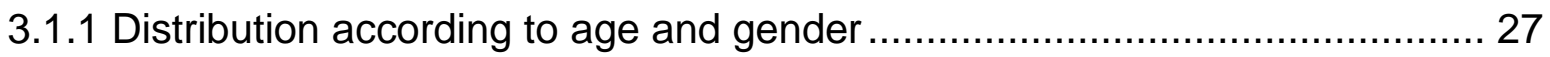

3.1.2 Distribution of the patients according to their HIV status ........................... 28

3.1.3 Gender distribution in the different subgroups ......................................... 28

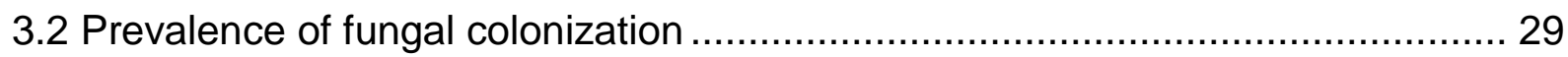

3.3 Degree of oral fungal burden in HIV-negative and -positive patients ................. 31

3.4 Classification of oral symptoms and diagnosis of oral candidiasis.................... 32

3.5 Prevalence of symptoms and oral yeast colonization in the different symptomatic

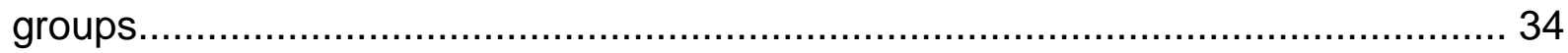

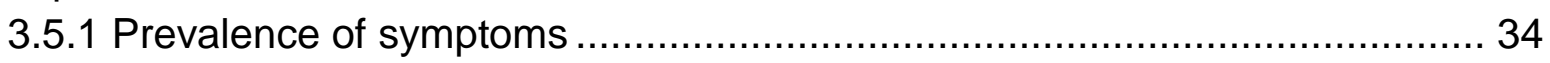

3.5.2 Prevalence of yeasts in the oral cavity of asymptomatic patients ................ 35

3.5.3. Prevalence of yeasts in the oral cavity of symptomatic patients .................. 35

3.6 Association between oral fungal burden and symptoms in the different subgroups

3.7 Prevalence of oral candidiasis in the different subgroups................................. 38

3.8 Prevalence of the different forms of oral candidiasis in HIV-positive patients..... 39

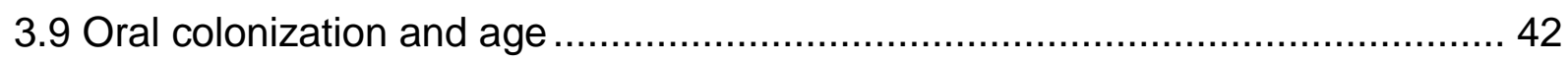

3.10 Oral yeast colonization and fungal burden in HIV-negative and -positive female and male patients 
3.12 Prevalence and distribution of yeast species

3.13 Association of CD4 T cell number with HAART, oral fungal burden, symptoms and yeast species

3.13.1 CD4 T cell counts and oral fungal burden

3.13.2 CD4 T cell counts in asymptomatic and symptomatic HIV-positive patients50

3.13.3 CD4 T cell counts, yeast species distribution and fungal burden 51

3.13.4 CD4 T cell counts, yeast species distribution and clinical symptoms .........54

3.13.5 Oral fungal burden, symptoms and species distribution with time of HAART

3.14 Efficacy of antimycotic treatment and antifungal drug susceptibility testing ..... 58

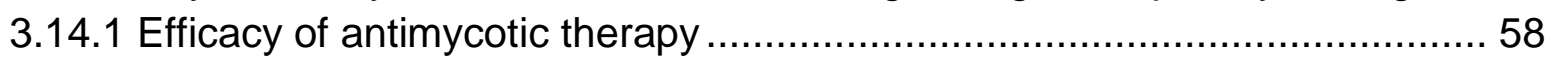

3.14.2 In vitro antifungal susceptibility of the isolated yeast species .................... 61

4. DISCUSSION

5. SUMMARY

6. APPENDIX

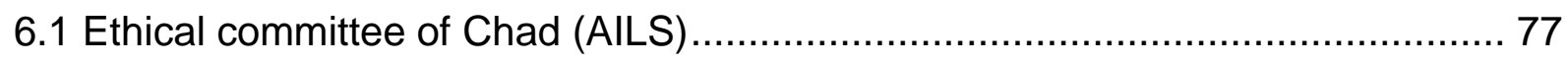

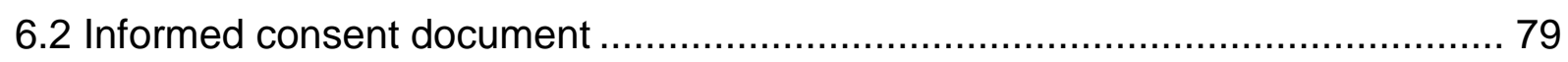

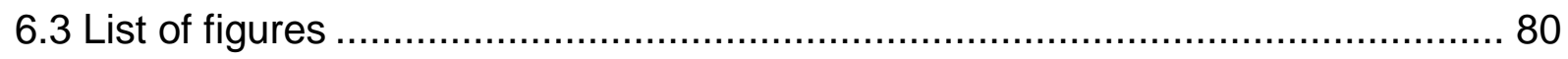

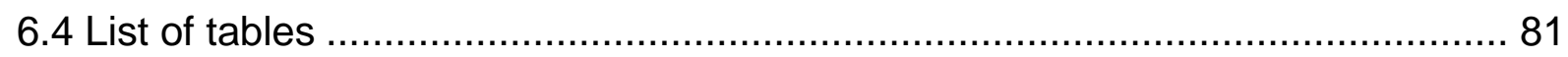

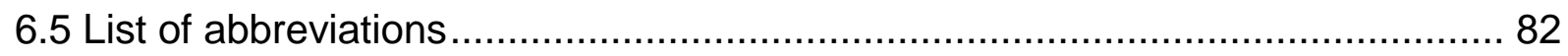

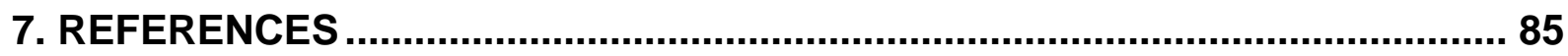




\section{Introduction}

\subsection{HIV and AIDS: history and epidemic}

The acquired immunodeficiency syndrome (AIDS) was recognized for the first time as a new disease in 1981, when the first clinical cases of AIDS were observed in a cluster of men who have sex with men and injecting drug users who presented with symptoms of Pneumocystis carinii infection, a rare opportunistic infection known to occur in people with a severely compromised immune system (Schliep and Yarrish 1999). Further symptoms were extensive mucosal candidiasis, cytomegalovirus infection and the development of rare malignancies as Kaposi's sarcoma (Gottlieb et al. 1981; Masur et al. 1981). In 1983, a retrovirus, which has later on been named the human immunodeficiency virus (HIV), was isolated and declared as the causative agent of the disease (Barre-Sinoussi et al. 1983; Gallo et al. 1984). Since its discovery, the disease has spread dramatically throughout the world and had infected over 38 million people by the year 2005 (UNAIDS 2006). Although the introduction of antiretroviral treatment in 1996 (Williams 1997) had led to a significant decrease of AIDS-related deaths (UNAIDS 2010), the HIV pandemic continues to be a big challenge in public health. In 2012, still 35.3 million people were living with HIV, 2.6 million new infections were occurring annually and still almost 2 million deaths per year were registered (UNAIDS 2013). Treatment still does not reach all affected people and even though a lot of prevention efforts have been done throughout the world, in some countries the epidemic continues to spread, due to obstacles as beliefs, value and education systems, ignorance, poverty, fear of discrimination, no access to a developed health care system and political instabilities within countries (UNAIDS 2010; UNAIDS 2013).

\subsection{HIV transmission pathway and pathogenesis}

"The $\mathrm{HI}$ virus is the causative agent of AIDS and AIDS is the end stage of a protracted pathogenic process in which the immune system of an infected person and its ability to control infections or malignant proliferative disorders are progressively destroyed" (Schüpbach 1999). 
The $\mathrm{HI}$ virus is transmitted through blood transfusions (infected blood products) contaminated drug injecting needles or shared razor blades, perinatal transmission (birth and breastfeeding) and unprotected sexual intercourse (sperm and vaginal secretions)(CDC 1985; Curran 1985). Sexual intercourse is the primary mode of HIV infection worldwide, followed by mother to child transmission and in some regions injecting drug users (UNAIDS 2007). The $\mathrm{HI}$ virus causes progressive immune failure by infecting and killing vital cells of the immune system, such as macrophages, dendritic cells and in particular CD4 T-helper cells, which are responsible for the cellmediated immune response. A decline of the CD4 T-helper cells below a critical level leads to a loss of adequate immune response and the body becomes progressively more susceptible to opportunistic infections (Ascher and Sheppard 1988; Levy 1993; Douek et al. 2009). Therefore, the measurement of CD4 T cell counts has become an important tool in the management and therapy of HIV-infected persons and is a criteria included in the CDC classification of HIV/AIDS (CDC 1992). AIDS is only the end stage of the progressive destruction of the human immune system, in which the host has become unable to defend itself against opportunistic infections (Schüpbach 1999).

\subsection{HIV/AIDS epidemic in Sub-Saharan Africa}

Nearly $95 \%$ of the people infected with HIV/AIDS live in the developing world and of all people infected worldwide, $70 \%$ live in Sub-Saharan Africa. $76 \%$ of all deaths related to AIDS occur in this region. The main affected group of individuals is those who are the most productive socially, reproductively and economically. Extinction of this group of people affects the country's economy and its further development. More than half the adults infected with HIV in Africa are women and there is also a high incidence of vertical transmission (UNAIDS 2013). The high incidence of infectious diseases (malaria, tuberculosis and others), poverty, malnutrition and limited access to health care worsens the situation of the HIV epidemic in Africa. HIV/AIDS remains one of the top leading causes of death in this region of the world (UNAIDS 2007). Main cause of AIDS death are the opportunistic infections (UNAIDS 2007). An opportunistic infection is defined as an infection which is caused by a microorganism normally non-pathogenic in healthy hosts, which acts as a pathogen under certain favorable circumstances such as a compromised immune system and causes 
infection (Symmers 1965). One of the most common opportunistic infections in HIV/AIDS is oral candidiasis (OC) (Scully et al. 1991; Samaranayake et al. 2002).

\subsection{The importance of oral lesions in people living in Sub- Saharan Africa}

Early detection, monitoring and treatment of individuals infected with HIV, besides prevention and information campaigns, is an important task in the fight against the HIV epidemic and the fatal consequences that the progress of this disease may have on a country.

As resources and diagnostic tools in Sub-Saharan Africa are very scarce, the inspection of the oral cavity often remains the only (and an important) detection tool of a possible HIV infection, noting that HIV infection and AIDS are highly associated with several oral lesions (Wanzala et al. 1989). One of them, OC, is still reported to be strongly associated with the HIV infection in Africa and also remains the most common oral lesions associated with HIV around the world (Damtie et al. 2013; Kumar et al. 2013; Naidu et al. 2013). It may be more severe in African than in similar patients in Western Europe (Enwonwu 1994; Curtis et al. 2012; De Beaudrap et al. 2013) and significantly impair the nutrition and quality of life of the HIV-infected people, leading to malnutrition and rapid disease progression (Hodgson and Rachanis 2002). This emphasizes the importance of the early detection of these oral lesions to improve the morbidity associated by offering appropriate treatment and reduce the fatal consequences of the progress and continuous spread of the disease. With the advent of the antiretrovirals, in places where this treatment has been introduced, rates of $\mathrm{OC}$ and AIDS-related deaths have been reported to decrease (Nkuize et al. 2010; De Beaudrap et al. 2013; Meless et al. 2014), potentially signalizing an improvement of the immune system under this regimen. But in many African countries the treatment coverage of patients in need of antiretrovirals remained for long insufficient; in many countries below $20 \%$, which accounts for only one quarter of the people living with HIV in Sub-Saharan Africa that had access to antiretroviral treatment in the year 2006 (UNAIDS 2006). Therefore OC remains highly prevalent among HIV-infected individuals in Africa (Kamiru and Naidoo 2002; Damtie et al. 2013; Okoje et al. 2013) and an important tool in the diagnostic and management of the disease (Ranganathan et al. 2004), as in most cases it can be diagnosed by its clinical appearance alone (Thompson et al. 2010). It gives a hint to 
HIV disease status, progression and eventual treatment failure (Greenspan 1997; Coogan et al. 2005).

\subsection{Oral candidiasis}

\subsubsection{Oral candidiasis and HIV}

OC, also known as "thrush" (Macher 1988), was included in the first descriptions of the acquired immune deficiency syndrome (AIDS) (Gottlieb et al. 1981; Klein et al. 1984; Fisher-Hoch and Hutwagner 1995), a state of disease caused by the HIV (Macher 1988). It is a common opportunistic infection in patients who suffer from this disease and one of the first clinical signs of a deteriorating immune system (Scully et al. 1991; Samaranayake et al. 2002). Therefore it has been included as a "symptomatic condition" highly associated with HIV infection in the CDC and WHO classification of HIV/AIDS (CDC 1992; WHO 2007); but it also affects patients with other immune disorders, patients undergoing chemotherapy against cancer (Baixench et al. 2008) or taking immunosuppressive drugs to protect transplanted organs, as well as sometimes healthy subjects (Gupta et al. 1994; Fisher-Hoch and Hutwagner 1995; Patterson 1999; Redding et al. 1999; Dongari-Bagtzoglou et al. 2009; Lopez-Pintor et al. 2013). Nevertheless it is more commonly seen in HIVinfected individuals and there seems to be a high association between the presence of the HIV and eventually the viral load, and appearance of OC (Schuman et al. 1998; Gottfredsson et al. 1999; Mercante et al. 2006; Fidel 2011; Cassone and Cauda 2012). OC is as well an indicator of severe immunosuppression (Klein et al. 1984; Schuman et al. 1998), correlating with CD4 T cell counts $<200$ CD4 T cells/ $\mu l$ (Mercante et al. 2006; Witzel et al. 2008). Infected individuals with the symptoms of OC progress more rapidly to AIDS and death than those without (Greenspan 1997). In a study of Lindan et al. (Lindan et al. 1992) in Kigali, Rwanda, the presence of a clinically detectable candidiasis in a known HIV-positive female was associated with a $40 \%$ risk of death within two years. Early recognition and treatment of these lesions are therefore very important in the management of HIV-infected patients.

\subsubsection{Diagnosis of oral candidiasis}

The diagnosis of $\mathrm{OC}$ has been based on the presumptive criteria set by the ECClearinghouse (ECC) classification in 1993, which has been and still is the most 
widely used classification in clinical and epidemiological studies (EC-Clearinghouse 1993; Patton et al. 2013). According to this classification, there are two different clinical types of OC that are distinguished: the pseudomembranous candidiasis (PC) which is the most usual form (Leao et al. 2009), described as "white or yellow spots or plaques" which may have thick creamy, curd-like appearance, "that may be located in any part of the oral cavity and can be wiped off to reveal an erythematous surface which may bleed" (EC-Clearinghouse 1993; Thompson et al. 2010). The second type is the erythematous candidiasis (EC) described as "red areas located on the palate or the dorsum of the tongue". Both types belong to the category of "lesions highly associated with HIV" (EC-Clearinghouse 1993). But there are also various other different clinical presentation forms of $O C$ known as: angular cheillitis (AC), median rhomboid glossitis (MRG), atrophic, nodular, plaque-like or hyperplastic candidiasis (Lalla et al. 2010; Tarcin 2011). All these forms may also be seen, but less frequent, although MRG and $A C$ have been cited by Gazzard and Smith as well to be common in HIV-infected people (Gazzard and Smith 1990). Anyhow, these other forms are not included in the ECC classification. Several attempts have been made to classify these forms beginning with Lehner in 1964, who distinguished between acute and chronic forms and ending with a revised classification of Lehner by Axell et al. in 1997 (Axell et al. 1997; Parihar 2011). This last classification better considers the different clinical subdivision and unusual variants of $\mathrm{OC}$.

It needs a trained and experienced medical personal to recognize and to distinguish between these different presentation forms. Sometimes these different forms may present as combinations (EC-Clearinghouse 1993) and some, like the atrophic form, occur in earlier stages and may frequently be missed or more difficult to diagnose (Gazzard and Smith 1990). OC may be quite often asymptomatic or accompanied by symptoms as cotton taste, dysgeusia or burning; it can furthermore spread to the esophagus (Tavitian et al. 1986; Gupta et al. 1994; Ally et al. 2001; Nishimura et al. 2013) and cause swallowing pain, or to other organs, which is associated with a high mortality rate (Gudlaugsson et al. 2003; Gautam et al. 2010). Systemic infection in HIV patients is rare but there are few case reports (Gautam et al. 2010; Anwar Khan 2012). 


\subsubsection{Causative agent of oral candidiasis}

The causative agent of $\mathrm{OC}$ is yeast fungi from the genus Candida. The yeast species Candida is a harmless commensal of the human which may colonize skin and mucous membranes like the gastrointestinal or urogenital tract. It is found in the oral flora of $15-60 \%$ of healthy individuals (Sanchez-Vargas et al. 2005a; Yang et al. 2011). It causes infection when there is a disturbance in the host's specific (humoral) and non-specific (cellular) defense systems and virulence genes of the normally commensal Candida are activated (Cannon et al. 1995; Sturtevant 2000; Cassone and Cauda 2012). It may then cause superficial infection of the skin or mucous membranes or penetrate into deeper tissue layers, and disseminate in the blood system and organs causing candidemia (Pfaller and Diekema 2007).

More than 200 species of Candida are known today, but only few are pathogenic to humans. Out of these, Candida albicans (C. albicans) has been described to be the main pathogen of oral and systemic candidiasis and remains until date the main pathogen in this context (Thompson et al. 2010). However, other non-C. albicans yeast species (spp.) like C. glabrata, Issatchenkia orientalis (I. orientalis/ C. krusei), C. tropicalis are increasingly being described to cause infection and they are becoming of increased importance as they show patterns of antifungal resistance to azoles, the antifungals still used as first line treatment (Krcmery and Barnes 2002; Snydman 2003; Nadagir et al. 2008; Bassetti et al. 2009; Pappas et al. 2009). Especially patients with extensive exposure to antifungals or recurrent $O C$ as it is in patients with advanced stages of AIDS are affected (Patel et al. 2006; Nadagir et al. 2008). A relatively new species closely related to $C$. albicans identified is $C$. dubliniensis. C. dubliniensis has been mainly recovered from the oral cavity of HIVinfected individuals and AIDS patients in association with OC (Sullivan et al. 1995; Coleman et al. 1997; Loreto et al. 2010). This species seems to be linked to HIV infection and may also be resistant to Fluconazole (Moran et al. 1997; Nadagir et al. 2008; Scheid et al. 2012). It is therefore important to be aware of the emerging new pathogens in this context. This rise in Candida species other than C. albicans and the continuous incidence of resistant species makes the management of the infection more and more difficult. Species determination and susceptibility testing should therefore be included in the management of the disease caused by these pathogens. 
This is a problem in settings where further diagnostic facilities to determine and differentiate species and perform resistance analysis are not available.

\subsection{Chad}

\subsubsection{The country's geography, climate and population}
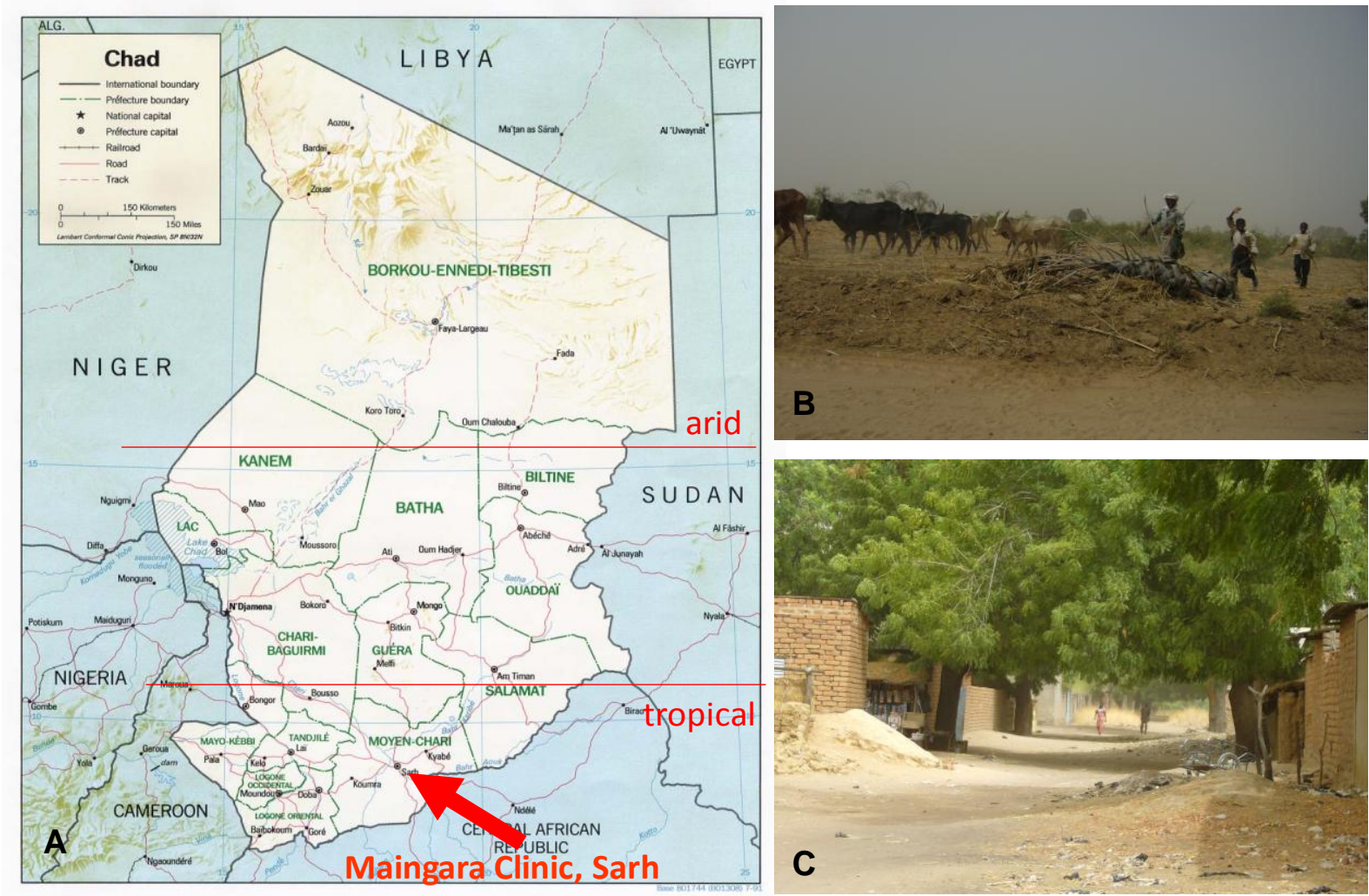

Figure 1: Map of Chad and landscape impressions. A. Map of Chad (from: http://www.loc.gov/item/91681423/, accessed 20.03.15). B. northern arid and C. southern tropical region. The clinic of Maingara, where the study took place was located in the southern tropical part of the country.

Chad is a land-locked country located in north central Africa measuring 1,284,000 square kilometers. In the language of the Buduma (an ethnic group who inhabits Lake Chad) it is called "big water" which refers to the Lake Chad, the second largest lake in West Africa and one of the most important wetlands on the African continent (Room 2008). It is enclosed by its neighbors: Libya in the north, Sudan in the east, Central African Republic in the south, Cameroon and Nigeria in the south-west and Niger in the north-west (Figure 1A). The population counts 11,193,452 inhabitants, of which most concentrate in the tropical south part of the country where the picture of wet savanna with an annual rainfall of 600-1200 mm/year dominates. The northern part is a Sahara-like region (dry savanna) with less than $200 \mathrm{~mm}$ of rainfall annually 
(Figure $1 \mathrm{~B}+\mathrm{C}$ ). The temperature varies between $13^{\circ} \mathrm{C}$ to $29^{\circ} \mathrm{C}$ in January and $25^{\circ} \mathrm{C}$ to $44^{\circ} \mathrm{C}$ in May in the northern part and between $15^{\circ} \mathrm{C}$ and $34^{\circ} \mathrm{C}$ in January and $23^{\circ} \mathrm{C}$ and $35^{\circ} \mathrm{C}$ in May in the southern part of the country (LCBC 2013).

Ndjamena is the capital with 808,000 inhabitants located at the west border of the country. The next biggest cities are Moundou, Sarh and Doba which are mainly concentrated in the south. Sarh is the third biggest city of Chad after Ndjamena and Moundou with around 100,000 inhabitants (http://www.geoba.se/population.php?cc= TD, accessed 19.06.14). The average population is very young with a median age of 16.9 years. $47 \%$ are under the age of 15 and only $2.9 \%$ are above 65 . Till 2010 , the life expectancy was 46 (WHO 2010).

$80 \%$ of the Chadians live in rural areas from agriculture (although only $4 \%$ of the country's land is arable) and subsistence economy. It is one of the poorest countries in the world [Ranking 184 of 186 in the Human development Index (HDI)] (UNDP 2013). The geographical circumstances influence the differences in the socioeconomic living styles. In the northern part of the country the population is largely nomadic. They have some livestock with mostly small ruminants and camels. In the southern part the population is more settled.

Chad has more than 200 different ethnic groups and more than 120 different languages and dialects. The biggest group is the Sara $(27.7 \%)$ settled in the southern part of the country which speaks Sara. Further $26 \%$ of the population speaks Arabic, one of the official languages of Chad. The other official language is French. The illiteracy rate is high: $76 \%$ among women and $55 \%$ among men (UNESCO 2012).

The majority of the population is Muslim (approx. 55\%) of which most live in the northern part of the country and speak Arabic. Further 35\% are Christian and are more concentrated in the southern part of the country. The rest belongs to traditional African religions (animist, 7\%) and others (CIA 2014).

\subsubsection{History and politics}

Chad became colonized in 1920 by the French and acquired its independence in 1960. Since, it has been marked by political instability with several civil wars and attempted coup d'états due to tensions between the Arab-Muslim north and Christian 
south. The Darfur crisis in the neighboring Sudan which started in 2003 also affected the nation's instability with hundreds and thousands of refugees cumulating at the Chadian border. Despite all Mr. Idriss Deby who became president in 1990 managed to stay in power until today (Prunier 2008; BBC 2015).

\subsubsection{Health care system}

The health care system in Chad is marginally developed and insufficient to provide the necessary health care needed. Only $30 \%$ of the population has access to the health care system (WHO 2010). The physician density is 0.04 per 1,000 inhabitants which are concentrated in the urban areas and the existing hospitals are only rudimentarily equipped. In this context especially in the rural area, traditional healing methods are being favored. The situation is worsened by the political conflicts in Darfur, Sudan and Central African Republic which have led to a refugee's movement especially in the southern-east part of the country. Furthermore food crisis, missing sanitation and water sources affect the country's development and economy.

\subsubsection{Chad and HIV}

In Chad, the HIV prevalence was about 3.3\% in 2007 and 2.7\% in 2012 (UNAIDS 2007 ; CNLS 2012; UNAIDS 2013). The distribution is inhomogeneous within the country with a prevalence of $2.3 \%$ in the rural and $7 \%$ in the urban area (UNGASS 2008). In the region of Sarh, the HIV prevalence of pregnant women was about $4 \%$ in 2012, and among sexual workers the prevalence was highest with 20\% (CNLS 2012). The main transmission pathway remains the heterosexual unprotected intercourse (including paid sex) and the vertical transmission pathway from mother to child and breastfeeding. As in the overall region, women are more affected than men; in Chad $4 \%$ compared to $2.6 \%$ within the same age group. In Chad this is particularly due to polygamy (UNGASS 2008).

The HIV prevalence is not yet as high as in other African countries, but multiple factors promote the spreading of the disease. These include poverty, religious and cultural taboos, ignorance and lack of knowledge about the modes of transmission of the disease ongoing with high prevalence of unprotected sex, illiteracy of women, sex workers, high prevalence of sexually transmitted diseases, a rudimentary insufficient health care system, and persistence of the internal and external political conflicts with 
the neighboring countries Sudan and Central African Republic which lead to a rising number of refugees at the south and south-eastern borders of Chad. In some regions it is reported that the prevalence may be as high as 10\% (UNAIDS 2009; CNLS 2012).

A lot of efforts are being done to elucidate the population and projects for the prevention of the transmission of the disease, detection and a close follow-up of the infected individuals are being established (UNGASS 2008; CNLS 2012). The creation of the "Centre de Santé de Maingara" in Sarh, Chad in 2004 was part of one of those projects.

\subsubsection{The clinic of Maingara in Sarh}

Maingara is a city district of Sarh. The clinic (Figure 2), in which we found a collaboration partner to conduct our study, was founded with the support of the BELACD (Bureau d'Études et de Liaison des Actions Caritatives et de Développement) of Sarh, a non-governmental national aid organization, and could open its activities in 2004 to offer counseling, HIV testing, treatment and follow-up for HIV-infected individuals.

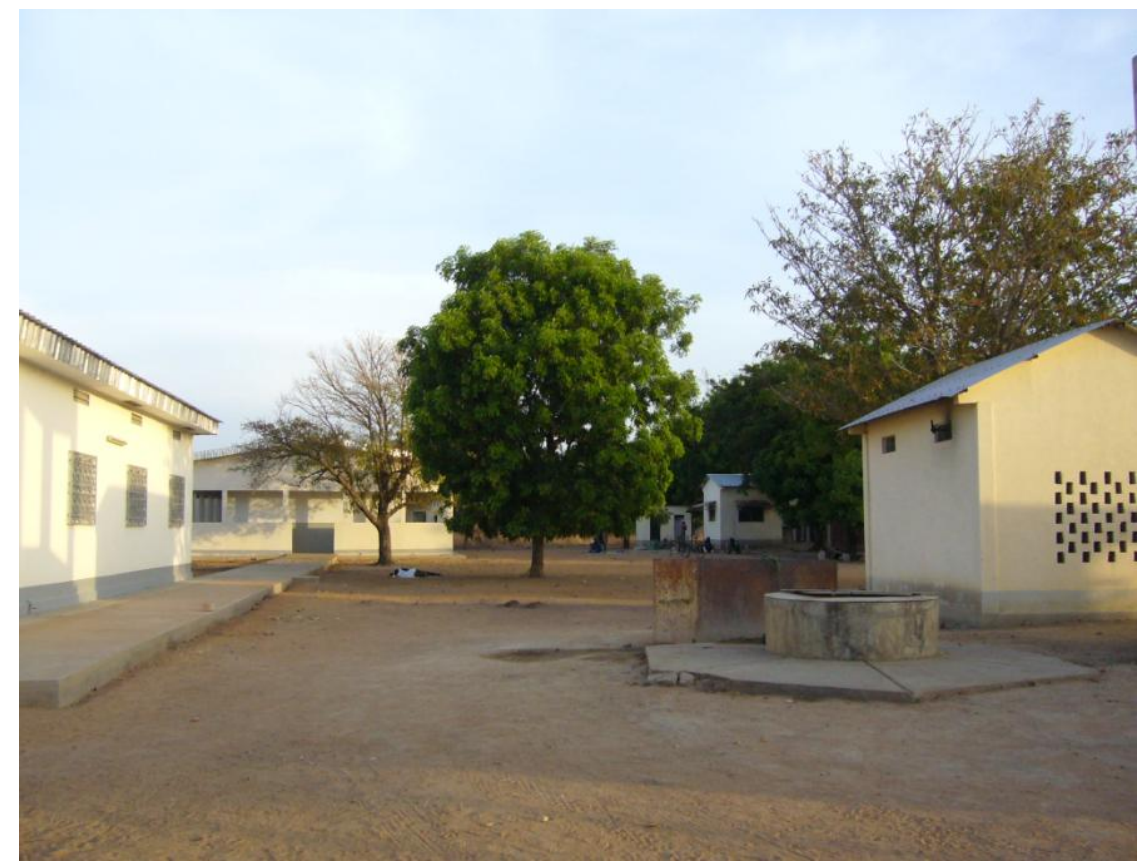

Figure 2: The clinic of Maingara

At the time of the study Dr. Lydia Kersch from Germany was the leading head of the center and the only doctor. The clinic team furthermore consisted of five trained 
nurses, two social workers, three trained assistants for lab diagnostics and a secretary for patients' registration and file establishment. There was a section for HIV screening and counseling with social attendance, a day clinic equipped with an ultrasound and ECG machine, a lab with a microscope, photometer, and a CD4 T cell counting machine. Since August 2005 it had furthermore been supplemented with 18 beds to receive and treat severely ill cases.

Due to the educational and awareness training especially among the analphabetic youth, schools and young couples in the surrounding villages of the parish and the installment of institutions able to receive and to take care of affected people, the number of people presenting for a screening test rose constantly and a decline in HIV seropositivity of the tested persons could be observed from 2004 to 2006 (42\% to 18.5\%) (Dr. L. Kersch personal communication).

By the year 2006 the clinic was taking care of 1279 affected individuals (18\% of the patients screened in Maingara) which were followed regularly at monthly intervals. $82 \%$ of the examined patients were in the reproductive age of 12 to 45 and 627 (49\%) were under antiretroviral treatment at that time. Of these, $89.4 \%$ had been followed regularly, $11 \%$ went out of sight and $7 \%$ went elsewhere.

By $2007,71.3 \%$ of the patients were under antiretroviral treatment. Female patients were in the majority (60\%) and also in the majority put under antiretroviral treatment. Still, the mortality rate in 2006 was high with $28.1 \%$ for the hospitalized patients and $15 \%$ for all the followed patients (Dr. L. Kersch personal communication).

Only a basic selection of drugs was available to treat and prevent the most common AIDS-related opportunistic diseases and diagnostic relied mainly on the clinician's subjective clinical impression. Antifungals were available in a very limited amount and therefore rarely prescribed.

\subsubsection{HAART at the clinic of Maingara}

The antiretroviral treatment available at the center was the highly active antiretroviral treatment (HAART) regimen. It is a combination of three antiretrovirals which was given according to the National Guidelines of Chad for antiretroviral therapy which refer to the WHO standards of 2006 (WHO 2006). The center was mainly financed by 
the parish of Sarh and its international and private donors. Patients of the day clinic also had to provide a small contribution of about 3000 Francs CFA (approx. 4.60€) in quarterly payments. As the government did not yet provide antiretrovirals for free until the year 2007, patients had to contribute partially to the treatment costs (5000 Francs CFA/approx. 7.60€ per month). In case of inability to pay, the medication was given on credit when already started. To avoid HAART interruption, the patients were informed about the danger and consequences of an interruption always in the presence of a family member and had to oblige themselves in written form to take the medication as prescribed and take a responsible behavior towards others before the start of the treatment. Furthermore medical records were established and social workers looked up for the patients under HAART in their homes if they did not appear to their regular control. Nevertheless, $8.2 \%$ had an interruption of more than 45 days (Dr. L. Kersch personal communication).

\subsection{Aim of the study}

In Chad, no data on the prevalence of OC or oral colonization with Candida species in HIV-infected and healthy subjects were available. Neither there was known which kind of Candida species colonize the oral cavity of the Chadian population or cause infection in HIV-immuno-compromised patients and if they are susceptible to the existing antifungals. The clinical importance of OC in association with HIV in Chad was therefore unclear.

The first aim of the study was to determine the type of the existing yeasts colonizing the oral cavity of the Chadian healthy and HIV-infected population and test their sensitivity to five common antifungals in use (Amphotericin B, Nystatin, Fluconazole, Itraconazole and Caspofungin) with the goal to give a picture of the current situation and eventually improve the management of the oral fungal burden of HIV/AIDS patients in that specific country. Furthermore we wanted to define the prevalence of $\mathrm{OC}$ in the HIV-infected and healthy population, and analyze the influence and association of other factors like age, sex, HAART and antimicrobial therapy and CD4 $\mathrm{T}$ cell counts on that opportunistic disease. 


\section{Material and methods}

\subsection{Materials}

\subsubsection{Machines and instruments}

Autoclave, steam sterilizer

unknown

AXIMA Assurance ${ }^{\mathrm{TM}}$ platform

Bruker MALDI Biotyper 2.0 ${ }^{\circledR}$

CD4 counter, cyFlow ${ }^{\circledast}$

Centrifuge, type 5417R

Dynex Revelation microplate reader

Incubator, type BB 6220 CU Heraeus ${ }^{\circledR}$ Thermo Fisher Scientific, Langenselbold, DE

Microscope

Multichannel pipet, Multipette ${ }^{\circledR}$-Plus

pH-meter, $\mathrm{HI} 221$

Photometer, Mac Farland ${ }^{\circledR}$

Pipets "Reference", type 4810;

0,5-10 $\mu \mathrm{l} ; 10-100 \mu \mathrm{l} ; 50-200 \mu \mathrm{l} ; 100-1000 \mu \mathrm{l}$

Pipet pump, Pipetus ${ }^{\circledR}$-Akku

Reading mirror, Microtiter ${ }^{\circledR}$
Zeiss, Jena, DE

Eppendorf, Hamburg, DE

HANNA Instruments, Vöhringen, DE

BioMérieux, Marcy, FR

Eppendorf, Hamburg, DE

Hirschmann, Eberstadt, DE 
Sterile bench BDK Luft- und Reinraumtechnik GmbH, Sonnenbuehl-Genkingen, DE

Vortex REAX-top

Weighing machine type BL 310

\subsubsection{Single-use material}

Cryobank system

Eppendorf tubes $0,5 \mathrm{ml}$ safe-lock

Eppendorf tubes 2,0 $\mathrm{ml}$ safe-lock

Flat bottom microdilution plates, 96 wells

Glas test tubes, round bottom

Glas test tubes, flat bottom

Graduated glas pipets $10 \mathrm{ml}, 20 \mathrm{ml}, 50 \mathrm{ml}$

Graduated cylinder $1000 \mathrm{ml}$

HIV testkits ImmunoComb ${ }^{\circledR}$ / Determine ${ }^{\circledR}$

Inoculating loop white $1 \mu$ l

Microscope slides and square cover glass

Pipet tips, blue, $1000 \mu \mathrm{l}$
Heidolph, Schwabach, DE

Sartorius, Göttingen, DE
Mast Diagnostica, Reinfeld, DE

Eppendorf, Hamburg, DE

Eppendorf, Hamburg, DE

Greiner, Kremsmünster, DE

Roth, Karlsruhe, DE

Roth, Karlsruhe, DE

Brand, Wertheim, DE

Roth, Karlsruhe, DE

Orgenics, Yavne, IL

Sarstedt, Nürmbrecht, DE

Knittel, Braunschweig, DE

Sarstedt, Nümbrecht, DE 
Pipet tips, yellow, $200 \mu \mathrm{l}$

Plastic test tubes $50 \mathrm{ml}$ with cap

QIAamp DNA MIni Kit

Rice agar

Sterile agar gel transport swabs

Sterile Combitips $5 \mathrm{ml}$

Sterile cotton swabs
Sarstedt, Nümbrecht, DE

Sarstedt, Nümbrecht, DE

Qiagen, Hilden, DE

Oxoid, Wesel, DE

Copan, Brescia, IT

Eppendorf, Hamburg, DE

Copan, Brescia, IT

Sterile-Filter Corning ${ }^{\circledR} 0,22 \mu \mathrm{m}$ (cellulose-acetate) Corning GmbH, Wiesbaden, DE

Sterile Plastic Petri Dish 90mm Ø with cover

Greiner, Kremsmünster, DE

\subsubsection{Addings and chemicals}

Agar (for STAIB-Agar)

Merck, Darmstadt, DE

Antibiotic Medium 3, AM3

Becton Dickinson $\mathrm{GmbH}$, Heidelberg, DE

A-D(+)-Glucose-Monohydrate

Roth, Karlsruhe, DE

Creatinine (for STAIB-Agar)

Merck, Darmstadt, DE

Dimethyl Sulfoxide, DMSO, Hybri-Max ${ }^{\circledR}$

Sigma-Aldrich, Steinheim, DE

Glucose

Roth, Karlsruhe, DE

Guizotia abyssinicia seed (for STAIB-Agar)

Merck, Darmstadt, DE 
$\mathrm{KH}_{2} \mathrm{PO}_{4}$, (for STAIB-Agar)

Natrium chloride $\mathrm{NaCl}$

3-(N-morpholino) propansulfonic acid, MOPS

Sabouraud powder medium

RPMI -1640 media

\section{Antibiotics}

Gentamicin (Merck,

Darmstadt, DE)

Chloramphenicol

(Sigma-Aldrich,

Steinheim, DE)
Merck, Darmstadt, DE

Merck, Darmstadt, DE

Sigma-Aldrich, Steinheim, DE

Merck, Darmstadt, DE

Sigma-Aldrich, Steinheim, DE

Stock

Final

concentration

$16 \mathrm{mg} / \mathrm{ml}$

$16 \mu \mathrm{g} / \mathrm{ml}$

$16 \mathrm{mg} / \mathrm{ml}$

$16 \mu \mathrm{g} / \mathrm{ml}$

\section{Antimycotics}

Amphotericin B

Sigma, Taufkirchen, DE

Caspofungin

MSD GmbH, Haar, DE

Fluconazole

Discovery Fine Chemicals, Bournemouth, UK

Itraconazole

Discovery Fine Chemicals, Bournemouth, UK

Nystatin

Sigma, Taufkirchen, DE 


\subsubsection{Recipes for culture mediums}

AM3

$17.5 \mathrm{~g} / \mathrm{l} \mathrm{AM3}$

$3 \mathrm{~g} / \mathrm{l}$ glucose

RPMI

$10.4 \mathrm{~g} / \mathrm{l} \mathrm{RPMI}$

$34.53 \mathrm{~g} / \mathrm{l}$ MOPS

$2 \mathrm{~g} / \mathrm{l}$ glucose

Sabouraud agar

$65 \mathrm{~g} / \mathrm{l} \mathrm{Sabouraud}$

$1 \mathrm{ml}$ Chloramphenicol (16mg/ml)

$1 \mathrm{ml}$ Gentamicin $(16 \mathrm{mg} / \mathrm{ml})$

Staib-Agar:

$5 \%$ pulverized Guizotia abyssinicia seed

$0.1 \%$ glucose

$0.1 \% \mathrm{KH}_{2} \mathrm{PO}_{4}$

$0.1 \%$ creatinine

$1.5 \%$ agar

\subsubsection{Patients}

Confirmed HIV-positive (HIV+) and -negative (HIV-) patients were recruited from the medical centre of Maingara in Sarh, Chad. As the majority of patients consulting at the clinic in Maingara were HIV-positive, a group of patients in a small dispensary $50 \mathrm{~km}$ away from Sarh was included to enlarge the control group. 


\subsection{Methods and study procedure}

\subsubsection{Ethics commission}

Before realization, the research proposal was presented and approved by the ethics commission of the Georg-August-University of Göttingen (Application- $N^{\circ}$ 21/06/07) and the participating institutions in Chad (see appendix). All patients involved in the study were orally informed about the aim of the study and asked for their agreement before implementation according to the Helsinki Declaration (WMA 2013).

\subsubsection{Patient acquisition}

All patients who presented for consultation at the clinic of Maingara in Sarh during the study period where orally informed (for the majority could not read or write) about the aim of the study (see appendix). Only those who gave their informed oral consent were included into the study, irrespectively of their age or sex. The majority was HIVinfected and came to their regular monthly health control, or had just been tested HIV-positive. To establish a control group, a group of patients had been seen in the "dispensary" (small health center) of Bemouli, in a rural area $50 \mathrm{~km}$ away from Sarh, a small health care point providing basic health attendance by a nurse for a normal population. Confirmed HIV-negative patients who presented at the clinic of Maingara were as well included.

\subsubsection{History taking and clinical inspection/examination}

After informing the patient about the study and getting his/her agreement, informations on the medical history, age, sex, HIV status, current opportunistic infections and medications, HAART, and the last CD4 T cell count were noted or taken from medical records. A brief clinical examination was done, the oral cavity inspected at day light additionally with a small torch and the observations noted. From patients presenting again during the study period, a consecutive sample and examination was taken to evaluate disease progression and effect of antimycotics or HAART if given. 


\subsubsection{HIV testing}

The HIV status of the patients was determined by a rapid test (Determine ${ }^{\circledR} \mathrm{HIV}-1 / 2$ ), and if positive it was confirmed through another rapid test kit (ImmunoComb ${ }^{\circledR}$ ॥ HIV $1 \& 2$ Bispot). If both were positive, the patient was considered HIV-positive.

\subsubsection{HAART}

The antiretroviral therapy available in Chad was TRIOMUNE $30^{\circledR}$ for patients with a body weight under $60 \mathrm{~kg}$ and TRIOMUNE $40^{\circledR}$ for patients above $60 \mathrm{~kg}$. TRIOMUNE is a combination of two nucleosid reverse transcriptase Inhibitors (NRTIs) Stavudine (30 or $40 \mathrm{mg}$ ), Lamivudine $(150 \mathrm{mg}$ ) and one non-nucleosid reverse transcriptase inhibitor (NNRTI) Nevirapine $(200 \mathrm{mg})$. The daily treatment regimen consisted of one tablet twice a day (WHOPAR 2011; NAM 2014) Patients received treatment according to the National Guidelines of Chad for antiretroviral therapy which had been based on the WHO Standards (WHO 2006). It was indicated when the patient had a CD4 T cell count $<200$ CD4 T cells/ $\mu$ l or was in a WHO clinical stage III or IV. Patients with a WHO clinical stage II could also get the therapy when CD4 T cells were between 200 and $350 \mathrm{CD} 4 \mathrm{~T}$ cells/ $\mu$ l (Table 1). In case of intolerability of Nevirapine or tuberculosis treatment with Rifampicin, patients received a combination with Efavirenz (NNTRI) and in very few cases of suspected therapy failure or Kaposi sarcoma, the protease inhibitor (PI) Indinavir was given.

Table 1: Indication for HAART according to the National Guidelines of Chad

\begin{tabular}{|l|l|l|l|l|}
\hline & $\begin{array}{l}\text { WHO } \\
\text { clinical stage I }\end{array}$ & $\begin{array}{l}\text { WHO } \\
\text { clinical stage II }\end{array}$ & $\begin{array}{l}\text { WHO } \\
\text { clinical stage III }\end{array}$ & $\begin{array}{l}\text { WHO } \\
\text { clinical stage IV }\end{array}$ \\
\hline CD4 T cells & & & & \\
\hline$\geq 350$ & no HAART & no HAART & HAART possible & HAART \\
\hline $200-350$ & no HAART & HAART possible & HAART & HAART \\
\hline$\leq 200$ & HAART & HAART & HAART & HAART \\
\hline
\end{tabular}




\subsubsection{Swabs}

The oral cavity of the patients was sampled by taking swabs with a sterile cotton swab from visible oral lesions or when no visible symptoms, going over tongue, palate and side cheek pockets. Each swab was directly inoculated onto $1 / 8^{\text {th }}$ of a Sabouraud (SAB) agar plate (Figure 3). Due to the lack of an incubator the plates were cultured over night at room temperature (approximately between $26^{\circ} \mathrm{C}$ and 28 ${ }^{\circ} \mathrm{C}$ at night time and $30-36^{\circ} \mathrm{C}$ at day time) in the time from April to June. The plates were controlled for the growth of yeasts after 24 and 48 hours. If positive, the number of colony-forming units (CFU) was counted. A culture counting from 1 to $15 \mathrm{CFU}$ was considered as "low fungal burden" (LFB) and a counting from above 15 CFU or confluent growth on a $1 / 8^{\text {th }}$ surface of the plate as "high fungal burden" (HFB). Samples of several colonies from each morphologically distinct appearance were stored on slant agar at $4^{\circ} \mathrm{C}$ until they were transferred to Germany, were they were recultivated and separated for further analysis. The samples were collected over a period of time of 3 months, between April and June 2007.

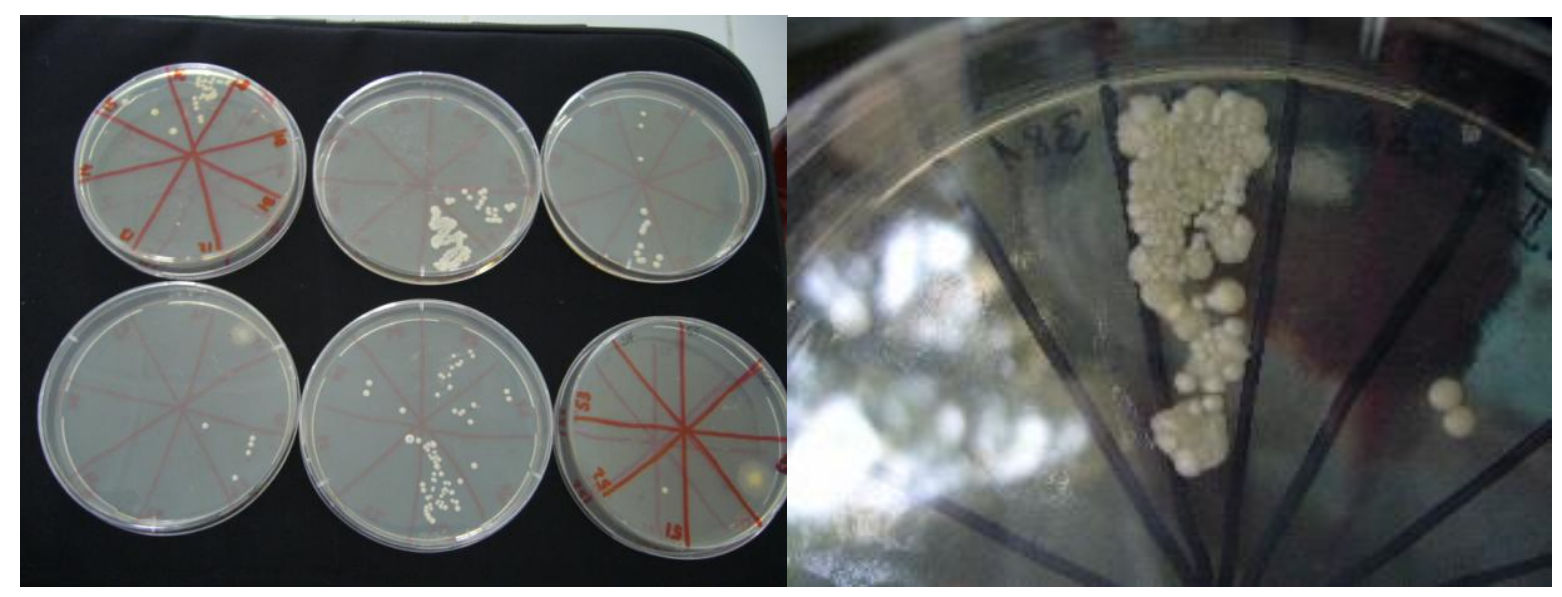

Figure 3: Growth of yeast on the agar plates from the direct smear of the patients. On each plate there was space for eight swab specimens. CFU were counted by hand. In the right picture confluent growth with mixed species.

\subsubsection{Differentiation (Germany)}

All collected samples were recultivated in Germany on Sabouraud agar. Swabs which presented apparent mixed cultures by colony morphology were separated and purified before differentiation. After verification and identification of yeasts under the microscope, two different methods were applied: the standard phenotypic methods 
with cultivation on different culture mediums, like rice and Staib agar, API differentiation kits, and in case of difficult identification polymerase chain reaction (PCR). Additionally, all samples were identified with two commercially available MALDI-TOF (Matrix Assisted Laser Desorption/Ionization Time Of Flight) identification systems: Bruker MALDI Biotyper 2.0 and AnagnosTec Saramis. Before use, all samples were cultivated over night at $37^{\circ} \mathrm{C}$ and in case of slow-growing organisms over two to three days.

\subsubsection{Microbiological and biochemical differentiation}

\subsection{Microscopy}

All isolated species were first identified as yeasts under the microscope by staining with methylene blue. Specimens with several colonies with distinct morphology were separated and purified before further differentiation process (Figure 4).

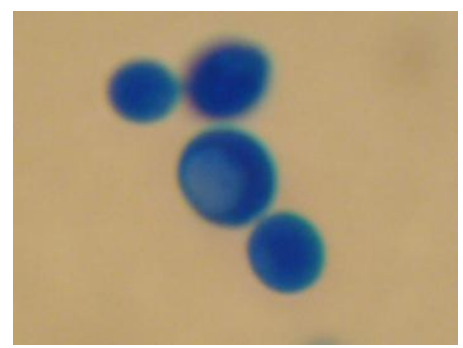

A. Microscopic image of yeasts

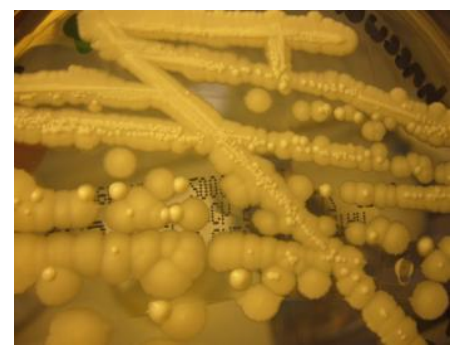

B. Mixed culture (on SAB agar)

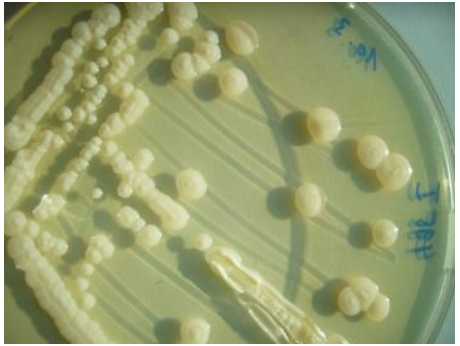

C. Purified culture (on SAB agar)

Figure 4: Images of yeasts and yeast culture. A.Typical ellipsoid shape of living yeasts stained with methylene blue under the microscope (X1000). B. Growth of two morphologically distinct yeasts (C. albicans (opaque) and $I$. orientalis (dull) on SAB agar. C.Purified yeast culture ( $P$. fabianii) with visible colonies.

\subsection{Rice agar, Staib agar and API}

All species identified as yeasts were cultivated on rice-tween agar covered with a glass slide (semi-anaerobic conditions) at $26.5^{\circ} \mathrm{C}$ for $48 \mathrm{~h}$ and checked for the growth of chlamydospores and pseudomycelium under the microscope (Figure 5). The isolates with visible growth of chlamydospores were again cultivated in the same way on Staib agar to differentiate between C. albicans and C. dubliniensis (Staib and Morschhauser 1999; Loreto et al. 2010). All the other isolates were differentiated with the API system (API $32 \mathrm{C}$ and API $20 \mathrm{C} \mathrm{AUX)} \mathrm{and} \mathrm{in} \mathrm{case} \mathrm{of} \mathrm{difficult} \mathrm{identification} \mathrm{a}$ PCR had been performed. 


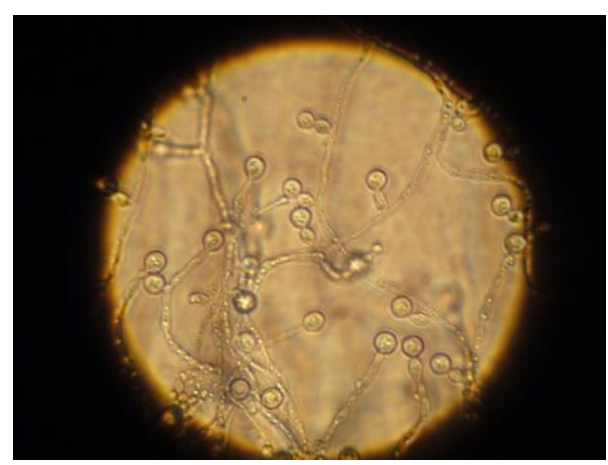

Figure 5: Chlamydospore formation by $C$. albicans on rice-tween agar. Induced pseudomycelium and chlamydospores formation by $C$. albicans on rice-tween agar.

\subsection{PCR}

For the samples that could not be identified by the biochemical standard methods, a PCR was performed to amplify the ITS2 rDNA region followed by sequencing of the PCR product (Chen et al. 2000). Fungal DNA from a single large colony was isolated with the QIAamp DNA Mini Kit. The ITS2 rDNA region was amplified and the product sequenced (SeqLab, Göttingen, Germany) and identified in the CBS yeast sequence database (http://www.cbs.knaw.nl/, accessed 20.05.14).

\subsubsection{Differentiation with the MALDI-TOF}

For the confirmation of the species identification, two MALDI-TOF systems were available for an evaluation period and the strains were included into that study (Bader et al. 2011).

\subsubsection{Bruker MALDI Biotyper 2.0 system}

For yeast identification (Bader et al. 2011) with the MALDI BioTyper 2.0 system (Figure 6), cells of approximately five colonies from Sabouraud agar plates were suspended in $300 \mu \mathrm{l}$ water and inactivated by addition of $900 \mu \mathrm{l} 96 \%$ ethanol. The cells were spun down and the pellet air dried at room temperature, resuspended in $50 \mu \mathrm{l} 70 \%$ formic acid and extracted by addition of an equal volume of acetonitrile and thorough mixing. Cellular debris were removed by centrifugation $(17,000 \times \mathrm{g}$ for 2 $\min$ ), $1 \mu \mathrm{l}$ of the clear supernatant was spotted onto a polished steel carrier (Figure 6), allowed to dry, overlaid with $1 \mu \mathrm{l}$ of HCCA matrix (saturated solution of a-cyano-4hydroxycinnamic acid in $50 \%$ acetonitrile, $2.5 \%$ trifluoroacetic acid, Bruker Daltonics) and allowed to dry again. The matrix could be stored for a maximum of two weeks at room temperature in a dark container. 
Measurement was done with the MALDI BioTyper 2.0 (library version 3.0) and FlexControl software on a Microflex LT20 mass spectrometer (20 Hz nitrogen laser), using a bacterial test standard (Bruker Daltonics) as a molecular weight standard. Spectra were detected in positive linear mode, mass range $2-20 \mathrm{kDa}$. Intensity of the laser was controlled by the FlexControl software driven in automatic mode, at the settings recommended by the manufacturer. Only species identifications with scores $>2.000$ were accepted, but proposed identifications at the genus level only were rejected.

\subsection{AnagnosTec Saramis system}

For yeast identification (Bader et al. 2011) with the Saramis system ("Spectral Archive and Microbial Identification System"), cells from a single colony on a Sabouraud agar plate were directly applied onto the steel carrier, dried for a short time ( $2 \mathrm{~min}$ ) and lysed by suspension in $0.5 \mu \mathrm{l} 25 \%$ formic acid. The sample was allowed to air dry at room temperature, overlaid with $1 \mu \mathrm{I} \mathrm{HCCA} \mathrm{matrix} \mathrm{(saturated}$ solution of $\alpha$-cyano-4-hydroxycinnamic acid in acetonitrile:ethanol:water 1:1:1 acidified with $3 \% \mathrm{v} / \mathrm{v}$ trifluoroacetic acid) (AnagnosTec) and again allowed to air dry.

Measurement was done on an AXIMA Assurance ${ }^{\mathrm{TM}}$ platform in positive linear mode, mass range $2-20 \mathrm{kDa}$, using E. coli strain CCUG 10979 as a molecular weight standard. Intensity of the $50 \mathrm{~Hz}$ nitrogen laser was under control of the acquisition software, at the settings recommended by the manufacturer. Only hits within the Superspectra database (Saramis ${ }^{\text {TM }}$ Premium, version 3.3.1) with scores $>80 \%$ were accepted, but identifications proposed from the single spectra database were excluded. 


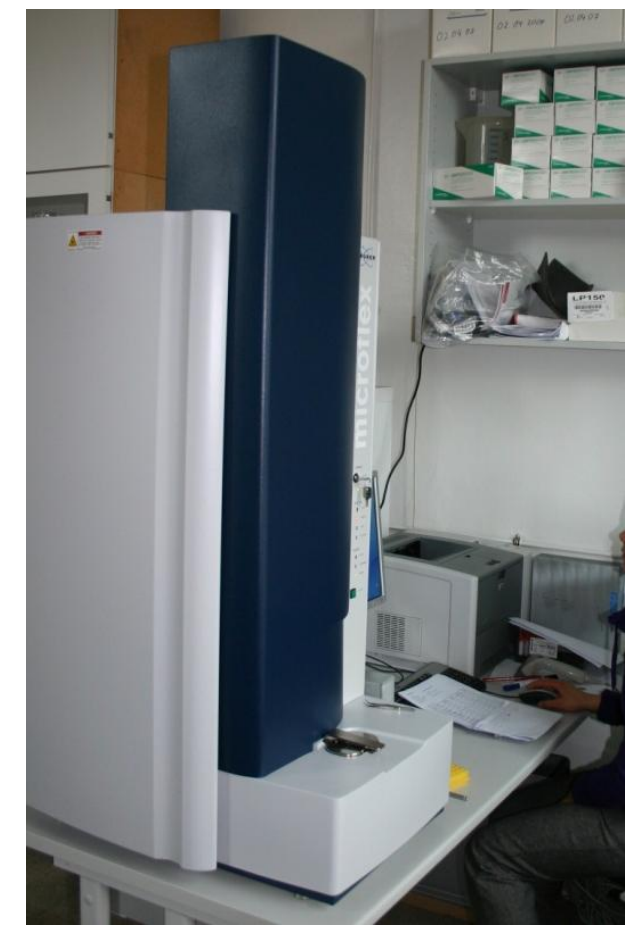

Bruker MALDI Biotyper 2.0 system

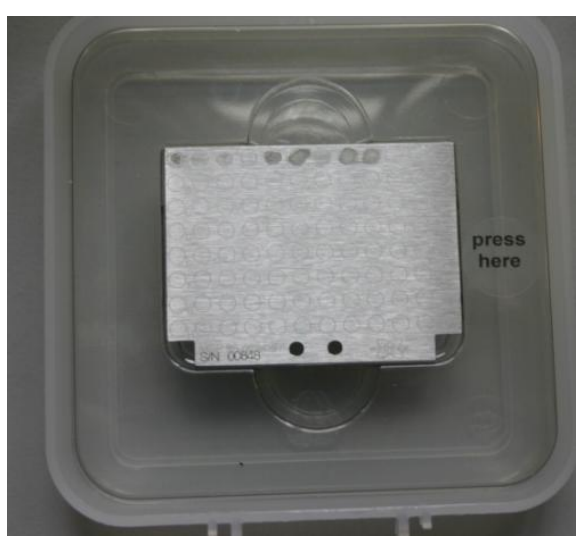

Polished steel carrier

Figure 6: MALDI Biotyper 2.0 system

\subsubsection{Antifungal susceptibility testing}

Antifungal susceptibility testing of the isolates obtained in this study was done according to the NCCLS reference method for broth dilution antifungal susceptibility testing of yeast; Approved Standard, M27-A2 (Guidelines of the Clinical and Laboratory Standard Institute, CLSI) (NCCLS 2002). The antifungals tested were Fluconazole, Itraconazole, Nystatin, Amphotericin B and Caspofungin.

\subsubsection{Broth mediums and preparation of the microdilution plates}

The broth microdilution test was performed in sterile microdilution plates with 96 flat bottom wells (Greiner). The broth mediums used were RPMI 1640 buffered with morpholinepropanesulfonic acid (MOPS) to a pH of 7.0 at room temperature $\left(21.3^{\circ} \mathrm{C}\right)$ and AM3 (Antibiotic Medium 3). The RPMI 1640 medium was being used for the testing of Caspofungin and the azoles and the AM3 medium for the testing of Amphotericin B and Nystatin. Amphotericin B, Nystatin and Itraconazole were dissolved in dimethyl sulfoxide (DMSO), Fluconazole in methanol and Caspofungin in water. The final drug concentration for the microdilution plates was prepared and 
adapted for each antifungal agent according to the MIC (minimal inhibiting concentration) ranges described in the NCCLS protocol $(0.063-1.5 \mu \mathrm{g} / \mathrm{ml}$ for Amphotericin B, $0.016-24 \mu \mathrm{g} / \mathrm{ml}$ for Nystatin, $0.016-16 \mu \mathrm{g} / \mathrm{ml}$ for Caspofungin and Itraconazole, and $0.250-256 \mu \mathrm{g} / \mathrm{ml}$ for Fluconazole). $100 \mu \mathrm{l}$ of medium with the highest drug concentration was dispensed into the wells of column 1 , column 11 contained the lowest concentration and column 12 served as the positive growth control, containing $100 \mu \mathrm{l}$ of a sterile drug-free medium. The trays were stored at $-70^{\circ} \mathrm{C}$ and thawed one hour before use.

\subsubsection{Inoculum stock suspension:}

The inoculum used was prepared from colonies cultured for $24 \mathrm{~h}$ under aerobic conditions at $37^{\circ} \mathrm{C}$, which were suspended in sterile saline $(\mathrm{NaCl})$. The turbidity was adjusted with a spectrophotometer to a value of $0.5 \mathrm{McF}$ arland.

\subsubsection{Working suspension and dispersion onto the plates:}

The final working suspension was prepared by diluting $1: 100$ in physiological $\mathrm{NaCl}$ followed by a 1:20 dilution in RPMI 1640 medium for Caspofungin and the azoles and in AM3 medium for Nystatin and Amphotericin B. The inoculum had $5 \times 10^{2}$ to $2,5 \times 10^{3}$ cells per $\mathrm{ml}$.

The wells were dispensed with $100 \mu \mathrm{l}$ of the prepared inoculum suspensions with a multichannel pipette, starting with the positive control well going downwards in the row. For the quality control of the plates, the strains recommended by CLSI (C. parapsilosis (ATCC 22019) and I. orientalis (ATCC 6258) were included in the testing procedure.

\subsubsection{Incubation and reading of the results}

The plates were incubated in a humid box at $36-37^{\circ} \mathrm{C}$ and analyzed after 48 hours for the presence or absence of visible growth with the help of a reading mirror. The growth of each well was compared to the growth control well and noted down as visible growth, low visible growth, no growth or contamination. Furthermore, the cells in each well were resuspended with a pipette and the optical density at $60 \mathrm{~nm}$ (OD $600)$ measured with a microplate spectrophotometer. The results were then compared with the results of the visual reading to evaluate and control the plausibility of the measured results. The minimal inhibitory concentration (MIC) for Amphotericin 
B and Nystatin was defined as the lowest concentration in which at least $90 \%$ of growth of the sample was inhibited, defined as $\mathrm{MIC}_{90}$, for Caspofungin and the azoles, as the lowest concentration in which at least $50 \%$ of growth was inhibited $\left(\mathrm{MIC}_{50}\right)$.

To minimize deviation, each organism was tested 2 to 4 times and the average MIC was calculated. An isolate was considered resistant if the average MIC was greater than their respective CLSI clinical breakpoints ( $\geq 64 \mu \mathrm{g} / \mathrm{ml}$ for Fluconazole, $\geq 1 \mu \mathrm{g} / \mathrm{ml}$ for Amphotericin B and Itraconazole). For Nystatin and Caspofungin no clinical breakpoints have yet been defined.

\subsubsection{Storage}

All isolates were stored in a Cryobank (Mast Diagnostica ${ }^{\circledR}$ ) - System at $-70^{\circ} \mathrm{C}$.

\subsubsection{Statistics}

Statistical significance was calculated using Student's T-test for quantitative variables, Chi-Square test for percentages and for small samples sizes the Fisher's exact test, where $p$-values $<0.05$ were considered as significant. 


\section{Results}

\subsection{Patient cohort}

\subsubsection{Distribution according to age and gender}

A total number of 589 patients were seen during the study period. The age distribution was between two and 70 years, whereas the majority of the patients was between 19 and 35 years old $(n=263)$. The average age was 34 in Maingara and 28 in Bemouli. Children below 12 years of age were represented in Maingara with 1.2\% $(n=5)$ and $2.0 \%(n=3)$ in Bemouli. From the five children in Maingara, two were HIVpositive and three HIV-negative. Seven patients were above the age of 60: three from Maingara, out of which one patient was HIV-positive. For a small fraction of patients the exact age remained unknown. In all age groups, female patients were dominant. In total, the distribution consisted of $73.5 \%(n=433)$ female and $26.5 \%$ $(n=156)$ male patients (Figure 7$)$.

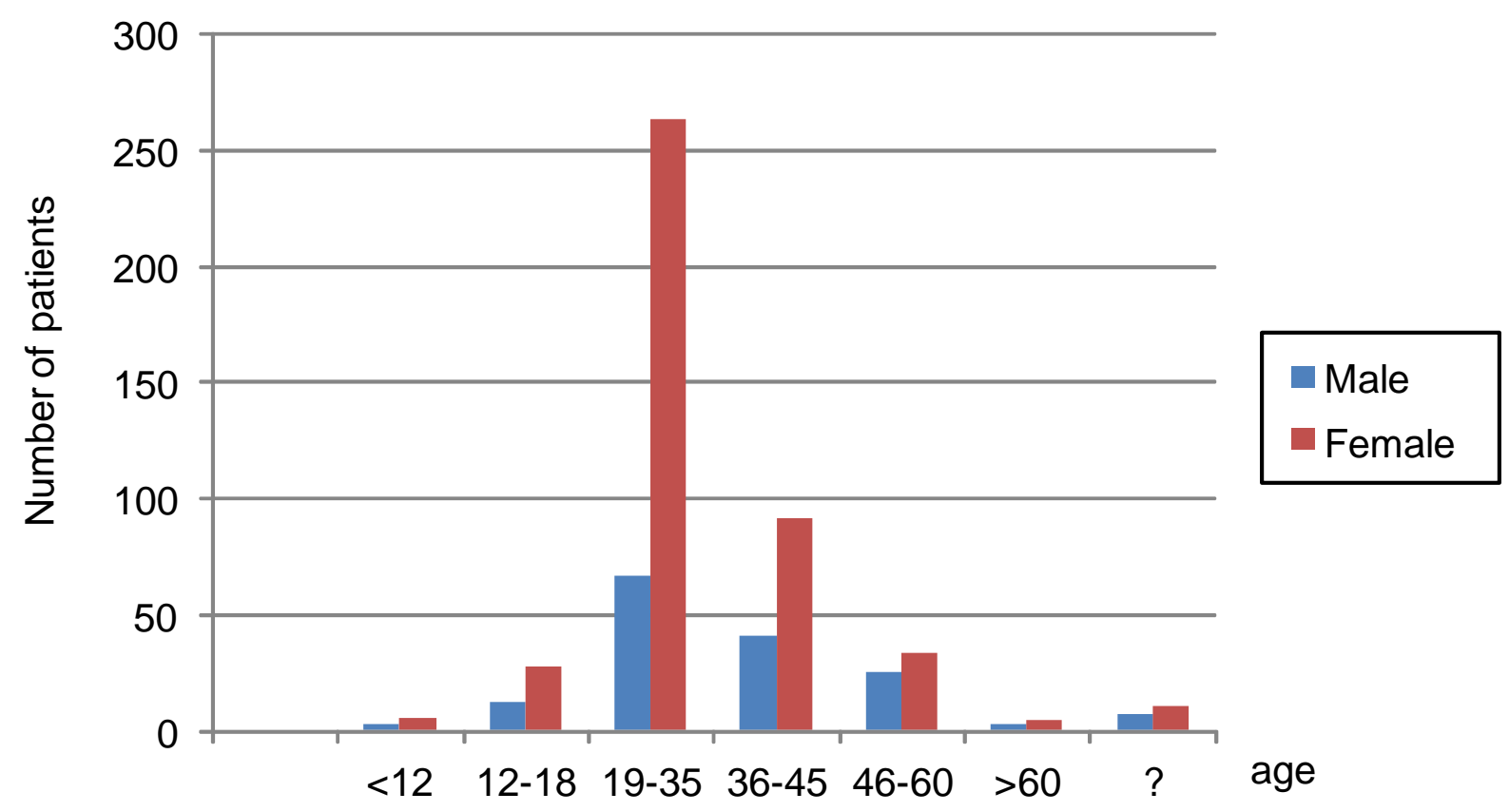

Figure 7: Distribution of the patients according to their age and gender in the general cohort. Patients aged 19-35 (mean 34) and the female gender was most represented. 


\subsubsection{Distribution of the patients according to their HIV status}

From the total number of 589 patients consulted, 441 were from the clinic in Maingara and 148 from the medical dispensary (health center) in the village of Bemouli. From the cohort consulted in Maingara, 384 (87.1\%) patients were HIVpositive. The patients for the control group of HIV-negative patients were recruited from Maingara (27.8\%; $n=57)$ and Bemouli $(72.2 \% ; n=148)$.

For the majority, patients recruited from Bemouli remained untested. HIV testing had not been performed among these patients, due to ethical considerations, as the medical dispensary was a small normal health care point providing basic health attendance by a nurse for a normal population. HIV prevalence in rural areas of Chad was very low and affected individuals or severe ill cases used to directly go to the specialized centers or hospitals in the urban area (CNLS 2012). The cohort of patients from Bemouli was therefore presumed to be HIV-negative. In the eleven cases of the patients where yeast growth was observed, HIV testing was performed, after their informed consent. All were confirmed to be HIV-negative, supporting the assumption that this clientele could be used as an additional HIV-negative control group. Furthermore clinical oral impression was without suspicious peculiarities. Patients from Bemouli were therefore considered HIV-negative for the purpose of this study and as there were no relevant significant differences between the HIV-negative patients from Maingara and Bemouli, these patients were combined into one group.

\subsubsection{Gender distribution in the different subgroups}

As in the overall cohort, in the HIV-positive and HIV-negative group female patients were most represented with $75 \%(n=287)$ in the HIV-positive and $71 \%(n=146)$ in the HIV-negative group (Figure 8). 


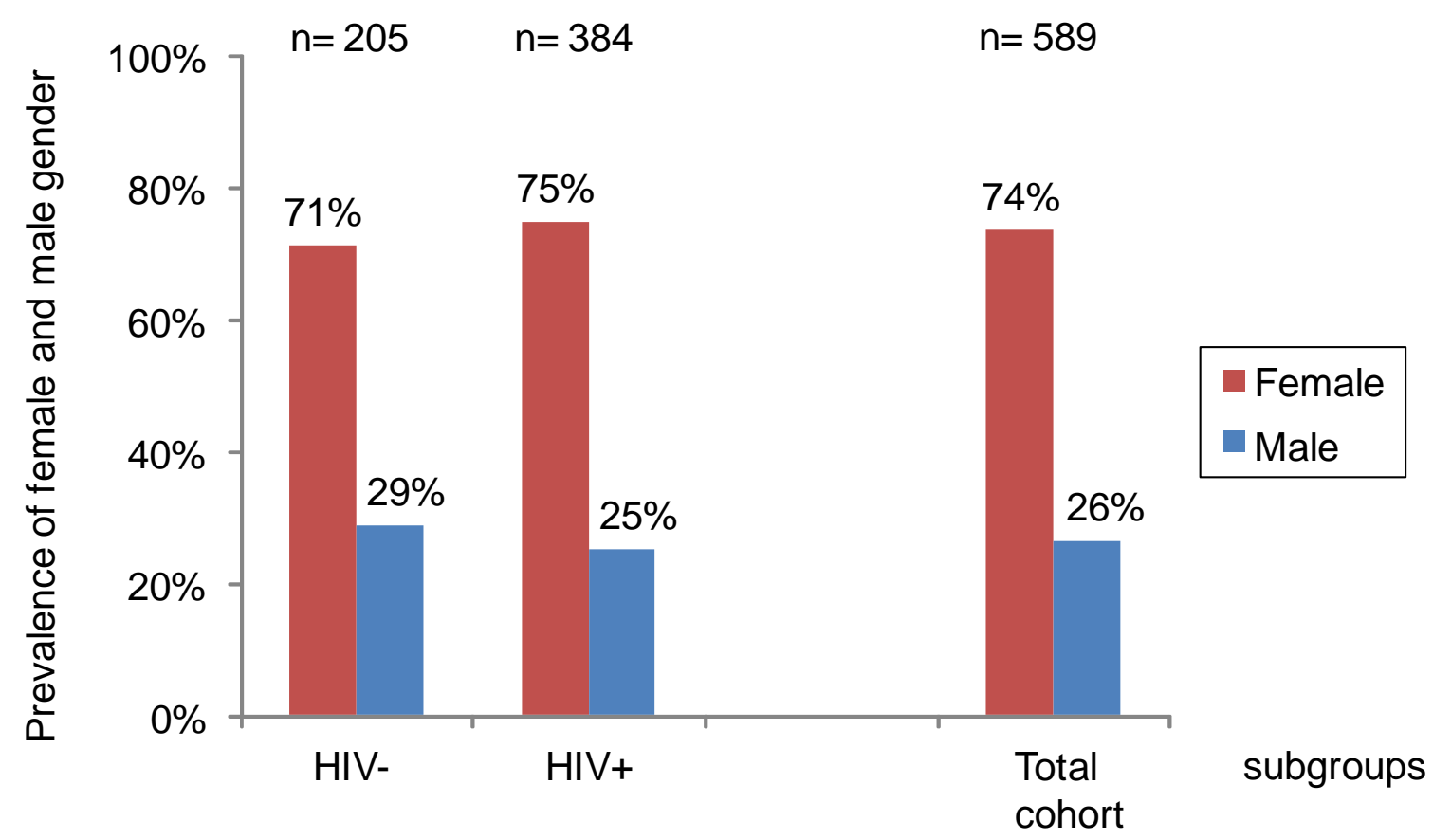

Figure 8: Distribution of the gender in the different subgroups. HIV-positive patients were recruited only from the clinic in Maingara, HIV-negative individuals mainly from Bemouli. Female patients were significantly more represented than male patients in all subgroups. HIV+= HIV-positive; HIV-= HIV-negative; $n=$ number of patients.

\subsection{Prevalence of fungal colonization}

In a first step, we analyzed to what degree the different patient subgroups (HIVpositive with and without HAART, HIV-negative control) were colonized with oral yeasts. For this analysis only samplings from the first visit of each patient were analyzed and categorized. Patients who had received antifungal or antibacterial treatment within the last three weeks before and at time of the first sampling were fully excluded from this evaluation and patients having received less than 25 days of HAART were excluded from the HAART+ group. (In a separate chapter (3.11) patients with antibacterial but without antifungal treatment will be included again for the analysis of the influence antibacterial treatment on oral colonization). After implementing all exclusion criteria, a total of 534 patients were included for further analysis: 343 HIV-positive, 56 HIV-negative from Maingara and 135 HIV-negative from Bemouli. 52.5\% $(n=180)$ of the HIV-positive patients were under HAART. The age and gender distribution in the HIV-positive subgroups were similar to the HIVpositive overall cohort. 
A total of 130 swabs from the 534 patients included in the study were yeast-positive $(=24.4 \%)$ at the patients' first visit. There was no significant difference in oral yeast colonization between the different subgroups: HIV-positive patients only had a slightly higher prevalence of oral yeast colonization (25.4\%) than HIV-negative patients (22.5\%). There was also no significant difference between the HIV-negative patients from Maingara and Bemouli (data not shown).

HIV-positive patients were therefore further divided into two subgroups: "with HAART" (HAART+) for those who had received HAART for at least 25 days and "without HAART" (HAART-) for the patients, who were without HAART at the time of and prior to examination. Here we found a significant difference between HAART treated and HAART non-treated patients: HIV+/HAART+ patients had a significantly $(p=0.003)$ lower colonization rate $(18.9 \% ; n=34)$ than HIV+/HAART- patients $(32.7 \%$; $n=53)$, but not $(p=0.111)$ as compared to the HIV-negative control $(22.5 \% ; n=31)$ (Figure 9).

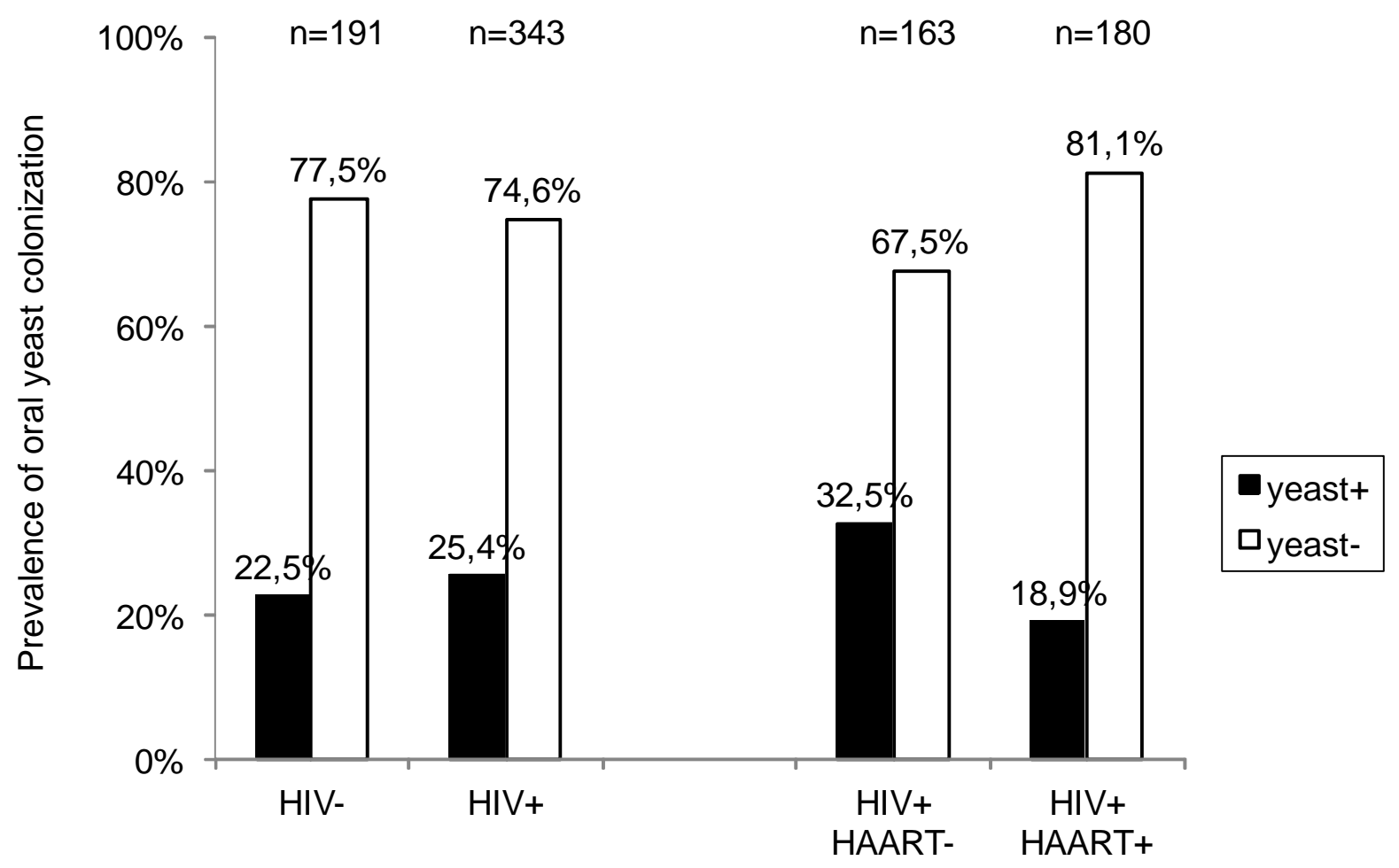

Figure 9: Prevalence of yeast growth in the oral cavity in the different subgroups. HIV+/HAART + patients had a significant lower colonization rate than HIV+/HAART- patients, but similar to the control group. $n=$ number of patients; yeast $+=$ yeast-positive; yeast-= yeastnegative. 


\subsection{Degree of oral fungal burden in HIV-negative and -positive patients}

A semi-quantitative analysis of the degree of fungal burden based on CFU counts on the agar plate of the positive oral swabs between the study group and the control group revealed no significant difference $(\mathrm{p}=0.7)$. The rate of high fungal burden (HFB; CFU $>16$ on a $1 / 8^{\text {th }}$ agar plate) was $32.2 \%$ for the HIV-positive and $35 \%$ for the HIVnegative patients (Figure 10). In contrast, within the HIV-positive subgroups, patients receiving HAART had a significantly $(p=0.02)$ lower prevalence of HFB $(18 \%, n=6)$ than those without HAART (42\%; $n=22)$, but not significantly lower than the controls $(p=0.09)$ (Figure 10).

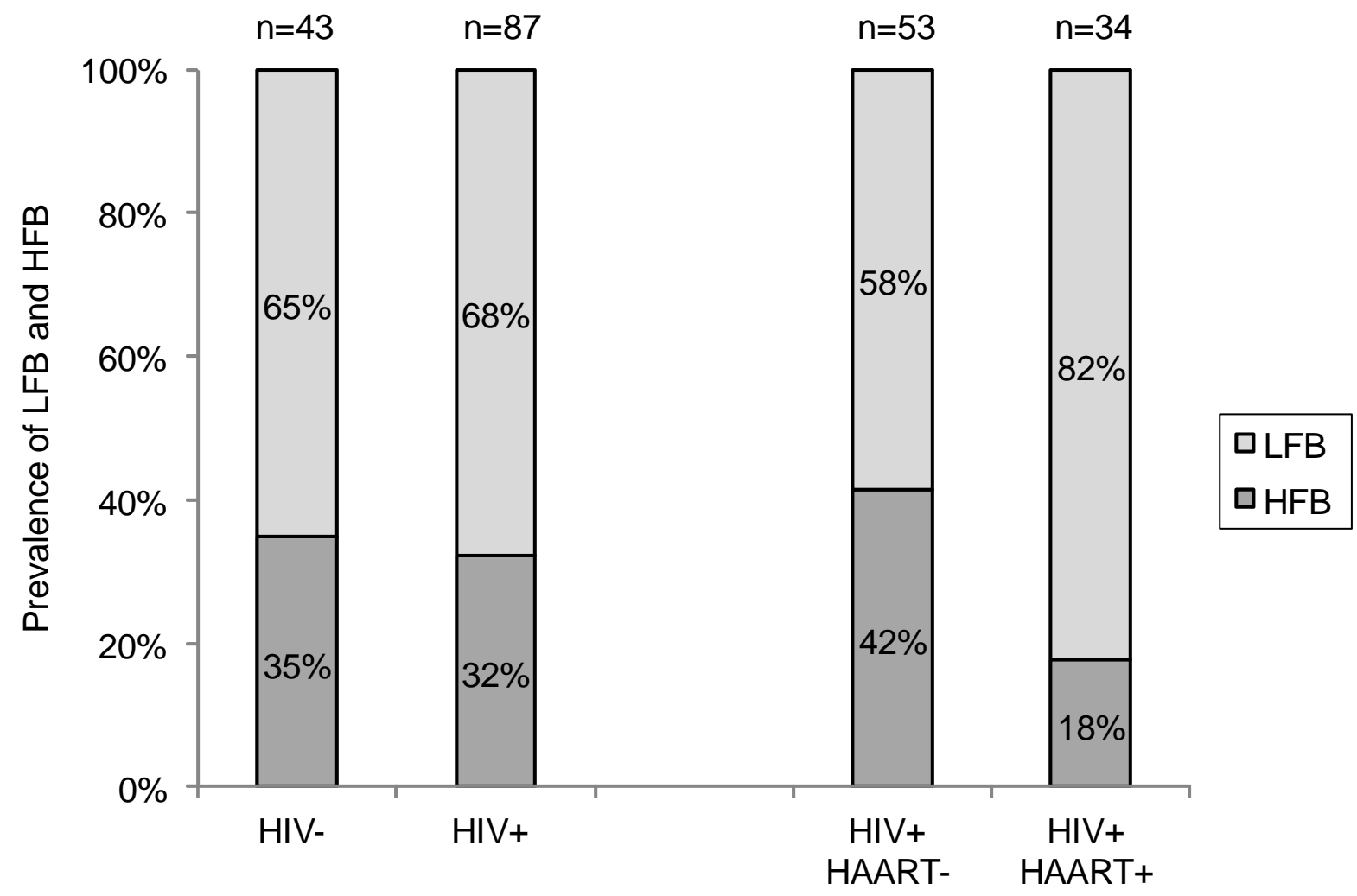

Figure 10: Prevalence of low and high fungal burden in the positive oral swab. There was a significant difference in oral fungal burden between HIV+/HAART+ and HIV+/HAARTpatient. HIV+/HAART+ patients had a significantly $(p=0.02)$ lower rate of high fungal burden $(18 \%)$ than HIV+/HAART- patients $(42 \%)$. $n=$ number of patients, LFB= low fungal burden= colonization with $1-15 \mathrm{CFU} / 1 / 8$ th of an agar plate, $\mathrm{HFB}=$ high fungal burden= colonization with $>15 \mathrm{CFU} / 1 / 8$ th of an agar plate. 


\subsection{Classification of oral symptoms and diagnosis of oral candidiasis}

Diagnosis of OC was more challenging than expected, as the typical clinical presentation of OC ("whitish plaque which can be whipped off easily revealing erythematous area beneath") (EC-Clearinghouse 1993) was rare. Subsequently, we therefore based our diagnostic and classification criteria on those proposed by Lehner (Lehner 1964; Parihar 2011) who classified OC based on clinical, mycological, histological, serological and therapeutic criteria. As additional tests such as exfoliative cytology or tissue biopsy for confirmation or rejection of OC were not available on site and antimycotics were rare, we classified our patients only according to the clinical observations and the result of the culture from the oral swab. Based on the symptoms observed and additionally inspired by the scoring index for oral mucositis proposed by McGuire et al. (2002) patients were first subdivided into the three following subgroups:

- $\underline{\text { noS }}=\quad$ asymptomatic: no visible alterations in the oral cavity

- $\underline{\mathrm{mS}}=\quad$ mild symptoms: whitish or yellowish coated tongue with $<50 \%$ affected area (Figure 11A+B).

- $\underline{\mathbf{S S}}=$ severe symptoms: one of the following symptoms or the combination of them: thick whitish or yellowish coated tongue with $>50 \%$ affected area and/or atrophy and/or erythema and/or other mucosal sites affected like palate or side cheek pockets (Figure 11C-E).

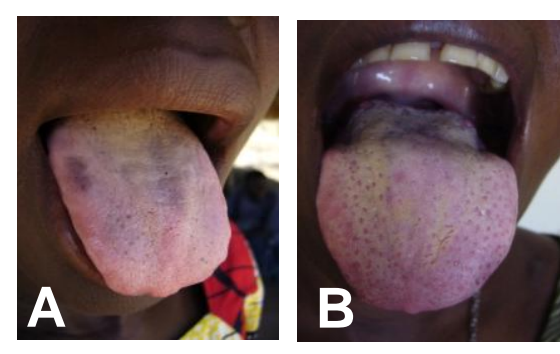

$<50 \%$ coated tongue

\section{A+B: mild symptoms}

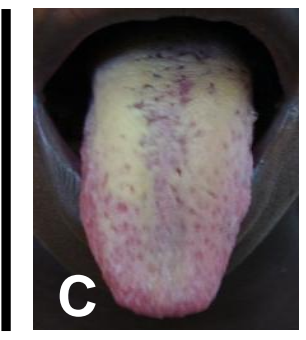

$>50 \%$ coated tongue

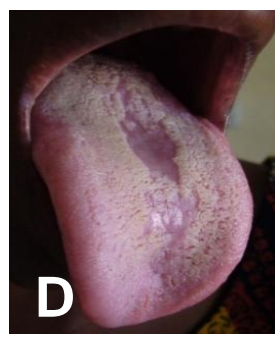

Median rhomboid glossitis with central atrophy

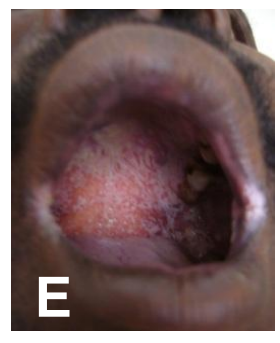

With involvement of the palate

Figure 11: Examples of classified symptomatic patients. Patients classified with "mild symptoms" only had a tongue coating affecting $<50 \%$ of the tongue $(A+B)$; patients with "severe symptoms" a thick white or yellowish coating affecting $>50 \%$ of the tongue area $(C)$, and/or atrophy (D), and/or additionally other mucosal sites affected (E). 
Together with the results from mycological culture (yeast negative vs. yeast positive), four different patient groups were defined (Table 2):

- Yeast- : all patients with absence of yeast (irrespectively of symptoms)

= non-carriers

- Ynos : Yeast positive patients with no symptoms

= asymptomatic yeast carriers

- Yms : Yeast positive patients with mild symptoms

= yeast carriers with mild symptoms

- YsS : Yeast positive patients with severe symptoms

$=$ yeast carriers with severe symptoms

Only patients from group YsS will further be discussed and classified as patients with oral candidiasis (Table 2).

Table 2: Classification of the patients including clinical presentation and oral swab culture

\begin{tabular}{|c|c|c|c|}
\hline Swab culture & Symptoms & Classification & \\
\hline Yeast- & $\begin{array}{l}\text { Asymptomatic or } \\
\text { symptomatic }\end{array}$ & $\begin{array}{l}\text { Yeast-/ } \\
\text { no,mild or severe } \\
\text { symptoms }\end{array}$ & uncolonized \\
\hline \multirow{3}{*}{ Yeast+ } & Asymptomatic & $\begin{array}{l}\text { Yeast+/ } \\
\text { no symptoms (YnoS) }\end{array}$ & colonized \\
\hline & \multirow{2}{*}{ Symptomatic } & $\begin{array}{l}\text { Yeast+/ } \\
\text { mild symptoms (YmS) }\end{array}$ & colonized? \\
\hline & & $\begin{array}{l}\text { Yeast+/ } \\
\text { severe symptoms (YsS) }\end{array}$ & Oral candidiasis (OC) \\
\hline
\end{tabular}

According to the symptoms observed and the result of the oral swab, four different clinical symptom groups were defined. 


\subsection{Prevalence of symptoms and oral yeast colonization in the different symptomatic groups}

\subsubsection{Prevalence of symptoms}

HIV-positive patients were significantly more often symptomatic than the controls $(p=0.03)$. The respective prevalence of symptoms in HIV-positive patients was $40 \%$ and $30 \%$ in HIV-negative patients. There was no significant difference in the prevalence of symptoms between HIV+/HAART- (44\%) and HIV+/HAART+ $(36 \%)$ patients $(p=0.13)$, but a significant difference in the prevalence of severe symptoms (HIV+/HAART-: $26 \%$ and HIV+/HAART+: 12\%; $p \leq 0.01$ ). HIV+/HAART- patients also had a significantly higher prevalence of severe symptoms (26\%) than the controls $(15 \%)(p \leq 0.01)$ (Figure 12).

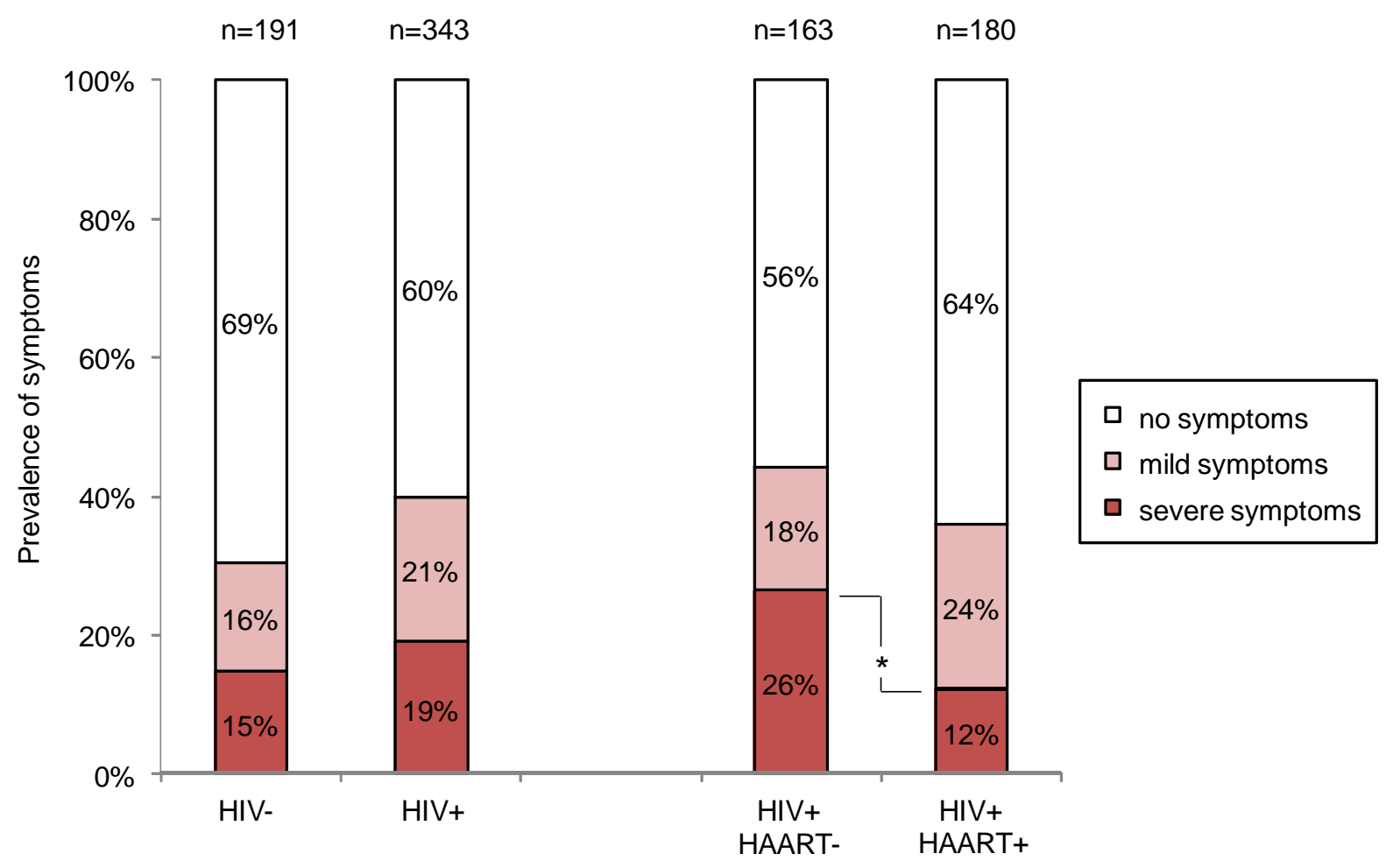

Figure 12: Prevalence of symptomatic patients in the different subgroups. HIV+/HAART- patients were significantly more often symptomatic than the controls $(p \leq 0.01)$ and had significantly more severe symptoms than HIV+/HAART+ patients $\left({ }^{*}=p \leq 0.01\right)$ and HIV-negative patients $(p \leq 0.01) . n=$ number of patients. 


\subsubsection{Prevalence of yeasts in the oral cavity of asymptomatic patients}

Asymptomatic HIV-negative and HIV-positive patients were in up to $80 \%$ of the cases yeast-free and there was no significant difference $(p=0.09)$ in the prevalence of oral yeast carriage in the HIV-positive subgroups (Figure 13).

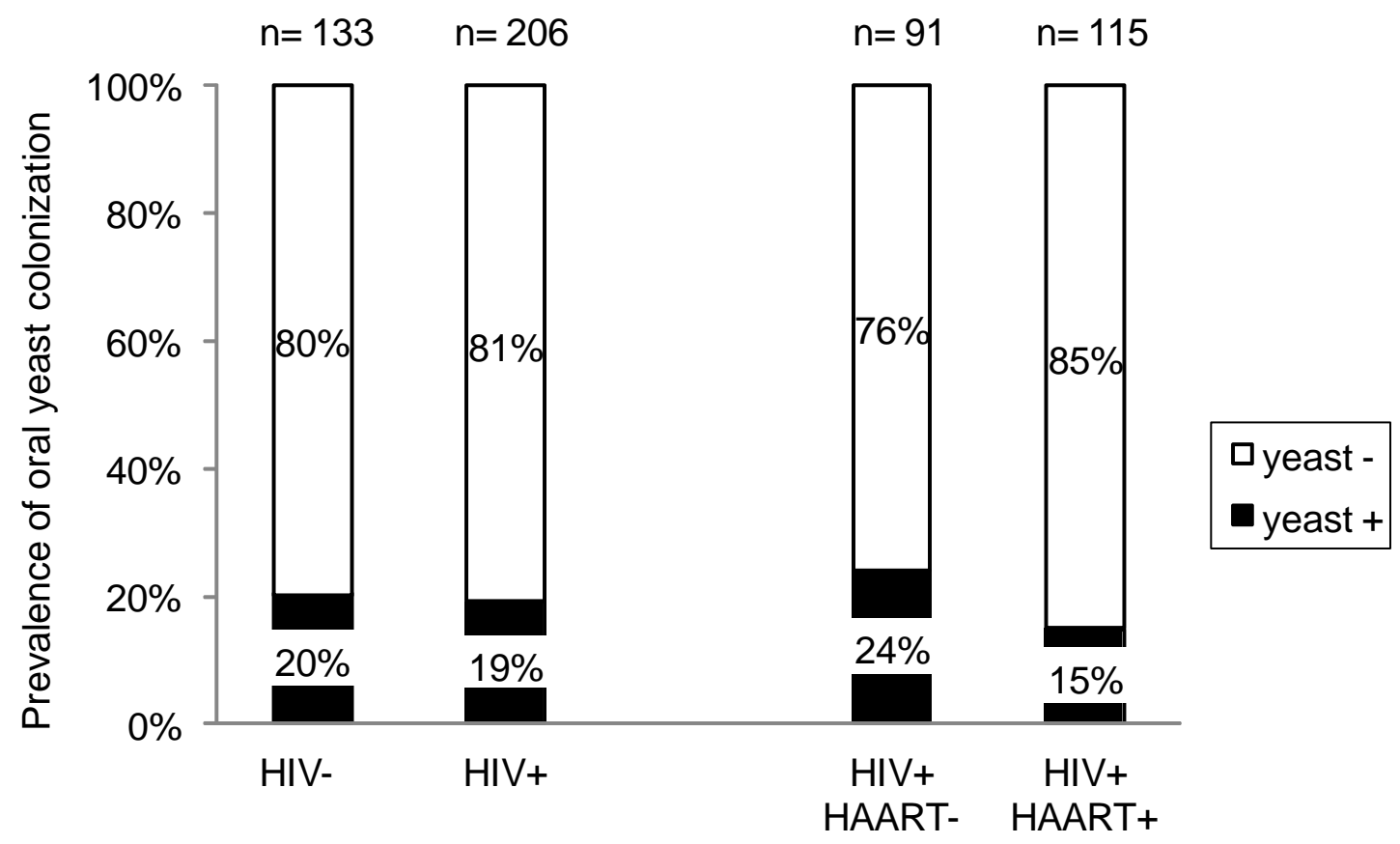

Figure 13: Prevalence of yeast in the oral cavity of asymptomatic patients. Asymptomatic HIV-negative and HIV-positive patients were mainly (in up to approximately $80 \%$ of the cases) free of yeast colonization. $n=$ number of patients

\subsubsection{Prevalence of yeasts in the oral cavity of symptomatic patients}

In HIV-positive patients the severity level of symptoms significantly correlated with the presence or absence of yeasts in the oral cavity $(p \leq 0.01$ for HIV+/HAART- and $\mathrm{p}=0.05$ for HIV+/HAART + patients). The oral cavity of patients with mild symptoms was in $83 \%$ (HAART-) and $81 \%$ (HAART+) of the cases yeast-free and up to $60 \%$ (HAART-) and $41 \%$ (HAART+) of the patients with severe symptoms where yeastpositive. In HIV-negative patients that correlation was not obvious (Figure 14). 


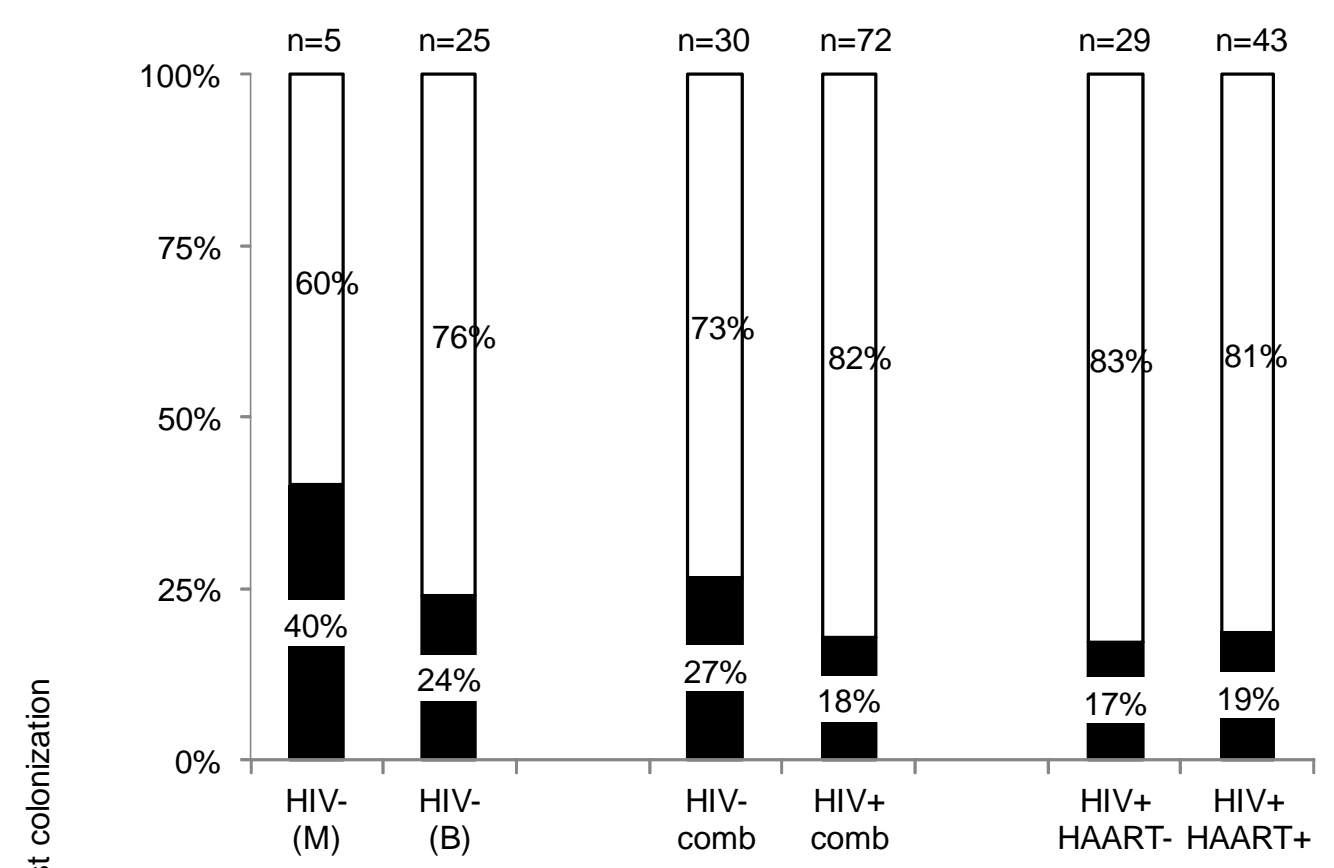

A. with mild symptoms

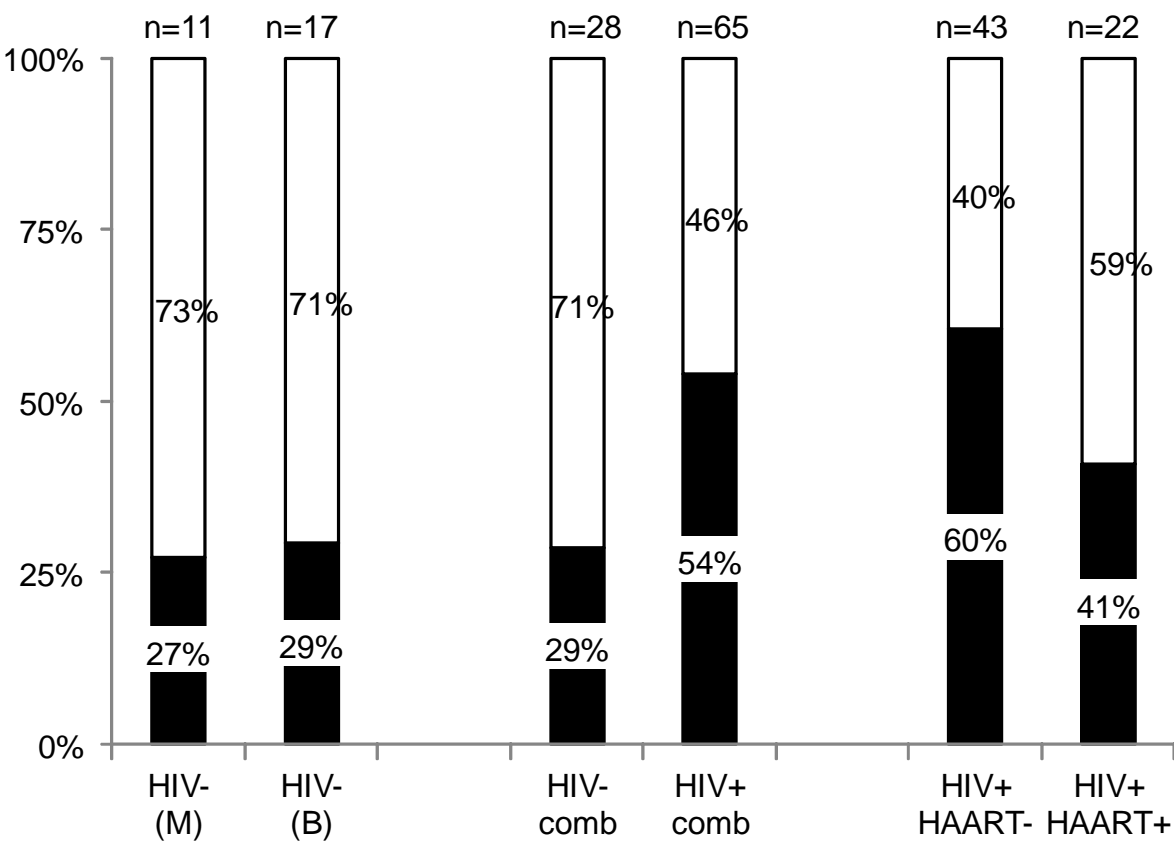

$\square$ yeast -

- yeast +

Figure 14: Prevalence of yeast in the oral cavity in symptomatic patients. Mild symptoms in HIV-positive patients were more associated with the absence of yeasts in the oral cavity and severe symptoms significantly correlated with the presence of oral yeast colonization in HIV+/HAART- $\left({ }^{*}=p \leq 0.01\right)$ and HIV+/HAART+ patients $\left({ }^{* *}=p=0.05\right)$. A. patients with mild symptoms, B. patients with severe symptoms; yeast-= yeast-negative; yeast $+=$ yeast-positive; $n=$ number of patients. 


\subsection{Association between oral fungal burden and symptoms in the different subgroups}

In all subgroups, asymptomatic yeast carriers (YnoS) mainly had a low fungal burden. In HIV-negative patients there was a higher prevalence of high fungal burden in patients with mild to severe symptoms (YmS and YsS). HIV+/HAART+ symptomatic patients had the lowest prevalence of high fungal burden and only in HIV+/HAART- patients high oral fungal burden was significantly associated with severe symptoms $(p \leq 0.01)$ (Figure 15).

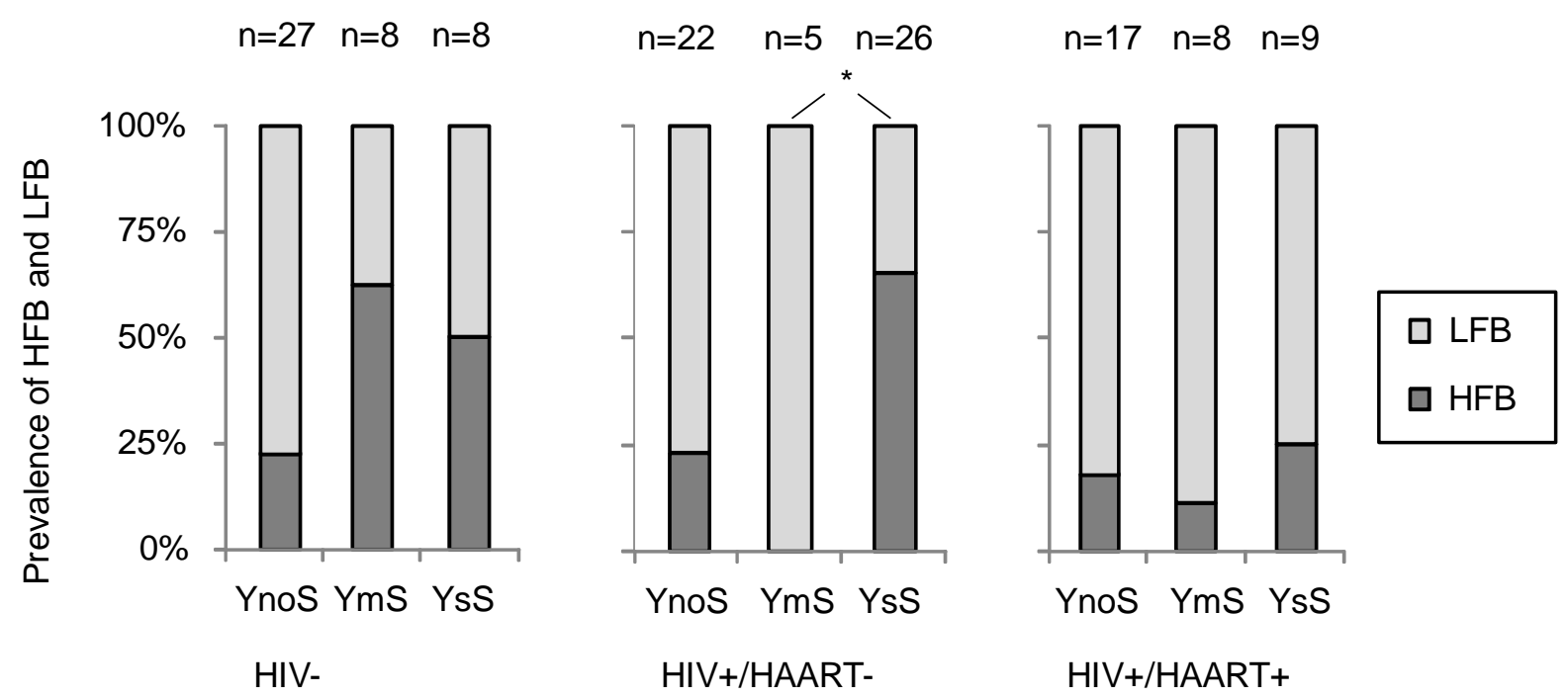

Figure 15: Prevalence of high oral fungal burden according to symptoms in the different subgroups. A high oral fungal burden was significantly associated with severe symptoms in HIV+/HAART- patients $\left({ }^{*}=p \leq 0.01\right)$. In HIV+/HAART+ patients this association was not obvious. YnoS= yeast positive/no symptoms; YmS= yeast positive/mild symptoms; YSS= yeast positive/severe symptoms; LFB= low fungal burden; HFB= high fungal burden. 


\subsection{Prevalence of oral candidiasis in the different subgroups}

For the patients classified with mild symptoms, the only symptoms noted were a mildly coated tongue ( $<50 \%$ of the area). Swab cultures showed a low prevalence of yeast colonization (Figure 14A) and colonized patients from that group (YmS) only had a low fungal burden (Figure 15). It is therefore highly probable, that these patients were only colonized with Candida, so that a classification into any form of OC was not undertaken in this group, but rather classified as "colonized patients".

Only yeast-positive patients with severe symptoms (YsS) were classified as patients with oral candidiasis. The prevalence of OC was highest in the HIV+/HAART- group with $16 \%$ and was reduced in the HIV+/HAART+ group to $5 \%$, which was similar to the one in the HIV-negative group (4\%). The prevalence of asymptomatic yeastcarriers (YnoS) was the same in HIV+/HAART- patients as in HIV-negative patients (14\%) and slightly reduced in HIV+/HAART+ patients (9\%) (Figure 16).

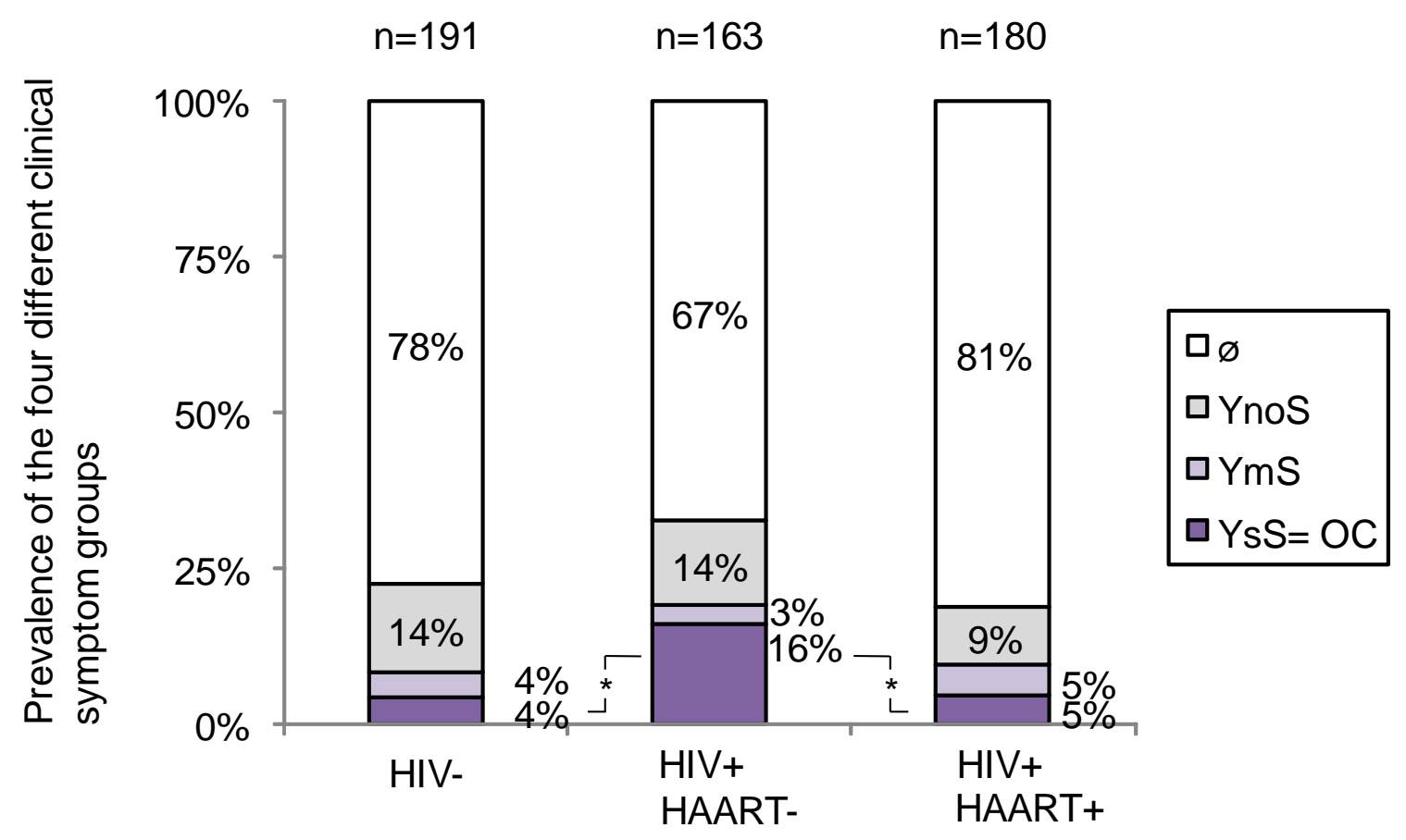

Figure 16: Prevalence of oral candidiasis. Yeast-positive patients with severe symptoms (YSS) were considered as patients with oral candidiasis (OC) and were significantly more prevalent in the HIV+/HAART- group with $16 \%\left({ }^{*}=p \leq 0.01\right) . \varnothing=$ yeast-negative patients; $\mathrm{YnoS}=$ asymptomatic yeast-carriers; $\mathrm{YmS}=$ yeast-carriers with mild symptoms; $\mathrm{YsS}=$ yeastcarriers with severe symptoms=patients with $\mathrm{OC} ; \mathrm{n}=$ number of patients. 


\subsection{Prevalence of the different forms of oral candidiasis in HIV-positive patients}

Only yeast-carriers with severe symptoms (group YsS), as defined above in 3.4 and 3.7, were further considered and discussed for the diagnosis of OC. In this group, we observed different clinical presentations among our HIV-positive patients, which we classified according to the classification proposed by Axell et al. (Axell et al. 1997; Parihar 2011) (Table 3).

Table 3: Classification of oral candidiasis by Axell et al.

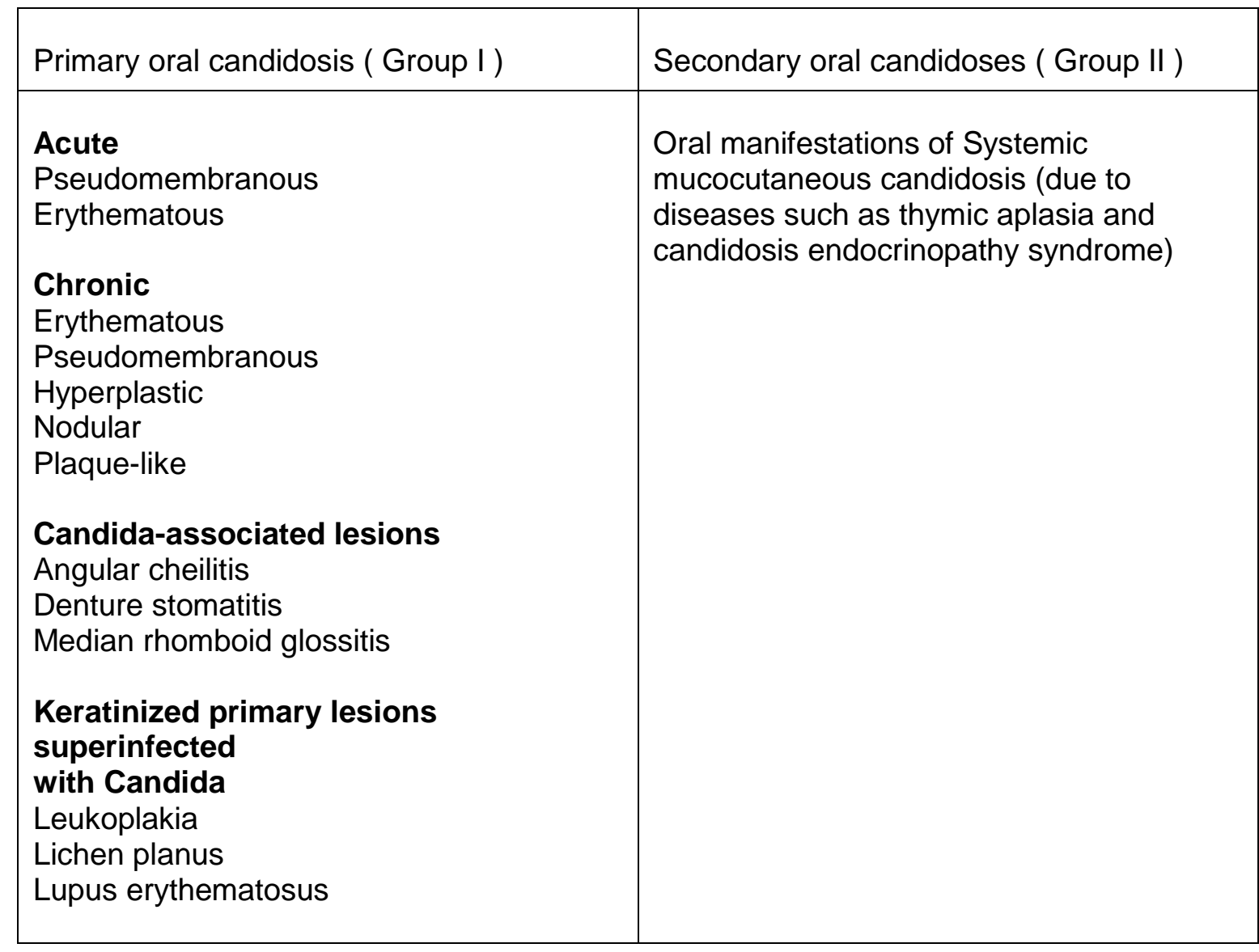

This table represents the revised classification of oral candidiasis by Axell et al. (Axell et al. 1997; Parihar 2011) on which we based our definition and classification of OC.

The majority of these patients presented with a coated (whitish) tongue affecting $>50 \%$ of the area (48.6\%; $n=17 / 35)$ in HAART- as well as in HAART+ patients (Table 4). However, the white lesions where not easily removable in our patients and had no visible signs of inflamed erythematous area beneath. Therefore these cases were not classified as acute pseudomembranous candidiasis (PC). The chronic "plaque-like" OC (also called "hyperplastic" or "nodular" candidiasis) and keratinized primary oral 
lesions superinfected with Candida as hairy leukoplakia or lychen planus were also taken into consideration. Due to lack of further investigations such as tissue biopsy or data about the onset of the symptoms this could, however, not be confirmed. As these variants were also clinically less likely, patients with the symptoms of white lesions as described above were classified as nonspecific OC.

The second most common clinical sign was the median rhomboid glossitis (MRG) (Figure 11D): white plaque on the tongue with central atrophy or erythematous area. Its prevalence was $25.7 \%(n=9 / 35)$. Nearly all of these cases appeared in the HIV+/HAART- group ( $n=8 / 9)$ and the median CD4 T cell count was 200 CD4 T cells/ $\mu \mathrm{l}$ (Table 4). Furthermore, we had 5 cases $(14.2 \%$ ) of clinically diagnosable acute pseudomembranous candidiasis with additionally affected palate. These patients had a median CD4 $\mathrm{T}$ cell count $<120 \mathrm{CD} 4 \mathrm{~T}$ cells $/ \mu \mathrm{l}$. Two cases had combined oral lesions (PC with MRG and PC with atrophy); their CD4 cell counts were $<60 \mathrm{CD} 4 \mathrm{~T}$ cells $/ \mu \mathrm{l}$ and two cases solely tongue atrophy (lingual papillary atrophy). The median CD4 T cell count of the latest was $338 \mathrm{CD} 4 \mathrm{~T}$ cells/ $\mu$ l.

Table 4: Distribution of the different clinical presentations of oral candidiasis in HIVpositive patients

\begin{tabular}{|c|c|c|c|c|c|}
\hline & $\begin{array}{c}\text { HIV+ } \\
\text { HAART- }\end{array}$ & $\begin{array}{l}\text { Median } \\
\text { CD4 T } \\
\text { cell count } \\
\text { (cells/ } \mu \mathrm{l} \text { ) }\end{array}$ & $\begin{array}{c}\mathrm{HIV}_{+} \\
\text {HAART+ }\end{array}$ & $\begin{array}{c}\text { Median } \\
\text { CD4 T } \\
\text { cell count } \\
\text { (cells/ } \mu \mathrm{l} \text { ) }\end{array}$ & Total \\
\hline $\begin{array}{l}\text { Nonspecific } \\
\text { OC }\end{array}$ & $31.5 \%$ & 149 & $17.1 \%$ & 126 & $48.6 \%$ \\
\hline Acute PC & $8.6 \%$ & 115 & $5.7 \%$ & $60^{*}$ & $14.3 \%$ \\
\hline MRG & $22.9 \%$ & 200 & $2.8 \%$ & n.d & $25.7 \%$ \\
\hline Atrophy & $5.7 \%$ & 338 & 0 & - & $5.7 \%$ \\
\hline Mixture & $5.7 \%$ & 51 & 0 & - & $5.7 \%$ \\
\hline Total & $74.3 \%(n=26)$ & & $25.7 \%(n=9)$ & & $100 \%(n=35)$ \\
\hline
\end{tabular}

The majority presented with a coated whitish tongue affecting $>50 \%$ of the tongues' surface classified as nonspecific OC. Second most frequent clinical presentation was the MRG, mainly in HIV+/HAART- patients. Acute $\mathrm{PC}=$ acute pseudomembranous candidiasis; $\mathrm{MRG}=$ median rhomboid glossitis; mixture= combination of acute $P C$ with atrophy or MRG; $n . d=$ not determined; "CD4 T cell count from one patient. 
Except for the patients with symptoms of papillary tongue atrophy, all patients from group YsS (with OC) had a median CD4 T cell count $\leq 200$ CD4 T cells/ $\mu$ l (Table 4 and Figure 17), reinforcing and supporting the diagnosis of $\mathrm{OC}$ in that group.

HIV-positive patients with severe symptoms who were yeast-negative had a median CD4 T cell count $>250$ CD4 T cells/ $\mu$ l (Figure 17) and the correlation between the absence of yeasts in the oral cavity of these patients and CD4 T cell counts $>250$ CD4 $T$ cells/ $\mu$ l was significant $(p \leq 0.01)$.

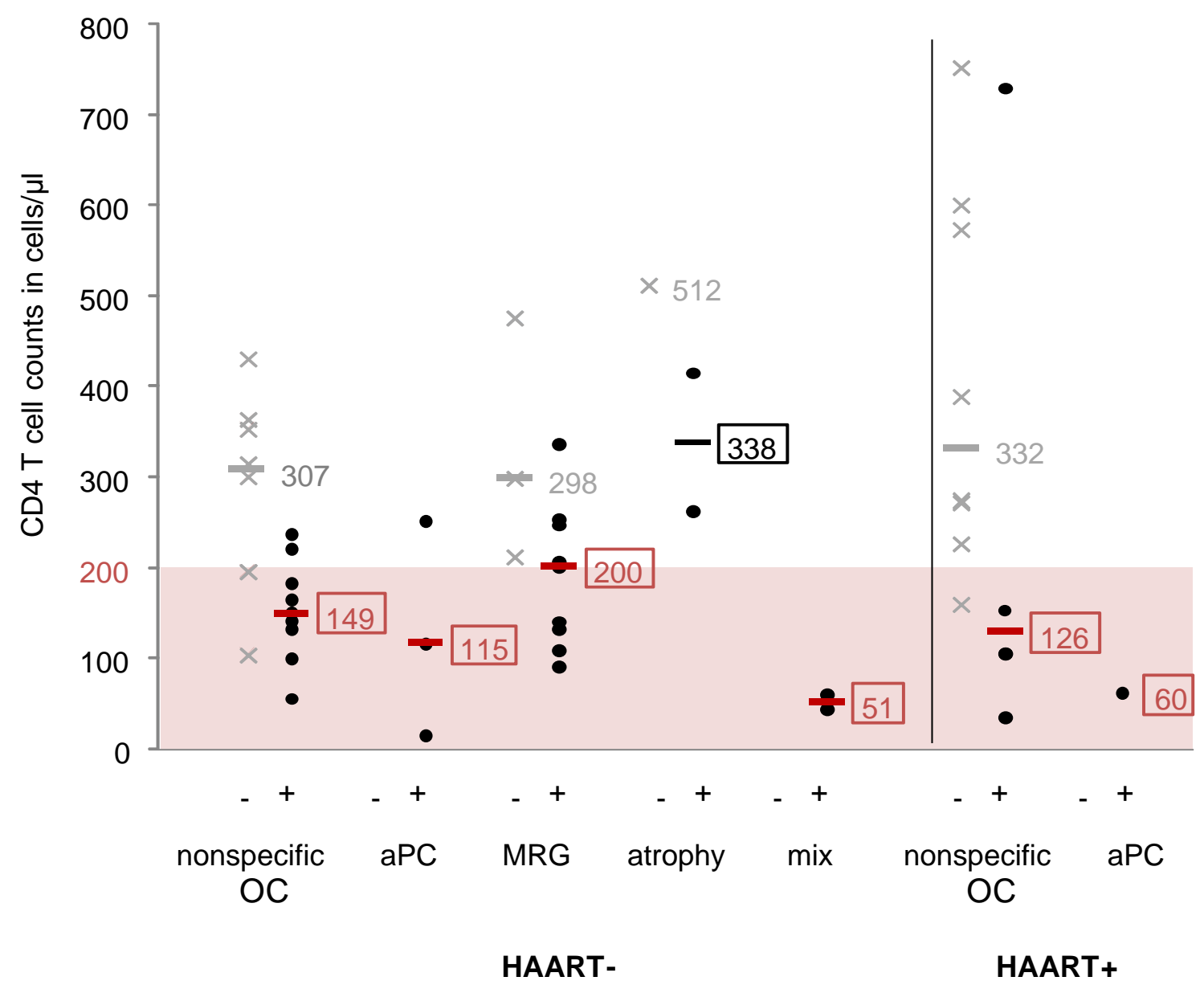

Figure 17: CD4 T cell count and clinical subtypes of oral candidiasis in HIV-positive patients. Patients with OC had a median CD4 T cell count $\leq 200$ CD4 T cells/ $\mu$, except for those with papillary tongue atrophy. In cases of OC-like lesions but no presence of oral yeast growth, median CD4 T cell count was always $>250 \mathrm{CD} 4 \mathrm{~T}$ cells $/ \mu \mathrm{l}$. - = yeast-negative, $+=$ yeast-positive; nonspecific $\mathrm{OC}=$ nonspecific oral candidiasis, $\mathrm{aPC}=$ acute pseudomembranous candidiasis, $M R G=$ median rhomboid glossitis, atrophy= papillary tongue atrophy, mix= combination of aPC with atrophy or MRG; horizontal bars indicate median CD4 T cell count; colored area indicates CD4 T cell counts $\leq 200$ CD4 T cells/ $/ \mu$. 


\subsection{Oral colonization and age}

There was no correlation or significance between age and colonization with yeasts in the different subgroups (Figure 18), although the median age of colonized HIVnegative patients (31 years) was slightly higher than the uncolonized ones (28 years).

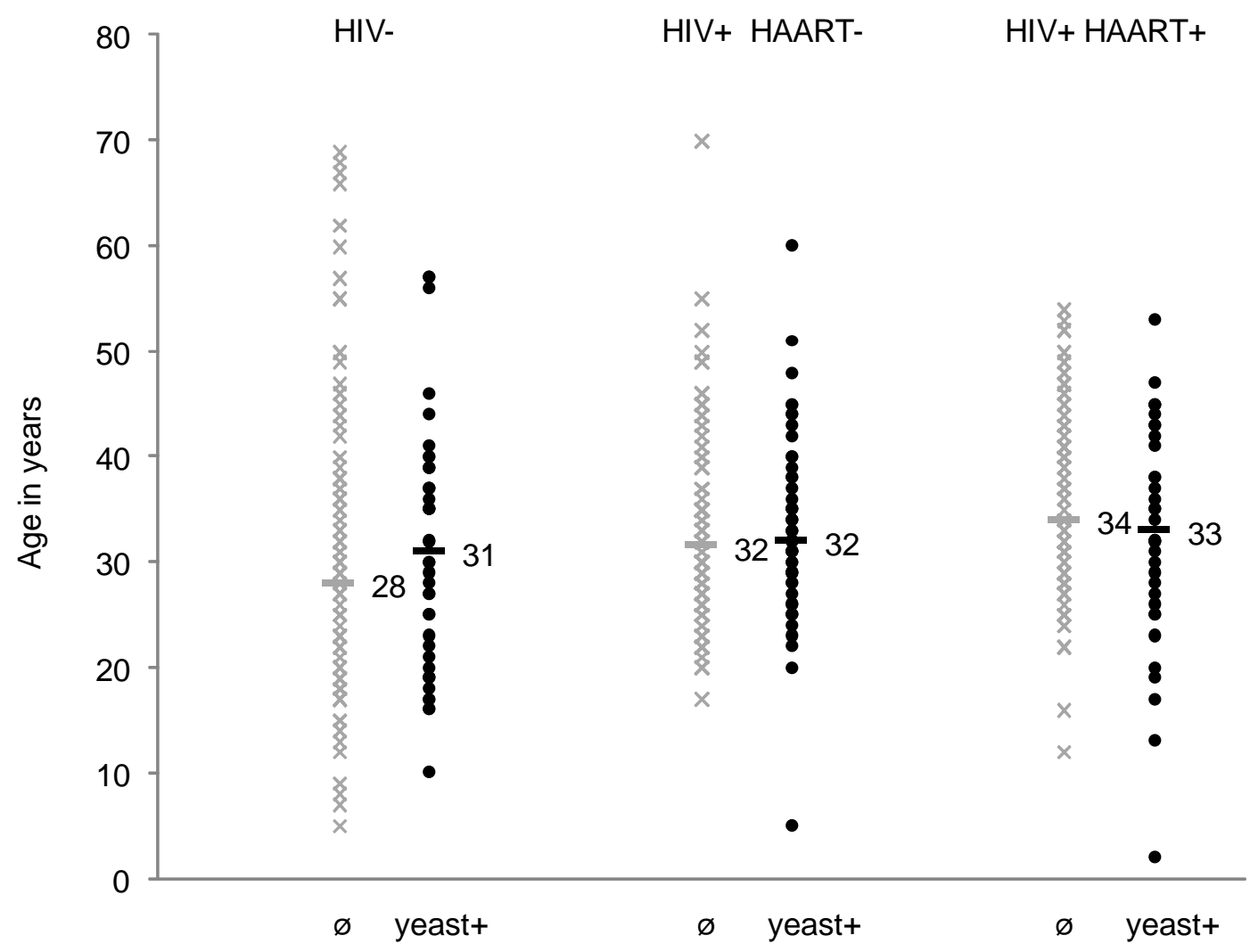

Figure 18: Age-dependent oral yeast colonization. In the control group median age of patients with oral yeast growth was sligthly higher than those without yeasts. In HIV-positive patients no significant differences were observed. $\varnothing=$ yeast. . Horizontal bars indicate median age.

If we looked at the different age groups in the different subgroups (Figure 19), in HIVnegative, as well as in HIV+/HAART- patients, the prevalence of oral yeast colonization was highest in the age group of 36-45. In the HIV+/HAART+ group the prevalence was highest in the 19-25 age group and decreased with higher age which correlates with a longer time on HAART for the 19-45 years old. With increasing age, the patients of that group had an increased average of days of HAART: 19-25 (323 days on HAART); 26-35 (483 days); 36-45 (539 days). 


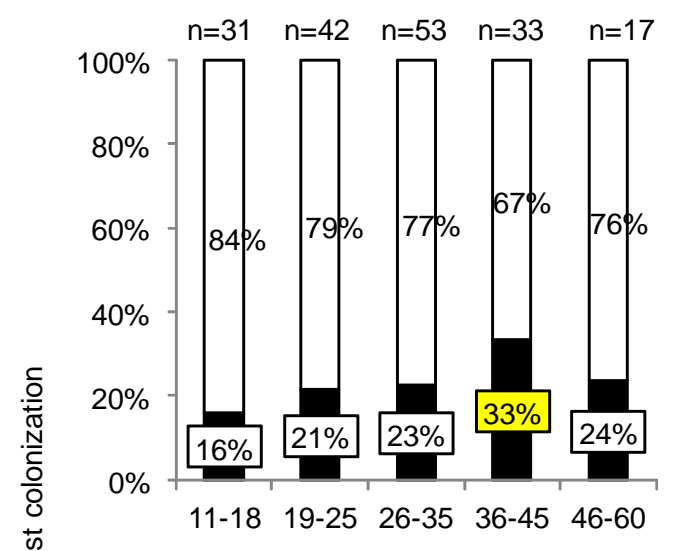

a. HIV-

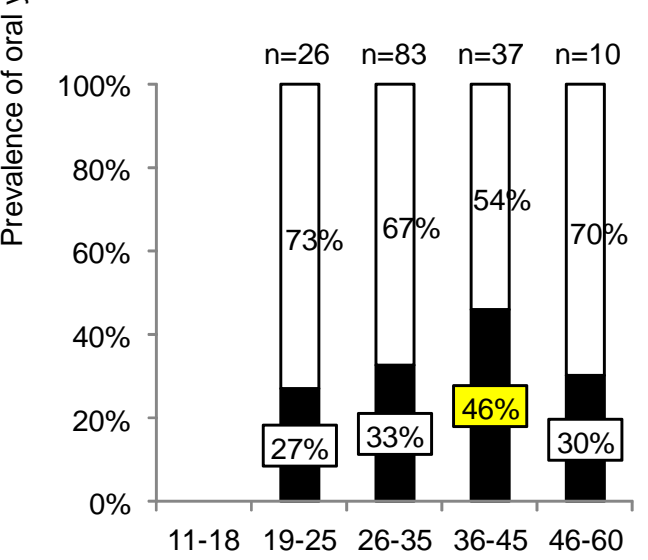

b. HIV+/ HAART-

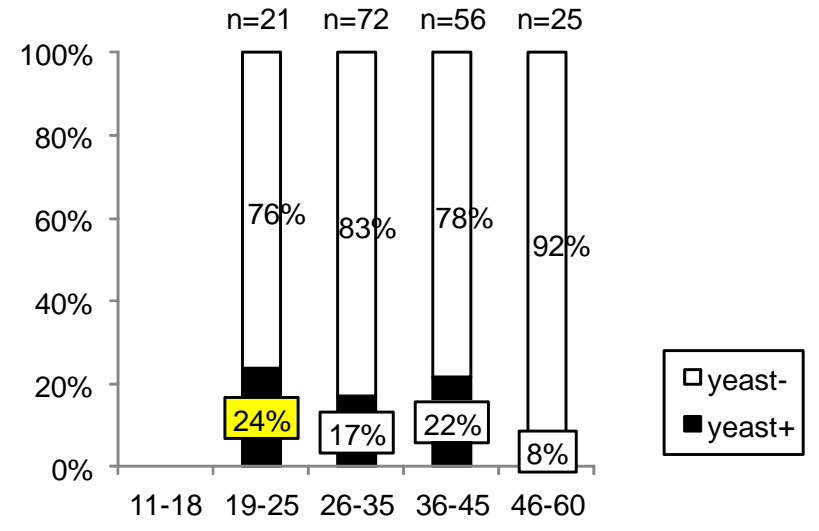

c. HIV+/HAART+

Figure 19: Prevalence of yeasts in the oral cavity according to age. In HIV- and HIV+/HAART- patients the highest prevalence of oral yeast growth was in the age group of 36-45, whereas in the HIV+/HAART+ group it was in the 19-25 age group. With rising age in HIV+/HAART+ patients (which correlated with a longer period of HAART), there was a decrease in oral colonization rate. $n=$ number of patients. 


\subsection{Oral yeast colonization and fungal burden in HIV- negative and -positive female and male patients}

There was no significant gender-dependent difference in the prevalence of oral yeast colonization in HIV-positive and -negative patients (Figure 20A). Although, yeastpositive male subjects had a higher oral fungal burden than female subjects in both groups; the difference was significant only in the HIV-negative group $(p=0.01)$ (Figure 20B)

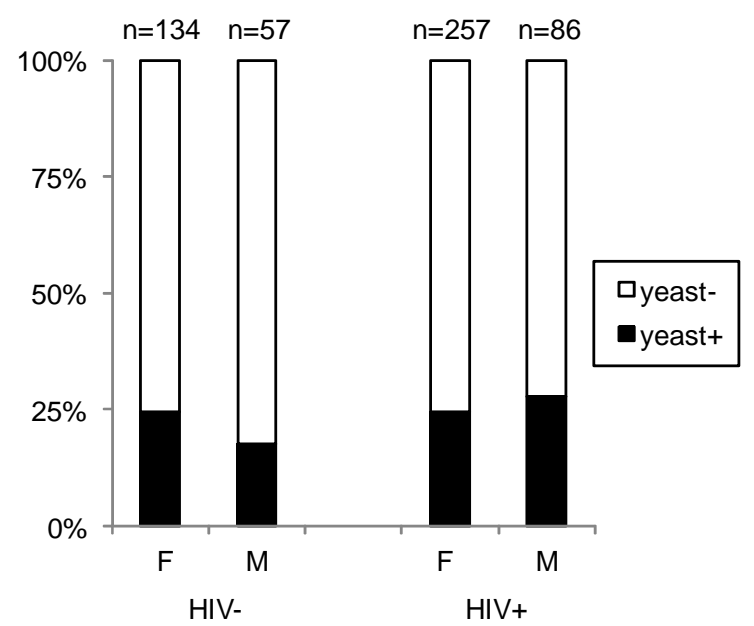

A. Prevalence of yeast colonization

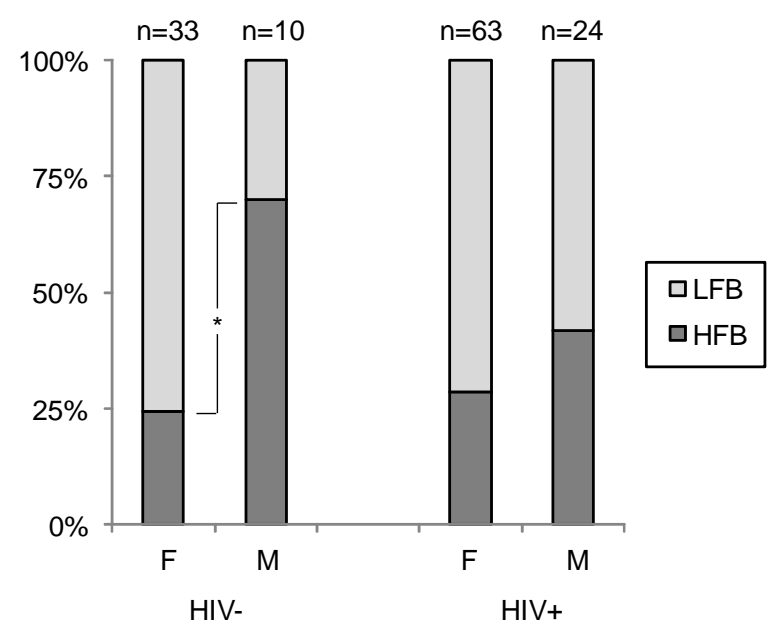

B. Prevalence of fungal burden

Figure 20: Prevalence of oral yeast colonization and fungal burden in HIV-negative and -positive female and male patients. In HIV-negative and HIV-positive patients there were no significant differences in the prevalence of oral yeast colonization between male and female. But in the HIV-negative group male patients had a significant higher oral fungal burden than female patients $\left({ }^{*}=p=0.01\right) . n=$ number of patients; $F=$ Female, $M=$ Male; yeast= yeast-negative; yeast $+=$ yeast- positive; $L F B=$ low fungal burden; $H F B=$ high fungal burden. 


\subsection{Influence of antibiotics on oral colonization and infection with yeasts}

We also analyzed the impact of antibiotics on fungal burden in the oral cavity among our patients. For this we excluded those patients which had taken antifungals at the time of or in the last three weeks before examination. Only drugs with antibacterial effectiveness at time of the first visit or in the last three weeks before were considered. Five different classes of antibiotics were in use: Co-trimoxazole, $\beta$-lactam antibiotics (Penicillin, Amoxicillin, Cloxacillin, Ampicillin), Ciprofloxacin, Metronidazole and Doxycyclin. Co-trimoxazole and $\beta$-lactam antibiotics were the most frequently prescribed. HIV+/HAART- patients more frequently received an antibiotic treatment. In total $26(7.0 \%)$ out of 369 HIV-positive and 13 (8.8\%) out of 148 HIV-negative patients had received an antibacterial treatment. Of these $26 \mathrm{HIV}$-positive patients, nine $(34.6 \%)$ had a positive yeast culture, out of which eight $(89 \%)$ where from the HIV+/HAART- group, and 17 (65.4\%) had no presence of yeast growth. Although HIV+/HAART- patients were more frequently yeast-positive, in the different patients group there were no significant differences in the prevalence of oral colonization between patients with and without antibiotic treatment $(p=1.0$ (HIV-); $p=0.3$ (HIV+/HAART-) and p=0.65 (HIV+/HAART+) (Table 5).

Table 5: Prevalence of oral yeast colonization with and without antibiotics

\begin{tabular}{|l|l|l|l|l|l|l|}
\hline \multirow{2}{*}{} & \multicolumn{2}{|l|}{ HIV- } & \multicolumn{2}{l|}{ HIV+/HAART- } & \multicolumn{2}{l|}{ HIV+/HAART+ } \\
\cline { 2 - 7 } & no AB & AB & no AB & AB & no AB & AB \\
\hline Yeast- & $77 \%$ & $77 \%$ & $67 \%$ & $56 \%$ & $81 \%$ & $87 . \%$ \\
\hline Yeast + & $23 \%$ & $23 \%$ & $33 \%$ & $44 \%$ & $19 \%$ & $13 \%$ \\
\hline Significance & $\mathrm{p}=1.0$ & $\mathrm{p}=0.3$ & $\mathrm{p}=0.65$ & \\
\hline
\end{tabular}

HIV+/HAART- patients were more likely to be colonized with yeasts than HIV- or HIV+/HAART + patients, but in general treatment with antibiotics had no significant influence on oral colonization with yeasts in all three subgroups. 


\subsection{Prevalence and distribution of yeast species}

In total, 156 yeast isolates from 166 positive oral swabs of the HIV-positive and negative patients were differentiated. 17 samples, due to longer storage, could not be recovered but 7 out of these could be differentiated by PCR.

In total, 171 yeasts were isolated and differentiated from the 156 yeast isolates. In all patient groups, $C$. albicans was the most prevalent species: $44.2 \%$ in HIV-negative (56.3\% in the Maingara and $37.0 \%$ in the Bemouli HIV-negative groups; data not shown) $58.6 \%$ in HIV+/HAART+ and $87.1 \%$ in HIV+/HAART- patients (Figure 21). The HIV+/HAART+ and the HIV-negative patients had a significantly lower prevalence of $C$. albicans and a larger variety of non-C. albicans yeasts than the HIV+/HAART- patients $(p \leq 0.01)$.

The next most prevalent yeast species were I. orientalis $(12.1 \% ; n=7)$ followed by $C$. tropicalis (8.6\%; $n=5)$ and Saccharomyces cerevisiae (S. cerevisiae) $(6.9 \% ; n=4)$ in the $\mathrm{HIV}+/$ HAART+ group and C. tropicalis $(4.3 \% ; n=3)$ followed by $S$. cerevisiae (2.9\%; $n=2)$ in the HIV+/ HAART- group. In the combined HIV-negative group the second next most prevalent species was $S$. cerevisiae $(14 \% ; n=6)$ (Figure 21). Although, in the HIV-negative patients from Maingara $C$. glabrata was the second most frequent species. Among the HIV-negative subjects from Bemouli, no $C$. glabrata was found; instead, S. cerevisiae $(18.5 \% ; n=5)$ and Pichia fabianii ( $P$. fabianii) $(14.8 \%$; $n=4)$ were the next most prevalent species (data not shown).

Other isolated species in the HIV-positive group were: C. parapsilosis, C. orthopsilosis, P. fabianii, P. farinosa (= C. cacaoi), P. guilliermondii, C. kefyr and C. rugosa. A $C$. orthopsilosis-like species together with $C$. tropicalis was isolated from the oral cavity of a HIV-positive patient undergoing HAART. In the HIV-negative groups further isolated species were $C$. orthopsilosis, $C$. valida and $C$. pararugosa. C. dubliniensis was not isolated from any of the patients, irrespectively of HIV status.

Across all subgroups, mixed colonization with $\geq$ two yeast species was observed: seven patients (13.7\%) in the HIV+/HAART+ group, three $(4.4 \%)$ in the HIV+/HAART-group and four (10.5\%) in the HIV-negative group. 
In the HIV+/HAART- group, mixed colonization always included $C$. albicans, whereas in the HIV+/HAART+ group, mixed colonization predominantly included non-C. albicans species (Table 6).

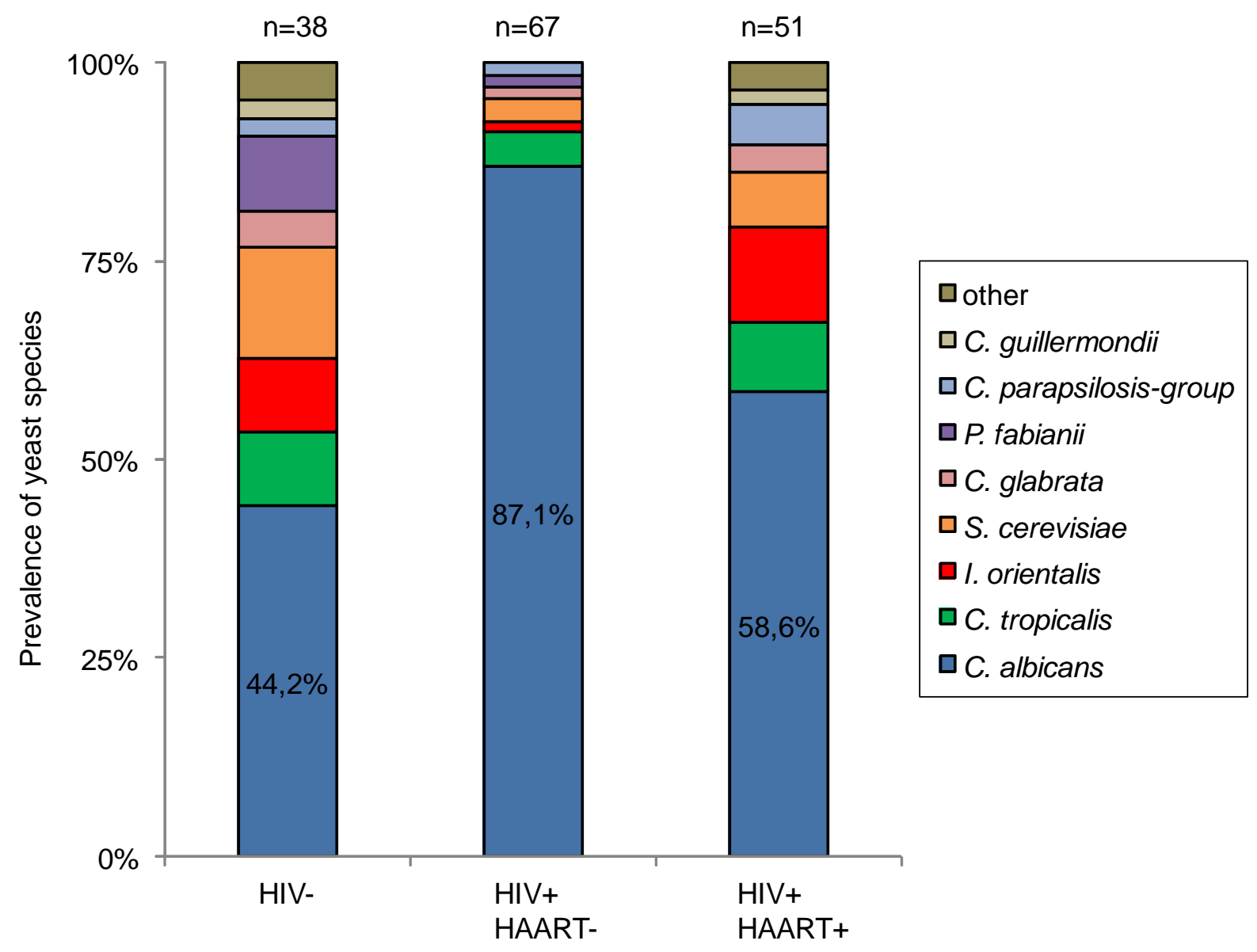

Figure 21: Species distribution. The number of patients with mixed colonization was: $n=4$ in the HIV- combined, $n=3$ in the HIV+/HAART- and $n=7$ in the HIV+/HAART+ group. The number of species which were not able to be recultivated from the transported agar slants was: $n=5$ in Bemouli, $n=2$ in the HIV+/HAART-, $n=3$ in the HIV+/HAART+ group. C. albicans (C.a) was the most prevalent species in all subgroups. HIV- and HIV+/HAART+ patients presented with a higher species diversity and lower prevalence of C.a. $n=$ number of patients. 
Table 6: Patients with simultaneous colonization of $\geq 2$ species

\begin{tabular}{|c|c|c|c|c|c|c|c|}
\hline $\begin{array}{l}\bar{d} \\
\overline{0} \\
\bar{d} \\
\mathbb{0}\end{array}$ & 要 & 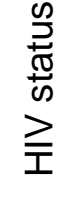 & 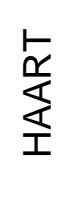 & 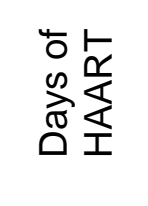 & 吉产 & $\begin{array}{l}\overline{0} \\
\frac{\pi}{\pi} \\
3 \\
\omega\end{array}$ & 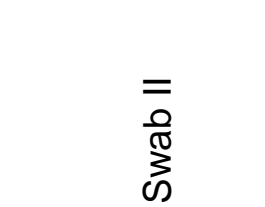 \\
\hline$F$ & 20 & + & + & 330 & 432 & $\begin{array}{l}\text { C. tropicalis } \\
\text { C. othopsilosis-like }\end{array}$ & n.d. \\
\hline$F$ & 31 & + & + & 996 & 703 & $\begin{array}{l}\text { C. tropicalis } \\
\text { I. orientalis }\end{array}$ & $\varnothing$ \\
\hline$F$ & 27 & + & + & n.a. & n.d. & $\begin{array}{l}\text { C. albicans } \\
\text { C. tropicalis }\end{array}$ & n.d. \\
\hline $\mathrm{M}$ & 2 & + & + & n.a. & n.d. & $\begin{array}{l}\text { I. orientalis } \\
\text { C. kefyr }\end{array}$ & $\varnothing$ \\
\hline$F$ & 32 & + & + & 60 / 92 & 54 & C. albicans & $\begin{array}{l}\text { C. albicans } \\
\text { I. orientalis }\end{array}$ \\
\hline$F$ & 34 & + & + & 1036 & 566 & $\varnothing$ & $\begin{array}{l}\text { I. orientalis } \\
\text { C. glabrata }\end{array}$ \\
\hline$F$ & 20 & + & + & 16 / 30 & 36 & C. albicans & $\begin{array}{l}\text { C. albicans } \\
\text { C. parapsilosis }\end{array}$ \\
\hline$F$ & 25 & + & - & & 140 & $\begin{array}{l}\text { C. albicans } \\
\text { C. parapsilosis }\end{array}$ & n.d. \\
\hline$F$ & 23 & + & - & & 131 & $\begin{array}{l}\text { C. albicans } \\
\text { l. orientalis }\end{array}$ & n.d. \\
\hline $\mathrm{M}$ & 31 & + & - & & n.d. & $\begin{array}{l}\text { C. albicans } \\
\text { C. tropicalis }\end{array}$ & n.d. \\
\hline $\mathrm{F}$ & 40 & - & n.a & & n.d & $\begin{array}{l}\text { C. albicans } \\
\text { S. cerevisiae }\end{array}$ & n.d. \\
\hline $\mathrm{M}$ & 39 & - & n.a & & n.d. & $\begin{array}{l}\text { C. albicans } \\
\text { C. glabrata }\end{array}$ & n.d. \\
\hline $\mathrm{M}$ & 56 & - & n.a & & n.d & $\begin{array}{l}\text { C. glabrata } \\
\text { C. tropicalis } \\
\text { I. orientalis }\end{array}$ & n.d. \\
\hline$F$ & 22 & - & n.a & & n.d & $\begin{array}{l}\text { C. albicans } \\
\text { S. cerevisiae }\end{array}$ & n.d \\
\hline
\end{tabular}

In HIV+/HAART- patients mixed colonization was always found in combination with $C$. albicans. $\varnothing=$ no yeast growth; n.a.= not applicable; $n . d .=$ not determined; in green= mixed colonization. 


\subsection{Association of CD4 T cell number with HAART, oral fungal burden, symptoms and yeast species}

For each HIV-positive patient, the initial CD4 T cell counts were routinely determined. Although patients were supposed to have their CD4 T cells regularly counted for the follow-up, a current CD4 T cell count was not available for all of the patients in the study due to limits in compliance. Therefore, only the subset of patients with recent CD4 $\mathrm{T}$ cell counts (within the last three months) could be considered for this evaluation.

\subsubsection{CD4 T cell counts and oral fungal burden}

Among the patients with an available recent CD4 T cell count (less than 90 days before sampling), its relationship with HAART and fungal burden (measured by the number of fungal CFU from the direct oral smear) was analyzed. In both HIV-positive subgroups the median average CD4 T cell count of the patients with a high fungal burden (HFB) was <150 CD4 T cells/ $\mu$ l. In contrast, there was a significant difference $(p=0.04)$ in the median CD4 T cell count between HAART-treated and untreated patients which only had a low fungal burden (LFB). The median CD4 T cell count was 214 CD4 T cells/ $\mu$ in the HIV+/HAART-group as compared to 336 CD4 T cells/ $\mu$ in the HIV+/HAART+ group (Figure 22). For those patients where no yeasts were found in the oral cavity, there was no difference between both subgroups. The mean average CD4 T cell count was 321 and 313 CD4 T cells/ $\mu \mathrm{l}$ in the HIV+/HAART- and HIV+/HAART+ groups, respectively.

The majority of the HIV+/HAART+ patients without yeasts in the oral cavity had been under treatment for over one year (median: 520 days). For those patients on HAART with low fungal burden, the median time of treatment was 346 days and for those with high oral fungal burden 51 days. Therefore, there was a significant quantitative reduction of colonizing yeasts depending on the duration of HAART.

In summary, there was a correlation between low CD4 T cell counts, no or only short time of HAART and high oral fungal burden. 


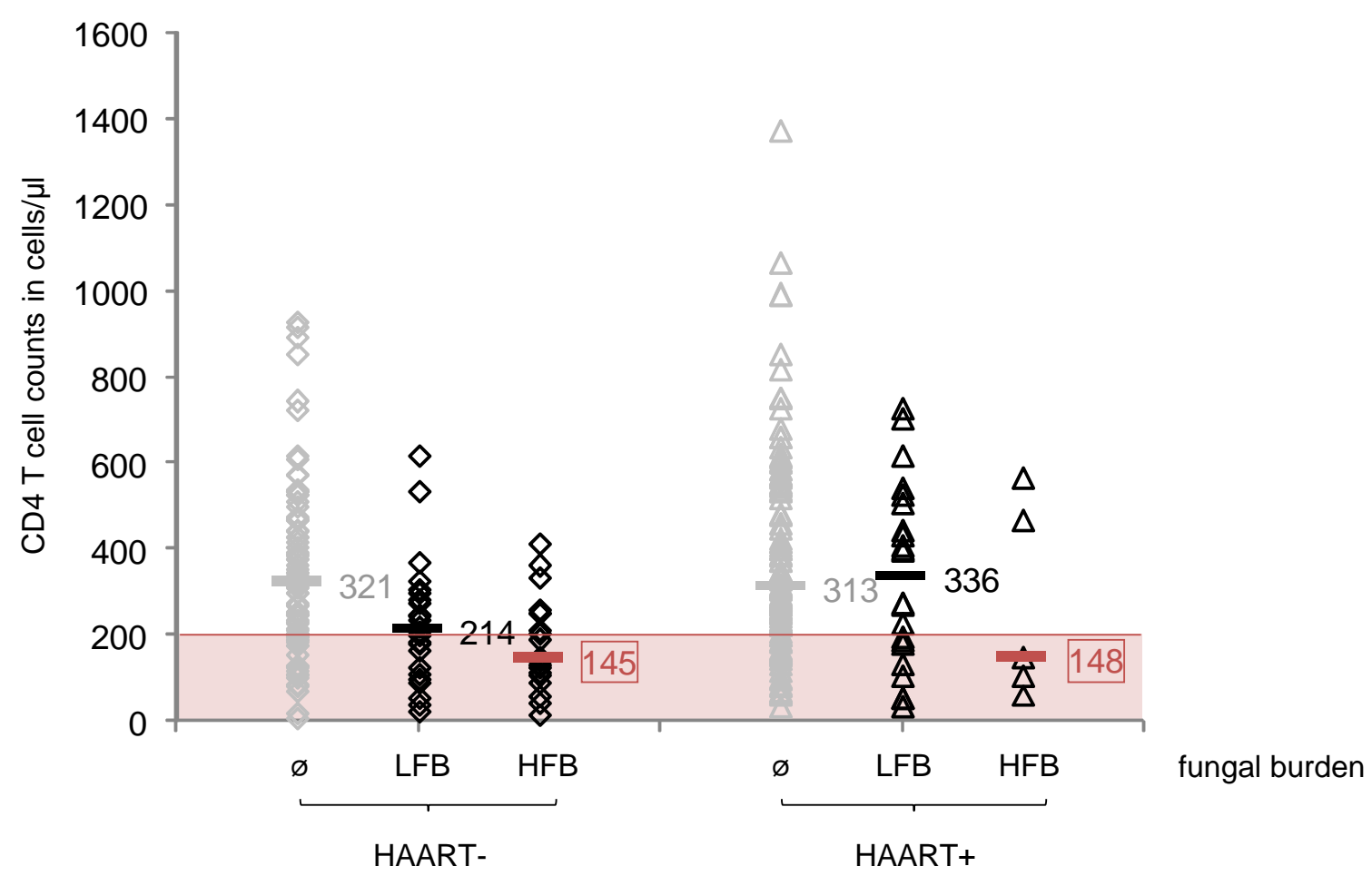

Figure 22: Relationship between CD4 T cell counts and fungal burden in HIV-positive patients with and without HAART. High fungal burden was associated with CD4 T cell counts <200 CD4 T cells/ $\mu$ l in HIV+/HAART- as well as in HIV+/HAART+ patients. $\varnothing=$ no fungal growth, $L F B=$ low fungal burden, $H F B=$ high fungal burden. Horizontal bars indicate the median CD4 $\mathrm{T}$ cell counts per subgroup

\subsubsection{CD4 $\mathrm{T}$ cell counts in asymptomatic and symptomatic HIV- positive patients}

There was no significant difference seen in the median CD4 T cell count between asymptomatic and symptomatic yeast-negative HIV-positive patients. Median CD4 T cell count of yeast-negative HIV-positive patients was 345 and 349 CD4 T cells $/ \mu \mathrm{l}$ in asymptomatic, 289 and $314 \mathrm{CD} 4 \mathrm{~T}$ cells/ $\mu \mathrm{l}$ in patients with mild symptoms and 307 and $293 \mathrm{CD} 4 \mathrm{~T}$ cells $/ \mu \mathrm{l}$ in patients with severe symptoms in the HAART- and HAART+ groups, respectively (Figure 23). In both subgroups, asymptomatic and symptomatic yeast-carriers with only mild symptoms had a median CD4 $\mathrm{T}$ cell count $>200 \mathrm{CD} 4 \mathrm{~T}$ cells $/ \mu \mathrm{l}$. However, HIV+/HAART + yeast-carriers without or with only mild symptoms had significantly $(p=0.02)$ higher median CD4 T cell counts (432 and 397 CD4 T cells/ $\mu$ l) than HIV+/HAART- yeast-carriers (212 and 207 CD4 T cells/ $\mu$ l) with the same symptoms. Only yeast-positive patients with severe symptoms had a median CD4 T cell count $<200 \mathrm{CD} 4 \mathrm{~T}$ cells/ $\mu$ (Figure 23). Therefore OC was highly 
associated with CD4 T cell counts $<200$ CD4 T cells/ $\mu$ l. Nevertheless, $47 \%(n=8 / 17)$ of asymptomatic yeast-carriers in the HIV+/HAART- group and $36 \%(n=4 / 11)$ in the HIV+/HAART+ group had CD4 T cell counts $<200 \mathrm{CD} 4 \mathrm{~T}$ cells $/ \mu$ l.

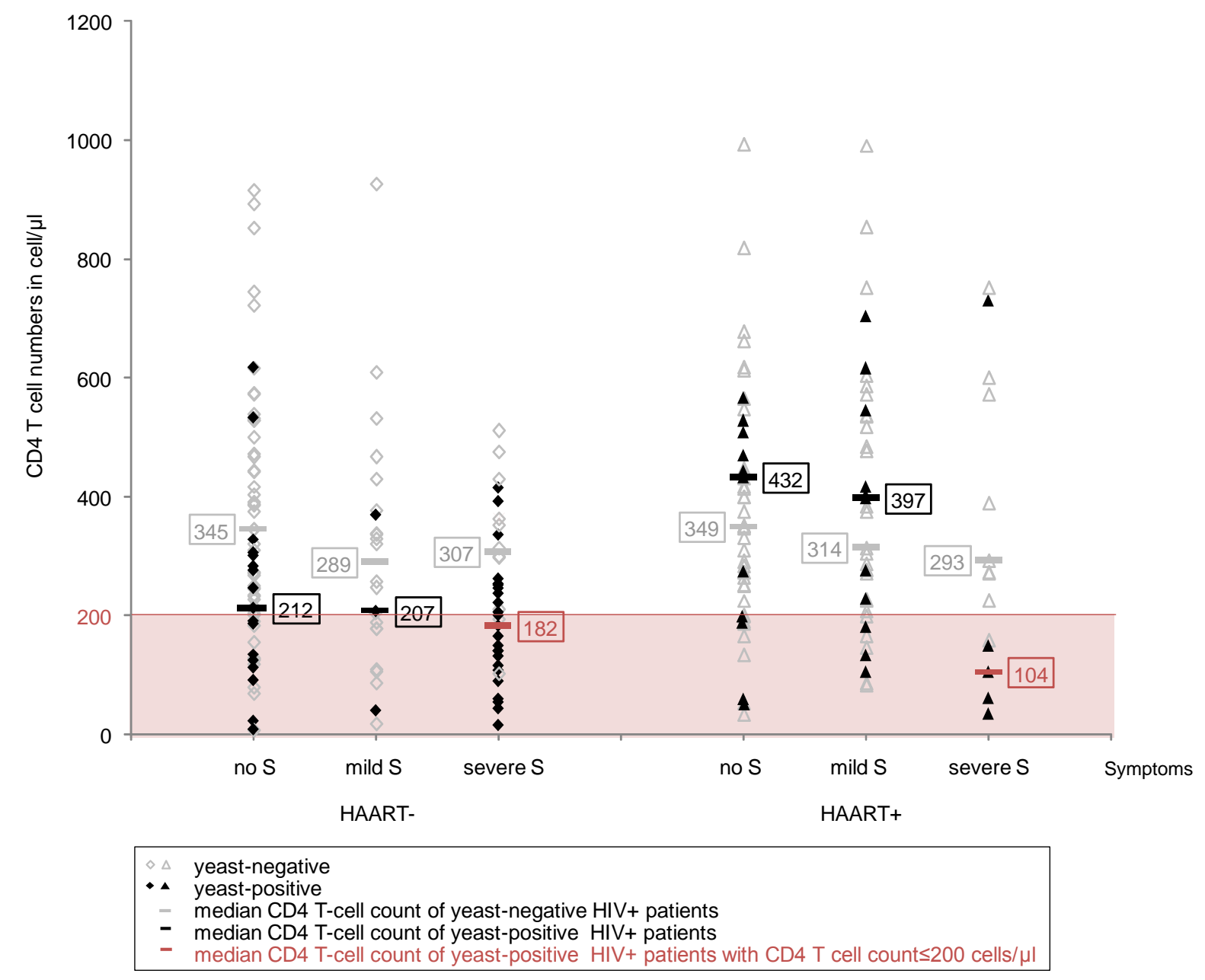

Figure 23: Asymptomatic and symptomatic HIV-positive yeast-carriers and their CD4 T cell counts. Only yeast-positive patients with severe symptoms had a median CD4 T cell counts $<200 \mathrm{CD} 4 \mathrm{~T}$ cells/ $\mu \mathrm{l}$ in HIV+/HAART- as in HIV+/HAART+ patients. S= symptoms.

\subsubsection{CD4 $T$ cell counts, yeast species distribution and fungal burden}

C. albicans was the most frequently isolated yeast species in HIV-positive patients and associated with a median CD4 T cell count $<200$ CD4 T cells/ $\mu$ especially in patients with high oral fungal burden (Table 7 and Figure 24). HIV+/HAART+ patients were significantly $(p \leq 0.01)$ more often colonized with non- $C$. albicans yeast spp. $(50 \%, n=13)$ than HIV+/HAART- patients $(12 \%, n=5)$ (Table 8$)$. Median CD4 T cell 
count of HIV+/HAART+ patients harboring non-C. albicans yeast spp. was 432 CD4 $T$ cells $/ \mu$ land was significantly $(p=0.01)$ higher than patients colonized by $C$. albicans (148 CD4 T cells/ $\mu$ l) in the same group (Table 7).

Table 7: Median CD4 T cell count for $C$. albicans and non- $C$. albicans yeast species

\begin{tabular}{lcc|c|cc|c}
\hline \multicolumn{3}{c|}{ HAART- } & \multicolumn{2}{l}{ HAART+ } \\
\hline \begin{tabular}{llll|ll} 
Fungal burden \\
Low
\end{tabular} & High & combined & Low & High & combined \\
\hline $\begin{array}{l}\text { C. albicans } \\
\text { Non-C. } \\
\text { albicans }\end{array}$ & 214 & 140 & 188 & 230 & 104 & 148 \\
\hline \begin{tabular}{l} 
Significance \\
\hline
\end{tabular} & 274 & 212 & 409 & 517 & 432 \\
\hline
\end{tabular}

High oral fungal burden and colonization with $C$. albicans was associated with CD4 T cell counts <200 CD4 T cells/ $\mu$ lirrespectively of HAART. In HIV+/HAART+ patients colonization with non- $C$. albicans yeast spp. was significantly associated with CD4 T cell counts $>400$ CD4 T cells/ $\mu \mathrm{l}(\mathrm{p}=0.01)$.

Table 8: Distribution of $C$. albicans and non- $C$. albicans yeast species

\begin{tabular}{|c|c|c|c|c|c|c|}
\hline \multicolumn{4}{|c|}{ HAART- } & \multicolumn{3}{|c|}{ HAART+ } \\
\hline $\begin{array}{l}\text { Growth } \\
\text { category }\end{array}$ & Low & High & total & Low & High & total \\
\hline C. albicans & $\begin{array}{c}20 \\
(87 \%)\end{array}$ & $\begin{array}{c}18 \\
(90 \%)\end{array}$ & $\begin{array}{c}38 \\
(88 \%)\end{array}$ & $\begin{array}{c}10 \\
(47 \%)\end{array}$ & $\begin{array}{c}3 \\
(60 \%)\end{array}$ & $\begin{array}{c}13 \\
(50 \%)\end{array}$ \\
\hline $\begin{array}{l}\text { Non- } C \text {. } \\
\text { albicans }\end{array}$ & $\begin{array}{c}3 \\
(13 \%)\end{array}$ & $\begin{array}{c}2 \\
(10 \%)\end{array}$ & $\begin{array}{c}5 \\
(12 \%)\end{array}$ & $\begin{array}{c}11 \\
(53 \%)\end{array}$ & $\begin{array}{c}2 \\
(40 \%)\end{array}$ & $\begin{array}{c}13 \\
(50 \%)\end{array}$ \\
\hline
\end{tabular}

Significance

$\mathrm{p} \leq 0.01$

There was a significantly higher prevalence $(p \leq 0.01)$ of non-C. albicans yeast spp. in the HIV+/HAART+ group. Colonization with non-C. albicans yeast spp. in that group was more associated with a low fungal burden. 


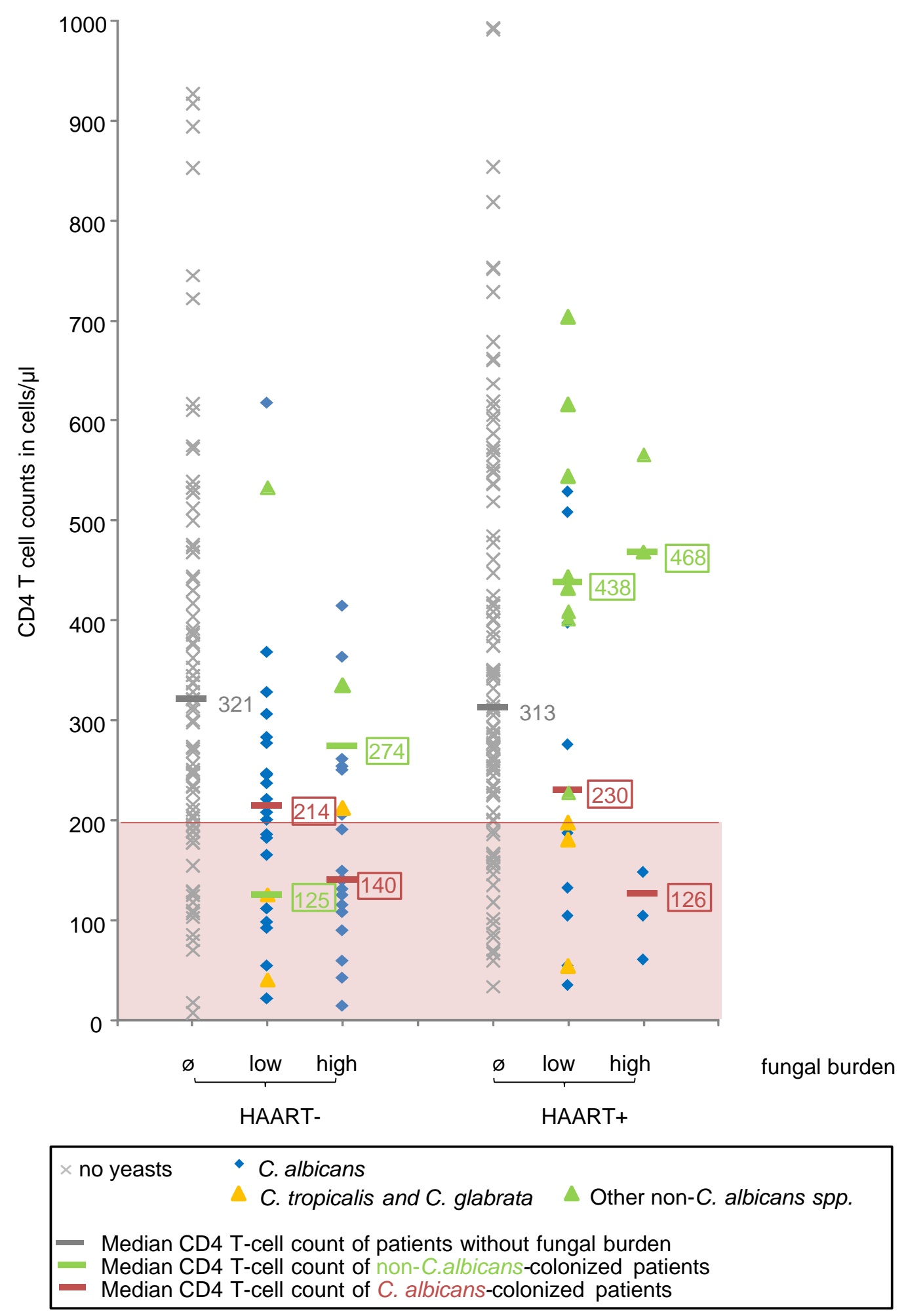

Figure 24: Species distribution in the oral specimen of HIV-positive patients according to their CD4 T cell count and oral fungal burden. Irrespectively of HAART, C. albicans was the most frequently isolated species and associated with CD4 T cell counts <200 CD4 T cells $/ \mu$ in patients with a high oral fungal burden. Colonization with non- $C$. albicans species was more frequent in HIV+/HAART + patients and in the majority of the cases associated with CD4 $\mathrm{T}$ cell counts $>350 \mathrm{CD} 4 \mathrm{~T}$ cells $/ \mu \mathrm{l}$ and a low oral fungal burden. Only the non- $C$. albicans species $C$. tropicalis and C. glabrata were associated with CD4 T cell counts $<200$ CD4 $\mathrm{T}$ cells/ $\mu$ in both subgroups. 


\subsubsection{CD4 $\mathrm{T}$ cell counts, yeast species distribution and clinical symptoms}

There was a high association between severe symptoms, colonization with $C$. albicans and CD4 T cell counts $<200$ CD4 T cells/ $\mu$ irrespectively of HAART (Figure 25A). Almost all patients with severe symptoms harbored $C$. albicans alone or $C$. albicans combined with a non-C. albicans yeast spp. In contrast, colonization with non-C. albicans yeast spp. was more often associated with mild or no symptoms, a low fungal burden, as well as with a high CD4 T cell count in HIV+/HAART+ patients (Figure $25 \mathrm{~A}+\mathrm{B}$ ). Interestingly, colonization with $C$. glabrata or $C$. tropicalis was associated with CD4 $T$ cell counts $<200 \mathrm{CD} 4 \mathrm{~T}$ cells $/ \mu \mathrm{l}$ in HIV+/HAART- and HIV+/HAART+ patients, but not with severe symptoms (Figure 25). Therefore colonization with these species was not associated with OC. There was only one case with severe symptoms and high fungal burden with a non- $C$. albicans yeast $s p p$. This patient was without HAART, had a CD4 T cell count of 335 CD4 T cells/ $\mu$ and was colonized by $P$. fabianii. 


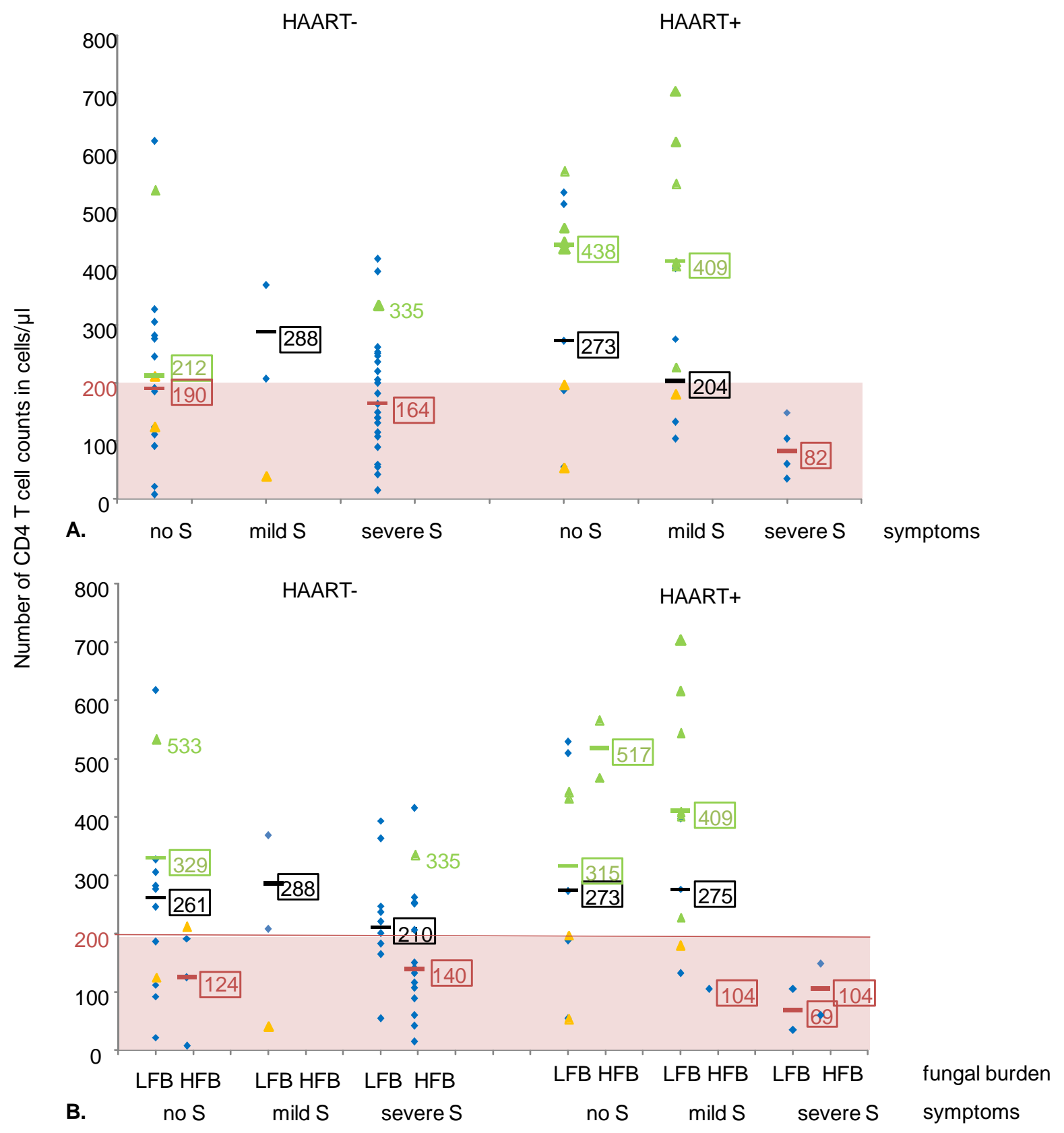

Figure 25: Distribution of the species in asymptomatic and symptomatic HIV-positive patients. Severe symptoms were highly associated with CD4 T cell counts <200 CD4 T cells/ $\mu \mathrm{l}$ and colonization with $C$. albicans irrespectively of HAART (A). Irrespectively of symptoms, patients with a high oral fungal burden and colonization with $C$. albicans mainly had CD4 T cell counts $<200$ CD4 T cells/ $\mu$ l (B). Colonization with non- $C$. albicans spp. in HIV-positive patients was more associated with mild or no symptoms, low fungal burden and CD4 T cell counts $>200$ CD4 T cells/ $\mu$, except for the species $C$. glabrata and $C$. tropicalis. $\mathrm{S}=$ symptoms; $\mathrm{LFB}=$ low fungal burden; $\mathrm{HFB}=$ high fungal burden. 


\subsubsection{Oral fungal burden, symptoms and species distribution with time of HAART}

Division of the patients into subgroups according to their length of HAART showed that the prevalence of colonization and symptoms changed over time. It was characterized by a general quantitative reduction of yeasts in the oral cavity (Figure 26A), reduced occurrence of severe symptoms (Figure 26B), as well as reduced colonization specifically with $C$. albicans with a shift towards colonization with non-C. albicans yeast spp. correlating with the increase in CD4 T cell number (Figure 27). High fungal burden and severe symptoms were highest in HIV-positive patients during their first month of therapy and decreased significantly $(p=0.01)$ during the first six months of therapy from $36.4 \%(n=4 / 11)$ to $3 \%(n=1 / 33)$. The prevalence of yeastpositive patients with severe symptoms (=patients with $\mathrm{OC}$ ) is not completely eradicated after this period of time, few cases are still seen even with a treatment exceeding this time. Similarly asymptomatic yeast-carriers and patients with high oral fungal burden are still present (Figure 26A+B).

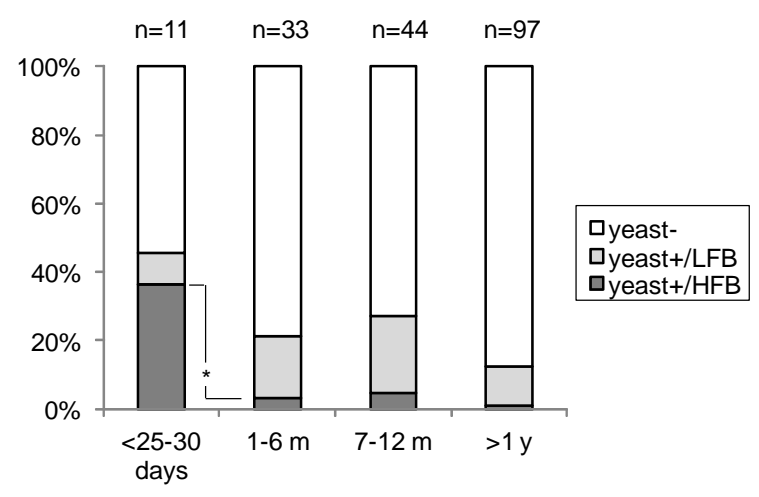

A. Prevalence of oral fungal burden

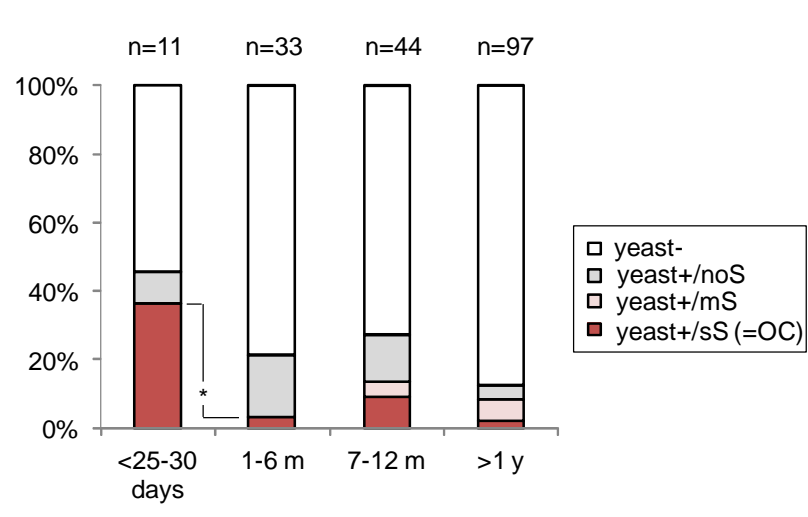

B. Prevalence of symptoms

Figure 26: Influence of the duration of HAART on oral fungal burden and symptoms. There is a diminution in oral fungal burden $(\mathbf{A})$ and symptoms $(\mathbf{B})$ with rising time of HAART which was significant in the first six months of HAART $\left({ }^{*}=p=0.01\right)$. yeast-= yeast-negative; yeast+= yeast-positive; $L F B=$ low fungal burden; $H F B=$ high fungal burden; noS= no symptoms; $\mathrm{mS}=$ mild symptoms; $\mathrm{sS}=$ severe symptoms; $\mathrm{OC}=$ oral candidiasis; $\mathrm{m}=$ months; $y=$ year. 


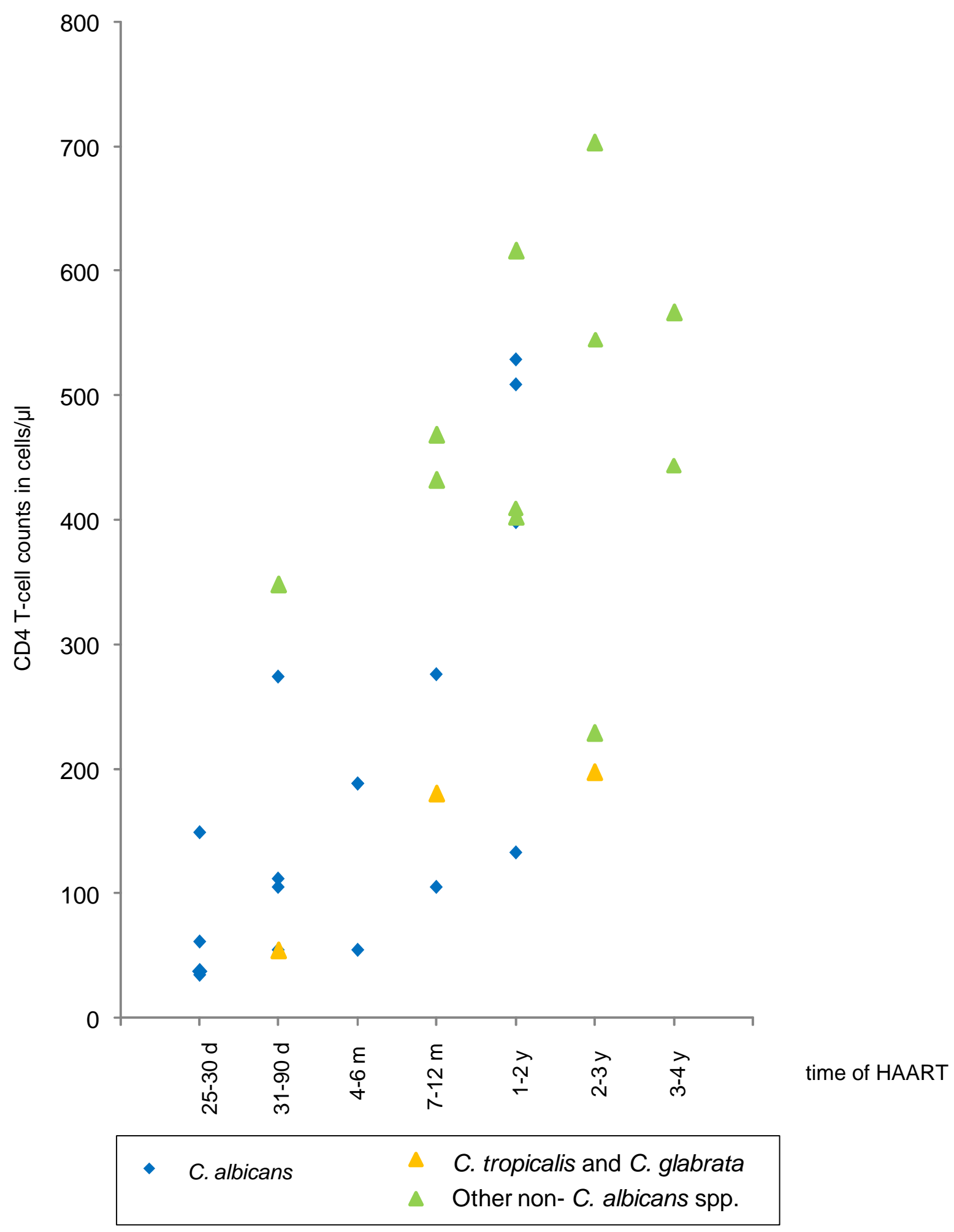

Figure 27: Influence of the duration of HAART on species distribution. There is a shift from colonization with $C$. albicans towards colonization with non- $C$. albicans yeast spp. with time of HAART, correlating with a rise in CD4 T cell number. Colonization with $C$. tropicalis and C. glabrata stayed associated with CD4 T cells <200 CD4 T cells/ $\mu$ l. $d=$ days; $m=$ months; $y=$ years. 


\subsection{Efficacy of antimycotic treatment and antifungal drug susceptibility testing}

\subsubsection{Efficacy of antimycotic therapy}

At time of the first visit or in the last three weeks before, 5 (1.4\%) out of 348 HIVpositive patients were under antimycotic treatment, at second visit 12 out of 134 $(8.9 \%)$ and 6 out of $25(24.0 \%)$ at third visit. Patients had received either treatment with azoles (oral Fluconazole or Ketoconazole), polyenes (mouthwash with Amphotericin B or Nystatin), or topical Clotrimazole, which was administrated when patients presented with dermatomycoses and/or oral thrush.

We analyzed the effect of antifungal treatment and HAART on oral fungal burden as well as on the oral clinical symptoms. A patient was considered to respond to treatment when there was an improvement in oral fungal burden (from yeast-positive to yeast-negative, or from HFB to LFB) and/or in symptoms (symptomatic to asymptomatic or severe to mild symptoms). The reverse cases were considered mild (yeast-negative to LFB or asymptomatic to mild symptoms) or severe worsening (HFB or severe symptoms) of the condition, respectively, and thus treatment failure.

All colonized HIV+/HAART- patients treated with only an antifungal $(n=11)$ responded with clearance of oral yeast or reduction in oral fungal burden (Figure 28A). Further two HIV+/HAART+ with severe symptoms and a high fungal burden (CD4 T cell counts were $<200$ cells $\cdot \mu^{-1}$ ) were treated with an antifungal and were cured (with no presence of yeast) (Figure 28).

In patients with no therapy at all the oral fungal burden got severely worse in $12 \%$ $(n=6 / 52)$ of the cases, stayed unchanged in $69 \%(n=36 / 52)$ of the cases and in $12 \%$ $(n=6 / 52)$ there was an improvement with clearance of yeast in the oral cavity. $\mathrm{HIV}+/ \mathrm{HAART}+$ patients showed almost the same outcome (Figure 28A). Although, the majority of the cases with unchanged oral fungal burden were patients with no fungal burden.

The analysis of the symptomatic outcome showed similar results except for the observed patients treated only with an antimycotic. There only $33 \%(n=5 / 15)$ had a clinically visible improvement of symptoms under antifungal treatment (Figure 28B). Seven patients out of ten presented with the severe symptoms before and after 
treatment. Anyhow, in six out of these seven cases there was an improvement in fungal burden with clearance of yeast. Antifungal treatment was therefore very effective against colonization with Candida even when not always clinically visible.
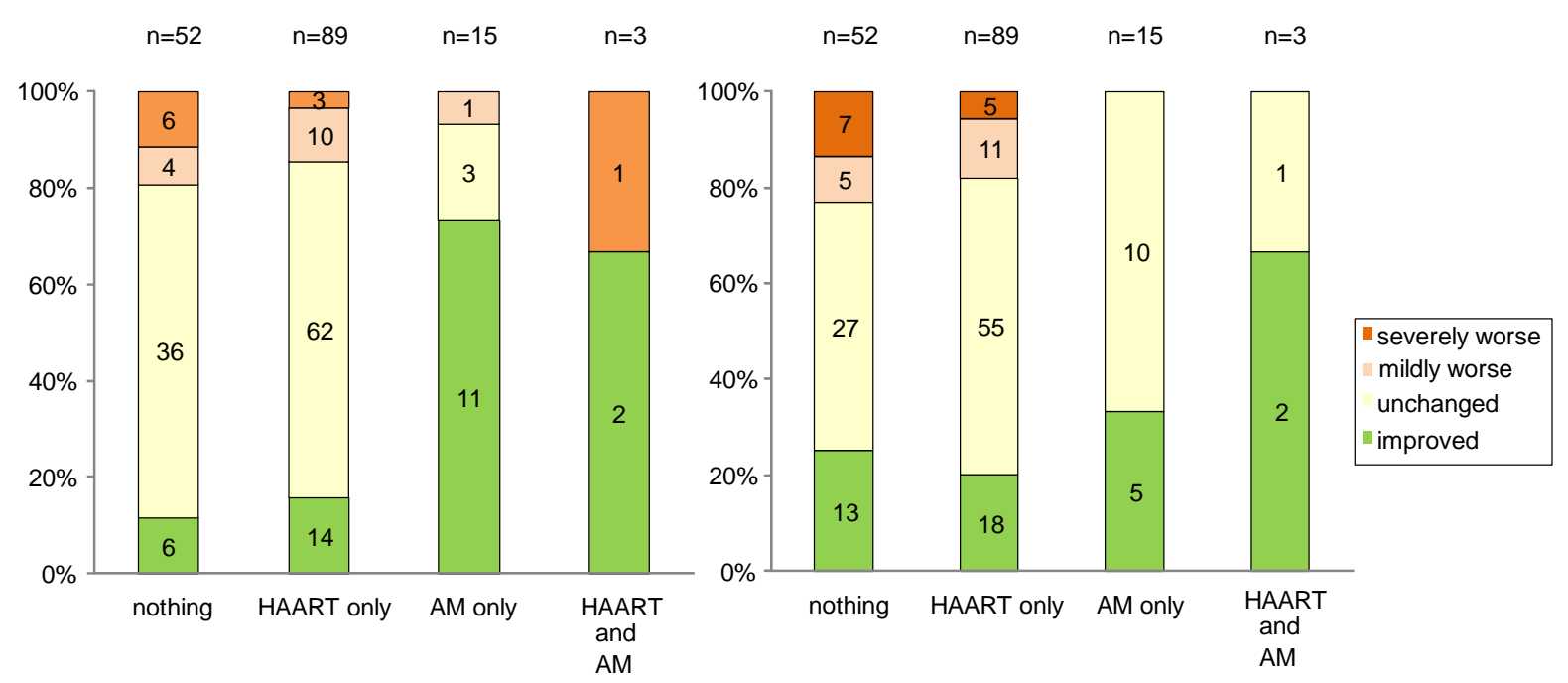

A. Effect on oral fungal burden

B. Effect on oral symptoms

Figure 28: Effect of HAART and antimycotic therapy on oral fungal burden. Oral fungal burden clearly improved under antimycotic treatment (A). All yeast-positive patients responded to solely antimycotic treatment with clearance of yeast, but not always with clinically visible change of symptoms (B). The majority of the patients with unchanged oral fungal burden $(\mathbf{A})$ were yeast non-carriers. Severely worse= shift from yeast-negative or LFB to $\mathrm{HFB}(\mathbf{A})$, or asymptomatic or mild symptoms to severe symptoms (B); mildly worse $=$ yeast-negative to LFB $(\mathbf{A})$, or asymptomatic to mild symptoms $(\mathbf{B})$.

A species shift under antimycotic treatment could neither be seen in HIV+/HAART+ nor in HIV+/HAART- patients (data not shown). Nevertheless, a shift from C. albicans or a mixed culture with $C$. albicans towards colonization with only non- $C$. albicans yeast spp. was seen in four (out of nine colonized) HIV+/HAART+ patients without any antifungal treatment (data not shown).

If we looked at the efficacy of antifungal treatment focusing on patients with $\mathrm{OC}$, there was a statistically significant difference between treated and non-treated patients $(p \leq 0.01)$. Patients with OC profited from HAART, antifungal therapy or the combination of both (Table 9). 
Table 9: Effect of treatment in patients with oral candidiasis

\begin{tabular}{lllll}
\hline & nothing & $\begin{array}{l}\text { HAART } \\
\text { only }\end{array}$ & AM only & both \\
\hline $\begin{array}{l}\text { Improvement of } \\
\text { visible symtoms } \\
\text { or/and fungal burden }\end{array}$ & 1 & $3(75 \%)$ & $8(100 \%)$ & $2(100 \%)$ \\
$\begin{array}{l}\text { No improvement } \\
\text { Total }\end{array}$ & $5(83.3 \%)$ & 1 & 0 & 0 \\
\hline Significance & 6 & 4 & 8 & 2 \\
\hline
\end{tabular}

Oral fungal burden of patients with $O C$ was significantly improved in treated patients with HAART, antimycotic or the combination of both (Fisher's exact test $p \leq 0.01$ ). 


\subsubsection{In vitro antifungal susceptibility of the isolated yeast species}

To determine the susceptibility towards common antifungal substances, all yeast strains isolated were tested according to the NCCLS Reference Method for Broth Dilution Antifungal Susceptibility Testing of Yeast, Approved Standard M27-A2. Substances tested were Amphotericin B, Nystatin, Fluconazole, Itraconazole, and Caspofungin. Yeast species were considered resistant when their MICs were above the clinical breakpoints set by the clinical laboratory standard Institute (CLSI). All isolates in this study were susceptible to Amphotericin B with MIC ranges between $0.031-0.5 \mu \mathrm{g} / \mathrm{ml}$. C. albicans had mainly MICs of $0.125-0.250 \mu \mathrm{g} / \mathrm{ml}$. All C. albicans isolates were fully susceptible to Fluconazole and Itraconazole. $15 \mathrm{l}$. orientalis isolates $(79.0 \%)$ were resistant to Fluconazole, eleven with a MIC of $64 \mu \mathrm{g} / \mathrm{ml}$ and four with a MIC of $96 \mu \mathrm{g} / \mathrm{ml}$. All the other non- $C$. albicans species were fully susceptible to Fluconazole. The nine isolated $C$. glabrata were fully resistant to Itraconazole, with MICs of mainly $2 \mu \mathrm{g} / \mathrm{ml} .17$ (89.5\%) out of 19 isolated I. orientalis, four (19\%) out of 21 C. tropicalis, all six S. cerevisiae, all two $P$. guilliermondii and the only isolated $C$. pararugosa were resistant to Itraconazole with MICs $\geq 1 \mu \mathrm{g} / \mathrm{ml}$. The MIC ranges of all isolates for Nystatin and Caspofungin were $1-8 \mu \mathrm{g} / \mathrm{ml}$ and 0.063 $0.5 \mu \mathrm{g} / \mathrm{ml}$ respectively. Only one C. parapsilosis isolate had a MIC of $1 \mu \mathrm{g} / \mathrm{ml}$ for Caspofungin (Figure 29).

Non- C. albicans yeast isolates with MICs above the clinical breakpoint were not more prevalent in patients with recorded history of one or more exposure to antimycotic therapy and there were no cases of clinical OC caused by species other than $C$. albicans. Furthermore all patients with $\mathrm{OC}$ responded to antifungal therapy (Table 9). 

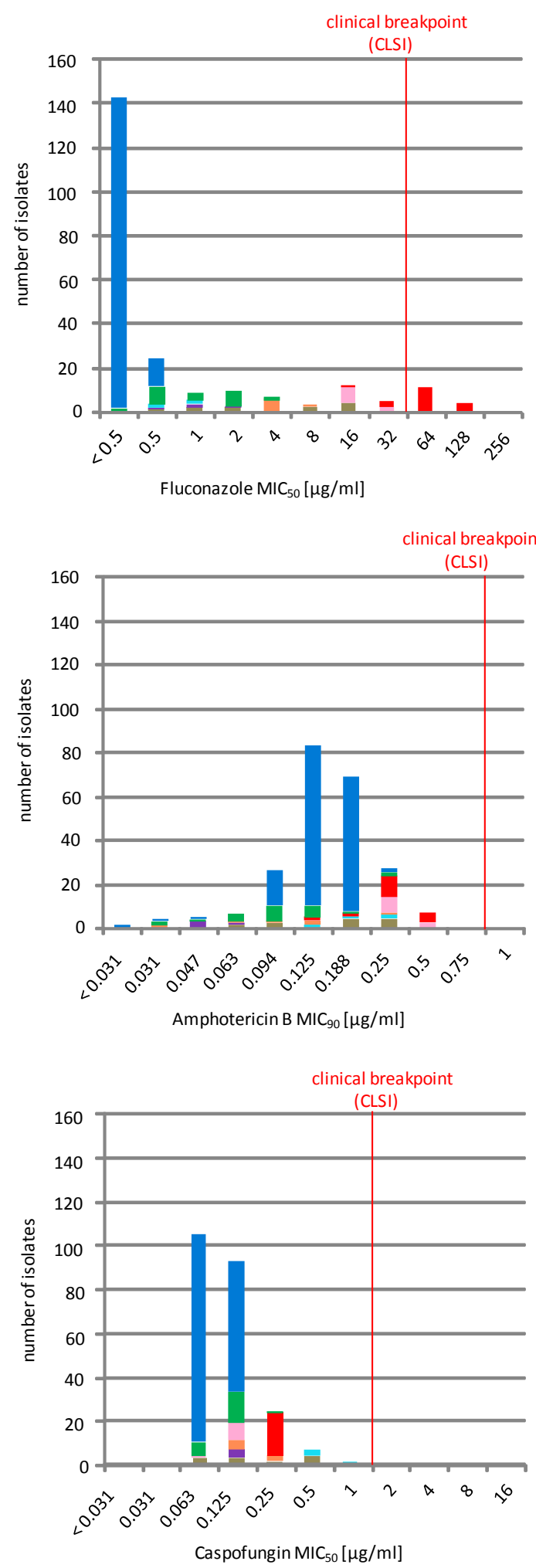
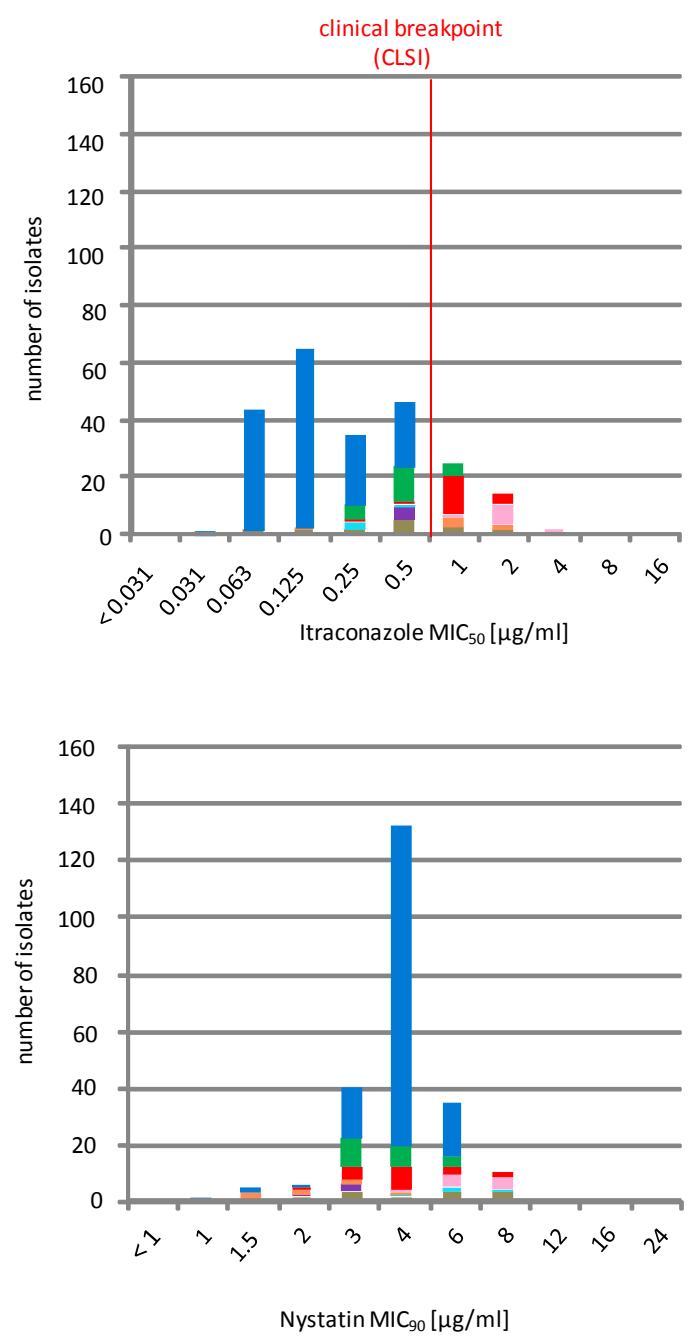

legend for all panels

- Candida albicans

Candida tropicalis

- Issatchenkia orientalis (Candida krusei)

Candida glabrata

Saccharomyces cerevisiae

Candida parapsilosis-group

- Pichia fabianii (Candida fabianii)

other

Figure 29: In vitro susceptibility of the isolated yeast species to the different antifungal agents. A clinical breakpoint was not yet defined for Nystatin. All species with MICs above the clinical breakpoint were considered resistant (in vitro). All C. glabrata isolates were resistant to Itraconazole but were susceptible to Fluconazole; resistance to Itraconazole was further seen for the species I. orientalis, C. tropicalis, all S. cerevisiae, P. guilliermondii and C. pararugosa spp. I. orientalis were the only species resistant to Fluconazole. All species were susceptible to Amphotericin $\mathrm{B}$ and Caspofungin. $\mathrm{MIC}=$ minimal inhibiting concentration. 


\section{Discussion}

Despite the introduction of antiretroviral therapy, under which the prevalence of opportunistic infections has decreased (Hood et al. 1998; Schmidt-Westhausen et al. 2000; Greenspan et al. 2004), OC still remains a significant and common opportunistic infection in HIV-infected individuals (Thompson et al. 2010; Mataftsi et al. 2011). This is especially true in Sub-Saharan Africa, where HAART is still not widely available (Hamza et al. 2006; Tirwomwe et al. 2007; Hamza et al. 2008). The prevalence of $\mathrm{OC}$ and the yeast species involved vary throughout the world, as well as within the countries themselves due to many confounding variables, such as the availability of HAART, access to health care, nutrition, present oral and environmental yeast flora. Candida albicans has been reported to be the most frequently isolated yeast species throughout the world. Also, the incidence of other Candida species less susceptible or resistant to the antifungal drugs in use has been increasing and has become a strong concern for clinicians in the management of affected individuals (Pfaller et al. 2007). Yeast identification and antifungal susceptibility testing have therefore become of high importance. As oral and invasive yeast infections are mostly caused by the endogenous colonizing yeasts of the mucosal surfaces (Fetter et al. 1993; Pfaller 1995; Vargas and Joly 2002; Grimoud et al. 2003) and the distribution as well as the pathogenicity and antifungal drug susceptibility of the species vary in the different geographical regions, it is important to investigate their prevalence and distribution throughout the world. Although numerous epidemiological studies in Europe and the Americas on the prevalence of yeasts causing candidiasis have been published, little is known about the yeast flora and etiology of candidiasis in people living in developing countries. In Sub-Saharan Africa, where the majority of HIV-infected individuals live, only few studies on the prevalence of yeasts in the oral cavity of HIV-positive patients (Hodgson and Rachanis 2002) have been performed. For Chad, even no data are available at all. We have therefore studied the prevalence and epidemiology of oral asymptomatic and symptomatic yeast carriage of HIV-positive vs. HIV-negative individuals from Southern Chad, identified the yeast species involved and analyzed the impact of age, sex, HAART, CD4 T cell numbers as well as the use of different antimicrobials on 
oral yeast colonization and infection. Susceptibility of the differentiated yeast isolates to common antifungals was determined.

\section{Prevalence of oral candidiasis}

The overall oral Candida carriage rate $(25 \%)$ as well as the prevalence of OC (10.2\%) of HIV-positive patients found in Chad was surprisingly low as compared to other African countries where numbers ranged from $41.2 \%$ in Cameroon (Lohoue Petmy et al. 2004) to $81.5 \%$ in Ghana (Kwamin et al. 2013) and $81.3 \%$ in South Africa (Patel et al. 2006). These differences may be due to the selected study groups (e.g. HIV disease stage and availability of antiretroviral treatment). However, chosen diagnostic tools and criteria and experience level of the investigators may also play a role. In the clinic of Maingara, as it is a specialized center for HIV/AIDS patients with rigorous follow up and availability of HAART, cases with advanced stages of immune deterioration were rare.

Many previous studies have demonstrated that potent antiretroviral treatment like HAART containing a combination of antiretrovirals significantly reduces opportunistic infections such as OC (Powderly et al. 1998; Yang et al. 2006; Lourenco et al. 2011). This has been found in Cameroun, were the prevalence of OC was $30 \%$ in HIV+/HAART+ versus $70 \%$ in HIV+/HAART- patients, as well as in Tanzania where values were $15 \%$ and $38 \%$, respectively (Hamza et al. 2006; Njunda 2011). This improvement of oral fungal infection by HAART is as well supported by our findings. Although our numbers of OC prevalence $(5 \%$ in HIV+/HAART+ and $16 \%$ in HIV+/HAART-) were far lower, they were closer to those of studies performed in South India (Umadevi et al. 2007) and Taiwan (Yang et al. 2006), where the prevalence of $O C$ reached $8 \%$ and $24 \%$ in South India and $2.1 \%$ and $10.6 \%$ in Taiwan in HIV+/HAART+ and HIV+/HAART- patients, respectively. A possible explanation for the very low prevalence of $5 \%$ OC found in our cohort of HIV+/HAART + patients might be the treatment duration. The prevalence of OC was significantly reduced with HAART over a period of six to twelve months and beyond. The same was found in a cohort of 532 HIV-positive patients recruited from the Muhimbili National Hospital HIV Clinic in Dar es Salaam, Tanzania (Hamza et al. 2006) and the prospective longitudinal study of 142 HAART-treated HIV-positive patients in Taiwan (Yang et al. 2006). In a cohort of 92 HIV-positive patients from Germany, the prevalence of OC was even reduced to zero (Jordan 2007). In our 
study, $53 \%$ of the patients were under HAART, $78 \%(n=141 / 180)$ for at least six months, and $54 \%(n=97 / 180)$ for 12 months or more.

Fungal infection is usually caused by commensal yeast species of the mucosa (Fetter et al. 1993; Pfaller 1995; Vargas and Joly 2002). Therefore, another factor explaining our results could be the general lower prevalence of colonizing yeasts in the Chadian population, represented by our HIV-negative control group (22.5\%).

It may also have been possible, that among the HIV+/HAART- patients, the HIV infection had been only recent and therefore at an early stage, where opportunistic infections like OC are not yet apparent (Wanzala et al. 1989; Owotade et al. 2008). In many developing countries, traditional herbal medicine is still widely used, some of which have been shown to have an anticandidal effect (Rukayadi et al. 2008; Marzouk et al. 2009). Due to the poor and marginally developed health care system, the use of traditional herbal medicine is widely spread in Chad. However, precise data concerning its use were not available for this study.

Saccharomyces cerevisiae was found to be the second (in Bemouli) and third (in Maingara) most common yeast species isolated among our Chadian patients without being a cause of infection. Potentially, these may originate from wild $S$. cerevisiae yeast strains used for the local home-brewed and widely consumed alcoholic beverage in Chad, known as bili-bili. Bili-bili is made by fermenting locally grown sorghum and millet (Maoura 2005). Oral uptake of $S$. cerevisiae is known to have an inhibitory effect on OC (Premanathan 2011).

Although the introduction of HAART has led to a significant decrease or even absence of oral lesions such as OC (Powderly et al. 1998; Yang et al. 2006; Jordan 2007; Lourenco et al. 2011), OC continues to be a significant oral lesion highly associated with HIV infection in both developed and developing countries (Ranganathan et al. 2004; Hodgson et al. 2006). Oral colonization with Candida, even though observed to decrease, was also still present: $9 \%$ of our HIV+/HAART+ patients were asymptomatic yeast carriers, including those with mild symptoms the prevalence rose up to $14 \%$. This correlated with the observations made in a study in Italy (Cauda et al. 1999) and in Taiwan (Yang et al. 2006). 


\section{Classification and epidemiology of the different clinical features of oral candidiasis (OC)}

Very few studies investigating on the prevalence of $O C$ describe the observed oral lesions in a defined way; and most rely on presumptive rather than definite diagnosis. The most common used classification for oral lesions in HIV-infected patients, especially in developing countries, is the ECC classification (EC-Clearinghouse 1993). In this revised classification from 1993 only two forms of OC are distinguished: the pseudomembranous (PC) and the erythematous candidiasis (EC). The description of the PC: "white or yellow spot or plaques that can be located in any part of the oral cavity and can be wiped off to reveal an erythematous surface which may bleed" (EC-Clearinghouse 1993, page 289) only fitted to five (14.3\%; 5/35) of our HIV-positive patients with OC. The majority of our HIV-positive patients with severe symptoms ( $n=41 / 64 ; 64 \% ; n=17 / 35=48.6 \%$ ) suffered from a whitish or yellowish coating affecting $>50 \%$ of the dorsum of the tongue, which was not easily removable. Only $39 \%(n=16 / 41)$ of these patients were yeast-positive and in 94\% $(n=16 / 17)$ of the cases colonized by $C$. albicans. The median CD4 T cell count of these yeastpositive patients was $<150 \mathrm{CD} 4 \mathrm{~T}$ cells/ $\mu$ l, so that the manifestation of oral lesions strongly associated with HIV was highly suspect. Although the diagnosis of OC still stays essentially clinical (Coronado-Castellote and Jimenez-Soriano 2013), none of the criteria of the described oral lesions of the ECC classification corresponded to the oral manifestations seen here. The proposed classification by Axell et al. (1997) differentiates between an acute and a chronic type of OC, Candida-associated lesions and keratinized primary lesions superinfected with Candida. Of these variants, superinfected keratinized primary lesions like oral hairy leukoplakia or lychen planus with Candida could be taken into consideration, as the lesions were not easily to remove. Anyhow, the coating in our patients affected the dorsum of the tongue, which is neither usual for the oral hairy leukoplakia nor the lychen planus. Oral hairy leukoplakia is usually described to be found on the lateral tongue, with eventually vertical corrugations or a flat appearance which cannot be wiped off (ECClearinghouse 1993). Lychen planus of the mouth appears as lace-like fine white lines usually at the inside of the cheeks (AAOMP 2005). These variants clinically seemed less likely. Another possible variant could be the hyperplastic plaque-like candidiasis. Tissue biopsy to confirm the hyperplastic form was not available and clinically, the hyperplastic candidiasis is described as lesions at the mouth 
commisures (Akpan and Morgan 2002; Williams and Lewis 2011; Madhu 2013), which did also not fit to our cases. Pseudomembranous candidiasis is highly associated with CD4 T cells dropping <200 CD4 T cells/ $\mu$, which is in accordance with our study (Ranganathan et al. 2004; Mercante et al. 2006; Witzel et al. 2008; Bodhade et al. 2011). Our yeast-positive patients with observed whitish or yellowish coating of more than $50 \%$ of the tongue area, classified as nonspecific OC, had a median CD4 $T$ cell count $<150$ cells, making a presumptive classification as pseudomembranous candidiasis reliable.

The second most common clinical sign in our patients was the median rhomboid glossitis which affected $20.3 \%(n=13 / 64)$ of the patients with severe symptoms. Out of these, $69 \%(n=9 / 13)$ were yeast-positive, in eight out of nine C. albicans was isolated. The median rhomboid glossitis presents as a central red area with papillary atrophy of the dorsum of the tongue or palate. Median rhomboid glossitis has infrequently been described as a lesion also seen in HIV-positive patients (Gazzard and Smith 1990; Flaitz and Hicks 1999; Barasch et al. 2000; Okunseri et al. 2003). In the classification of Axell et al. it has been included and mentioned as a distinct form of "Candida-associated lesions" (Axell et al. 1997). In the ECC classification it is not mentioned. Some authors suggest it is "a form of erythematous candidiasis " (Kolokotronis et al. 1994; Lalla et al. 2013). Therefore, it may have been misclassified as erythematous candidiasis in previous studies. As outlined above, the most common types mentioned and discussed are the pseudomembranous and the erythematous candidiasis. In accordance with the description of the erythematous candidiasis in the ECC classification ("red areas located on the palate or dorsum of the tongue"), the patients in our study group which presented with the features of the median rhomboid glossitis could be classified as erythematous candidiasis.

Since the erythematous candidiasis is as well described as a red atrophic area with loss of filiform papillae when affecting the tongue (Lalla et al. 2010), our patients with symptoms of tongue atrophy and positive yeast growth could as well be classified as erythematous candidiasis resulting in a total prevalence of $38.4 \% \quad(n=10 / 26)$ of erythematous candidiasis in HIV+/HAART- patients. This was similar to the findings in a study performed among HIV+/HAART- patients in India where the prevalence was $39.3 \%$ (Bodhade et al. 2011).

The epidemiology (relationship with HAART and CD4 T cell counts or other factors) of the different forms of candidiasis in HIV-positive patients has rarely been 
investigated. In a cohort from Germany the erythematous candidiasis was only found in patients not undergoing any antiretroviral treatment (Jordan 2007). It is not clear, if the patients classified as erythematous candidiasis included the features of the median rhomboid glossitis. Anyhow, if the median rhomboid glossitis is a form of erythematous candidiasis, our findings would be similar to the German and Indian study (Jordan 2007; Bodhade et al. 2011). In studies from Kenya and South Africa performed before the HAART era, the erythematous candidiasis was significantly more prevalent than the pseudomembranous candidiasis (Hodgson and Rachanis 2002) and in a Tanzanian study including HIV+/HAART+ patients, the prevalence of erythematous candidiasis was only $1.4 \%$ (Hamza et al. 2008). Therefore, a correlation between the appearance of erythematous candidiasis (and possibly median rhomboid glossitis) and the absence of HAART seems reliable, and is supported by our findings here, and the German and Indian study (Jordan 2007; Bodhade et al. 2011).

A correlation between erythematous candidiasis and CD4 T cell counts dropping $<400$ CD4 T cells/ $\mu$ l has been observed (Mercante et al. 2006; Witzel et al. 2008), which would correlate with our findings: patients with median rhomboid glossitis had a median CD4 T cell count of 200 CD4 T cells/ $\mu$ and those with atrophy 338 CD4 T cells/ $\mu$ l. In a study in Zambia, erythematous candidiasis was even found to be associated with CD4 T cell counts <200 CD4 T cells/ $\mu$ l (Hodgson 1997).

According to Bodhade et al. (2011), erythematous candidiasis may as well be a good marker of immunosuppression, anyhow, not as sensitive and specific as the pseudomembranous candidiasis.

The distribution of pseudomembranous and erythematous candidiasis among our patients with OC $(n=34)$ would then be $68 \%$ and $32 \%$ respectively, which matches the results in a study published in India (2008), where $83.3 \%$ of the cases with OC had pseudomembranous type lesions followed by erythematous candidiasis with $16.6 \%$ (Nadagir et al. 2008). The higher rate of pseudomembranous candidiasis in the Indian study can be explained by the fact, that the cohort consisted of terminally ill patients, here again underlining the high predictive value and correlation of pseudomembranous candidiasis with a severely deteriorated immune system (Bodhade et al. 2011). 


\section{Species prevalence and association with OC}

Worldwide, $C$. albicans has frequently been found to be the most prevalent yeast species found in the oral cavity of HIV-positive and healthy subjects ranging from $50 \%$ in Iran (Badiee et al. 2010) to $91.5 \%$ in South Africa (Blignaut 2007). This species was also predominant in our study performed in Chad; with $44.2 \%$ in the HIV-negative control group, $58.6 \%$ in the HIV+/HAART+ group, and $87.1 \%$ in HIV+/HAART- patients, which matches with the findings of Nweze and Ogbonnaya (2011) in Nigeria.

I. orientalis and $C$. tropicalis were the second most common yeast species isolated in the oral cavity of our HIV-positive patients, which correlates with the findings of a study in an HIV cohort from Nigeria (Enwuru et al. 2008) and partly with those from Uganda (Agwu et al. 2011). Other studies found C. glabrata at second position (Sanchez-Vargas et al. 2005a; Sanchez-Vargas et al. 2005b; Badiee et al. 2010). C. glabrata ranked only fifth in our HIV-positive patients.

As $C$. glabrata has often been co-isolated with $C$. albicans in patients with $O C$ its clinical relevance has been questioned (Dronda et al. 1996; Ally et al. 2001; Redding 2001). In our study groups of HIV-positive patients $C$. glabrata and C. tropicalis were more frequently present as sole colonizing yeasts of the oral cavity when CD4 T cell counts were $<200 \mathrm{CD} 4 \mathrm{~T}$ cells/ $/ \mu$. But these patients did not have any clinical signs of infection. Furthermore all the other non-C.albicans spp. were only associated with a low fungal burden, mild or no symptoms, as well as high CD4 T cell counts. This would underline the fact, that Candida species other than $C$. albicans are considered to be less pathogenic and may simply act as commensals (Dronda et al. 1996; Fidel et al. 1999).

Although isolation of non-C. albicans yeast spp. has been reported in HIV-positive patients, in almost all reports, OC has been reported to be mainly linked with the presence of $C$. albicans or $C$. albicans mixed with a non- $C$. albicans yeast spp. (Redding 2001; Patel et al. 2006; Agwu et al. 2011). Similarly in our cases of OC, C. albicans was also the most prevalent yeast. Consequently, $C$. albicans is considered to be more pathogenic than other Candida species. Its putative virulence factors seem to be expressed in higher ratios in HIV-positive patients when the hosts immune system fails (De Bernardis et al. 1996; Wu et al. 1996; Fidel 2011; Cassone and Cauda 2012). 
Nevertheless, C. glabrata should not be ignored as mixed infections of $C$. glabrata with C. albicans are more severe in patients with HIV infection (Redding 2001). Furthermore, the intrinsic resistance of $C$. glabrata to many azoles (Bagg et al. 2003), especially Fluconazole, makes co-infection due to this species more difficult to treat (Redding 2001).

The increasing reports of the emergence of non- $C$. albicans species associated with OC and HIV infection (Schoofs et al. 1998; Melo et al. 2004; Enwuru et al. 2008) has been explained by the repeated exposure to azoles, which results in the selection of less susceptible species like C. glabrata or I. orientalis (Cartledge et al. 1999; Hope et al. 2002; Snydman 2003; Hamza et al. 2008; Agwu et al. 2011). Antifungal exposure was rare in our study group and patients harboring non-C. albicans yeast spp. did not have a history of previous fungal therapy. Therefore, the emergence of non-C. albicans yeast spp.in our study cannot be explained by this hypothesis.

\section{Emergence and etiology of non-C. albicans yeast species}

Besides the overall reduced rate of yeast prevalence in the oral cavity and clinical manifestation of OC, our study group of HIV+/HAART+ patients also displayed an increased species diversity, as similarly seen in a study in Brazil (Melo et al. 2004). Non- $C$. albicans yeast spp. isolated from our patients were I. orientalis, C. tropicalis, C. glabrata, C. parapsilosis, C. orthopsilosis, P. fabianii, P. farinosa, P. guilliermondii, C. kefyr, C. pelliculosa, C. rugosa, C. pararugosa and one isolate of a novel C. orthopsilosis-like species. It is well established that the protease inhibitors (PI) that may be included in HAART have an effect on colonization at least with $C$. albicans, possibly through reduction in adhesion to epithelial cells by inhibiting the secretory aspartic proteases (SAP) of C. albicans (Borg-von Zepelin et al. 1999; Cassone et al. 1999; Witzel et al. 2008). The National Guidelines of the Republic of Chad, however, specify treatment of HIV-infected patients with a combination of the three reverse transcriptase inhibitors (RTI) stavudine, lamivudine, and nevirapine and patients were treated accordingly. Nucleoside reverse transcriptase inhibitors (NRTI) appear to have little in vitro effect on virulence traits of $C$. albicans (Ahmadou Ahidjo et al. 2008). Although the genome of $C$. albicans contains several transcriptionally active genes with similarities to reverse transcriptase (e.g. the "zorro element" family) which appear to be involved in the process of filamentous growth and are lacking from most non-C. albicans yeast spp. (Goodwin et al. 2001). This could explain the rise in non- 
C. albicans yeast spp. under this particular treatment, although no particular data are available on interaction of these $C$. albicans proteins with NRTIs. Therefore, in the absence of Pls and antifungal treatment, the improvement of the immune function under HAART with increased CD4 T cell counts and decreased viral loads is likely to be responsible for the decrease of OC (Fethi et al. 2005; Sanchez-Vargas et al. 2005a; Fidel 2006; Yang et al. 2006; Ortega et al. 2009; Wu et al. 2011) and the emergence of non-C. albicans yeast spp. colonizing the oral cavity of HIV-infected patients (Nweze and Ogbonnaya 2011).

HIV-negative subjects also presented with lower prevalence of $C$. albicans and higher diversity of non-C. albicans yeast spp. which is similar to the reports from Hauman, Mc Collough, Xu and Mitchell and Pomarico (Hauman et al. 1993; McCullough 2001; Xu and Mitchell 2003; Pomarico et al. 2009). A review giving an overview over oral fungal infection in Africa showed that the resident oral yeast flora of HIV-negative individuals in resource-poor countries is markedly different from that in developed countries with non- $C$. albicans yeast spp. being more prevalent (Hodgson and Rachanis 2002). This is in agreement with our study and a report from China in 2002 (Xu and Mitchell 2003): in healthy HIV-negative individuals from villages in China without antifungal history, the prevalence of $C$. albicans was only $9.4 \%$ compared to $77-84 \%$ in healthy HIV-negative individuals from Hong Kong (Sedgley and Samaranayake 1994). Poor oral hygiene and no access to dental health care or even malnutrition in the studied regions may favor colonization by non- $C$. albicans yeast spp (Jabra-Rizk et al. 2001). It has been further suggested that the wider spectrum of yeast species observed in antifungal naive HIV-negative individuals may reflect "an ancestral human-yeast association" and that development factors as industrialization, lifestyle and regular dental health care "may have favored the selection of $C$. albicans over other species" (Xu and Mitchell 2003). This is supported by the results of a study performed among an indigenous population in a remote area of French South Guiana, where it was found that the prevalence of colonizing non- $C$. albicans yeast spp. was far higher than $C$. albicans (Angebault et al. 2013). The fact that $C$. albicans is more prevalent in HIV-positive patients in Africa, may be due to the fact, that $C$. albicans is more pathogenic than other Candida species and highly associated with infection by the $\mathrm{HI}$ virus (Redding 2001; Agwu et al. 2011). Furthermore as extensive antifungal therapy and the availability of HAART are often rare in Africa, the shift 
towards non- $C$. albicans yeast spp. is less marked in African countries and $C$. albicans colonization more prevalent.

\section{Candida dubliniensis: an HIV-associated species?}

C. dubliniensis has repeatedly been reported to be highly prevalent in HIV-infected patients (Paugam et al. 2008). We did not find a single isolate of this species among our patients. However, most of the studies in which $C$. dubliniensis has been found have been conducted outside of the African continent (Sullivan et al. 1995; Binolfi et al. 2005; Loreto et al. 2010; Wu et al. 2011) and studies performed on the African continent in Tanzania, Uganda and Nigeria showed the same phenomenon like in our investigation (Enwuru et al. 2008; Hamza et al. 2008; Agwu et al. 2011). Technically, the absence of $C$. dubliniensis may have been due to the media we used for initial culture, where $C$. dubliniensis could not be discriminated from $C$. albicans and a lower number of $C$. dubliniensis colonies may have gone unnoticed. However, the absence of $C$. dubliniensis is in line with the hypothesis, that Africans may be less susceptible to colonization or infection with this species as shown in an South African cohort (Blignaut et al. 2003).

Under Fluconazole therapy, $C$. albicans may be replaced by $C$. dubliniensis (Martinez et al. 2002) as a colonizer of the oral cavity. This is supported by a study performed in India among terminally ill and patients not responding to Fluconazole therapy, where $C$. dubliniensis was the second most prevalent fungal species after $C$. albicans (Nadagir et al. 2008). Most of these subjects had been exposed to prolonged Fluconazole therapy. A rare practice of antifungal drug prophylaxis or extensive exposure to azoles in developing countries might be another explanation for the absence or very low prevalence (Hamza et al. 2008; Kwamin et al. 2013) of C. dubliniensis in low-resource settings.

In further contrast, $C$. dubliniensis has also been found to be more prevalent among HIV-negative subjects in studies in Tunesia (Khlif et al. 2009) and Brazil (Back-Brito et al. 2009) and in South African White healthy individuals (Blignaut et al. 2003) than in HIV-positive subjects. The epidemiology of this new species is therefore so far not yet well understood and needs further investigations. 


\section{Oral fungal burden and $\mathrm{OC}$}

A high fungal burden was highly associated with the presentation of severe symptoms, colonization with the species C. albicans and CD4 T cell counts $<200$ CD4 T cells $/ \mu$ irrespectively of HAART. These findings were comparable with the ones found in a study evaluating the clinical oral state of patients with the quantitative growth of $C$. albicans; patients with $\mathrm{OC}$ had higher CFU counts than Candida carriers although CFU counts in that study were counted from saliva (Epstein et al. 1980). Similarly, in a recent study from South Africa, high oral Candida CFU correlated with low CD4 T cell counts in HAART+ patients (Owotade et al. 2013). Patients with mild symptoms, defined as whitish or yellowish coating of the dorsum of the tongue $<50 \%$ of the area, were less likely to be yeast-positive and if yeast-positive, the number of CFU counts was very low. This would emphasize that our patients classified with mild symptoms and a positive yeast culture were less suspect to suffer from $\mathrm{OC}$, but were more likely to be colonized only.

Independently of the CFU counts and irrespectively of HAART, OC, especially with the features of the pseudomembranous candidiasis, was highly associated with CD4 $\mathrm{T}$ cell counts $<200 \mathrm{CD} 4 \mathrm{~T}$ cells $/ \mu \mathrm{l}$ and the isolation of $C$. albicans. This was not always as conclusive in patients with mild symptoms. As shown in several studies conducted in Tanzania (Matee et al. 2000), Ghana (Kwamin et al. 2013) and India (Lattif et al. 2004; Mane et al. 2010; Anwar Khan 2012), OC was highly associated with CD4 T cell counts $<200 \mathrm{CD} 4 \mathrm{~T}$ cells/ $\mu$ and as shown in a study in Brazil (Witzel et al. 2008) with isolation of $C$. albicans.

All our patients with severe symptoms and positive yeast growth were colonized by $C$. albicans, except for one case: here, the patient was colonized by $P$. fabianii and had the clinical features of the median rhomboid glossitis. The patient was HIV+/HAART- and had a CD4 T cell count of 495 CD4 T cells/ $\mu$ l. Median rhomboid glossitis is an HIV associated lesion and the patient had high oral fungal burden; nevertheless, we would rather suggest an oral yeast colonization in that case as $P$. fabianii is not common in causing infection (Dabas 2013). Although erythematous candidiasis may as well be a good marker of immunosuppression as postulated by Bodhade et al. (2011), it is not as sensitive and specific as the pseudomembranous candidiasis (Patton 2000). Nevertheless, when HIV-positive subjects present with severe oral lesions (as e.g. OC) a progression of immune failure or a signal for 
therapy failure in HIV+/HAART + patients with a dropping CD4 T cell count $<200$ CD4 $T$ cells $/ \mu$ l should be suspected, especially when CD4 T cell counts are not available. In the majority, OC can be diagnosed by the clinical appearance itself, but in HIV+/HAART + patients, the clinical impression of white coating on the tongue giving suspicion of OC may be misleading. In our study, in almost $60 \%$ of our HIV+/HAART + patients with severe symptoms no yeasts were found in the oral cavity, indicating, that antifungal treatment was not necessary. Therefore, analysis of further symptoms, like burning sensation, cotton taste, swallowing pain as well as the microbiologic diagnosis leading to the identification of Candida can help to identify patients in need of antifungal or antiretroviral treatment.

For HIV+/HAART- patients with severe symptoms, the probability of OC was higher. Here, $60 \%$ of our HIV+/HAART- patients with severe symptoms were yeast-positive, had a mean CD4 T cell count $<200 \mathrm{CD} 4 \mathrm{~T}$ cells/ $\mu$ land were mainly colonized with $C$. albicans. Anyhow, HIV+/HAART- patients may be severely immunocompromised without presenting any clinically visible lesions. Here, $14 \%$ were asymptomatic yeast carriers of which more than $50 \%$ had CD4 T cell counts $<200$ CD4 T cells $/ \mu$ l.

\section{Impact of age and gender}

Although a significant age influence on oral yeast colonization and infection could not be shown here, a tendency towards higher colonization rate with rising age and drop again after the age of 45 could be observed in both, HIV+/HAART- and HIV-negative subjects. This phenomenon has also been reported in Jordanian patients (Rawashdeh et al. 2011). In HIV+/HAART+ patients the observation was reverse. The younger group of patients aged from 18-25, which also was the group being sexually more active at highest risk for the HIV infection, had the highest prevalence of positive yeast growth. With rising age the yeast prevalence was decreasing, also correlating with the duration of HAART.

We did not find any significant differences according to the gender, only that the oral fungal burden was higher in male than in female patients. Alcohol consumption and smoking, which may influence oral candidal colonization and overgrowth (Nittayananta et al. 2001; Petruzzi et al. 2013), is more common among men; this fact and that HIV-infected male patients would only present themselves at the HIV health care center in a more advanced stage of the disease, thus have more severe symptoms and a higher oral fungal burden, could explain the difference observed. In 
a study among HIV-positive patients in Thailand, men were also significantly more likely to have oral lesions than women (Nittayananta et al. 2001).

\section{Susceptibility and effectivity of antifungal treatment}

In our setting, a basic selection of drugs was available to treat and prevent the most common AIDS-related opportunistic diseases, including a limited supply of antimycotics. During the study period, several patients were treated with antimycotics (oral Nystatin, Ketoconazole, or Fluconazole). All patients with severe symptoms and positive yeast carriage treated during the study period and seen for a follow-up were yeast free after treatment, including those under Fluconazole prophylaxis, confirming the absence of clinically resistant species. The observed effectivity of antifungal treatment seen in patients with severe symptoms treated during the study period was reflected in the in vitro susceptibility testing. All $C$. albicans isolates were susceptible to the antifungals tested. Decreased susceptibility was seen within the epidemiologic cut-offs for intrinsic resistance to azoles in C. glabrata, C. tropicalis and I. orientalis especially for Itraconazole (Pfaller et al. 2006). Otherwise, all the species were susceptible for Fluconazole, except for I. orientalis. That more species were resistant to Itraconazole may be due to the fact that Ketokonazole, which has a closer structural topology to Itraconazole, had been more available than Fluconazole in the clinic. Increased MIC values towards Caspofungin were determined for species of the C. parapsilosis complex, as also described previously (Badiee et al. 2010). Azole exposure has previously been described to lead to a shift in the pattern of colonizing yeast species towards less susceptible species like C.glabrata or I. orientalis (Cartledge et al. 1999; Hope et al. 2002; Snydman 2003; Hamza et al. 2008; Agwu et al. 2011). However, all of our patients harboring C. glabrata or I. orientalis had no previous history of antifungal treatment. A relationship between antifungal treatment and emergence of non-C. albicans yeast spp. was therefore not apparent among the patients from Chad, but rather a correlation with antiretroviral therapy and higher CD4 T cell counts. 


\section{Summary}

The study was performed to determine the prevalence and epidemiology of oral candidiasis among HIV-positive patients in Chad and evaluate the susceptibility of the yeasts found in the oral cavity to five antifungals.

The prevalence of oral candidiasis (10.2\%) and colonization (25.4\%) among HIVpositive patients in the studied area of Chad was surprisingly low. Several factors may have contributed to this result: (i) the fact that it was a specialized center with a high coverage of HAART and eventually a high prevalence of patients in early stages of HIV infection, (ii) a general low colonization rate among the population and (iii) use of medicinal plants or beverages which may have some antimicrobial effect.

The main types of oral candidiasis seen were an atypical type of pseudomembranous candidiasis and the median rhomboid glossitis. Last type was mainly seen in HIV+/HAART- patients. High fungal burden was highly associated with oral candidiasis, CD4 T cell counts $<200 \mathrm{CD} 4 \mathrm{~T}$ cells $/ \mu \mathrm{l}$ and the presence of $C$. albicans. There were no cases of oral candidiasis caused by non-C. albicans yeast spp.

Candida albicans was the predominant species found in all subgroups with the highest prevalence in HIV+/HAART- patients. HIV-negative as well as HIV+/HAART+ patients had a higher yeast species diversity, but no $C$. dubliniensis was found. HAART significantly reduced the rate of oral candidiasis and colonization with yeasts, and was associated with a shift towards non- $C$. albicans yeast spp. correlating with the duration of HAART.

Clinically, neither antifungal drug resistance nor therapy refractory cases were found, but higher MICs for azoles in the species C. glabrata, I. orientalis and C. tropicalis were present. The emergence of non- $C$. albicans yeast spp. was not associated with antifungal treatment, but was rather the result of a recovered immune system under extended HAART with a rise in CD4 T cell counts.

In conclusion, our results suggest that (i) severe oral lesions as oral candidiasis are strong markers of immunodeficiency and may be used to evaluate the patient's immune status and guide therapy, (ii) oral candidiasis is associated with the species Candida albicans, (iii) antifungal resistance and infection caused by non-C. albicans yeast spp. is not yet a point of concern in Chad; Fluconazole may be continued to be used as first-line treatment if available. 


\title{
6. Appendix
}

\subsection{Ethical committee of Chad (AILS)}

\author{
CONFERENCE EPISCOPALE DU TCHAD \\ ASSOCIATION INTERDIOCESAINE DE LUTTE CONTRE LE SIDA (AILS) \\ COORDINATION \\ BP 454 NDJAMENA - TCHAD \\ Tél. (235) 225223 48, fax: (235) 22522348 \\ Mail: cels@intnet.td/cet.ails@gmail.com
}




\section{TO WHOM IT MAY CONCERN}

This is to confirm that MRS LILIANE TAVERNE, a medical student from the University of Göttingen, Germany, undertook a research study in our facility, Medical Center of Maingara, Sarh, Chad, to determine the epidemiology of candidosis in HIV infected patients in Chad.

The study was conducted in collaboration with the University Medical Centre of Göttingen.

The research which was done during the period of April - June 2007, was undertaken in accordance with the ethical and medical requirements of the Medical Center.

During the research period, MRS LILIANE TAVERNE was under the tutorship and guidance of DR LYDIA KERSCH, the medical doctor in charge of the Medical Center.

\section{À QUI DE DROIT}

Par la présente il est confirmé que Madame LILIANE TAVERNE, étudiante à la Faculté de Médecine de l'Université de Göttingen/ Allemagne, a réalisé l'étude de recherche scientifique dans notre structure médicale, le Centre de Santé de Maingara à Sarh/Tchad en vue d'examiner la situation épidémiologique des candidoses buccales chez les malades vivant avec le VIH/SIDA.

L'étude a été menée en collaboration avec la Faculté de Medicine de l'Université de Göttingen.

Les recherches ont été effectuées durant la période d' avril - juin 2007 et elles correspondent aux éxigeances éthiques et médicales du Centre de Santé.

Durant la période de l'étude, Madame LILIANE TAVERNE a travaillé sous la responsabilité du Dr. LYDIA KERSCH, médecin responsable du Centre de Santé de Maingara.

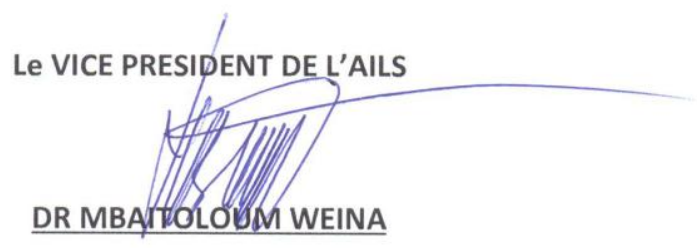




\subsection{Informed consent document}

Ville / Jour / Mois / Année

$|\ldots \ldots \ldots|+\ldots \ldots \ldots \mid \ldots \ldots \ldots$

OBJET : Accord écrit pour le projet «Infection de la muqueuse orale chez des patients atteints par le virus du SIDA »

Je soussigné (e), Nom:

Prénom:

Sexe :

Age:

Nationalité :

Adresse :

déclare participer de mon plein gré (sans contrainte d'une tierce personne) à l'étude concernant l'apparition de la colonisation de la muqueuse orale par le champignon de levure "Candida albicans " et l'évaluation de sa prévalence en rapport avec l'infection par le virus du SIDA.

Je suis bel et bien informé (e) que cette étude à laquelle je participe est une étude simplement descriptive qui n'intervient en aucun cas dans le traitement standard pratiqué à l'hôpital.

D'autre part, il m'a été certifié que le médecin en charge me fera un prélèvement buccal avec un bâtonnet enroulé du coton. Quant au traitement standard appliqué à l'hôpital, il restera le même. Après une période d'observation, dont la durée sera fixée par le médecin, le (la) patient (e) que je suis, devra se présenter de nouveau pour un deuxième prélèvement buccal.

Signé le / 2007 à 


\subsection{List of figures}

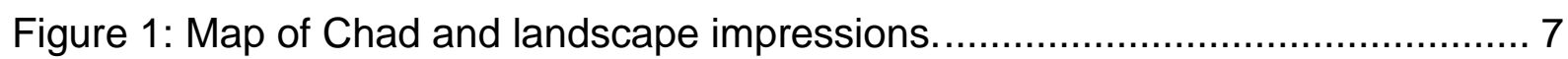

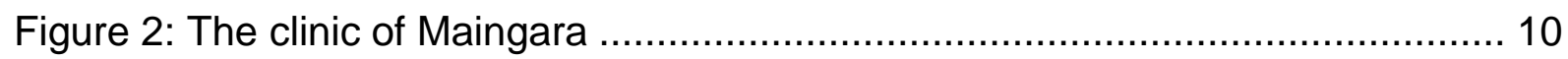

Figure 3: Growth of yeast on the agar plates from the direct smear of the patients.. 20

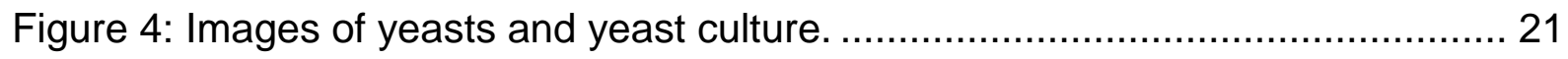

Figure 5: Chlamydospore formation by $C$. albicans on rice-tween agar. ................ 22

Figure 6: MALDI Biotyper 2.0 system ...................................................... 24

Figure 7: Distribution of the patients according to their age and gender in the general cohort

Figure 8: Distribution of the gender in the different subgroups.

Figure 9: Prevalence of yeast growth in the oral cavity in the different subgroups. .. 30

Figure 10: Prevalence of low and high fungal burden in the positive oral swab. 31

Figure 11: Examples of classified symptomatic patients. 32

Figure 12: Prevalence of symptomatic patients in the different subgroups. 34

Figure 13: Prevalence of yeast in the oral cavity of asymptomatic patients. 35

Figure 14: Prevalence of yeast in the oral cavity in symptomatic patients. 36

Figure 15: Prevalence of high oral fungal burden according to symptoms in the different subgroups.

Figure 16: Prevalence of oral candidiasis. 38

Figure 17: CD4 T cell count and clinical subtypes of oral candidiasis in HIV-positive patients.

Figure 18: Age-dependent oral yeast colonization. 42

Figure 19: Prevalence of yeasts in the oral cavity according to age. 43

Figure 20: Prevalence of oral yeast colonization and fungal burden in HIV-negative and -positive female and male patients. 44

Figure 21: Species distribution. 47

Figure 22: Relationship between CD4 T cell counts and fungal burden in HIV-positive patients with and without HAART. 50 
Figure 23: Asymptomatic and symptomatic HIV-positive yeast-carriers and their CD4 $T$ cell counts.

Figure 24: Species distribution in the oral specimen of HIV-positive patients according to their CD4 T cell count and oral fungal burden. 53

Figure 25: Distribution of the species in asymptomatic and symptomatic HIV-positive patients.

Figure 26: Influence of the duration of HAART on oral fungal burden and symptoms.

Figure 27: Influence of the duration of HAART on species distribution. 57

Figure 28: Effect of HAART and antimycotic therapy on oral fungal burden. 59

Figure 29: In vitro susceptibility of the isolated yeast species to the different antifungal agents.

\subsection{List of tables}

Table 1: Indication for HAART according to the National Guidelines of Chad 19

Table 2: Classification of the patients including clinical presentation and oral swab culture

Table 3: Classification of oral candidiasis by Axell et al. 39

Table 4: Distribution of the different clinical presentations of oral candidiasis in HIVpositive patients.... 40

Table 5: Prevalence of oral yeast colonization with and without antibiotics 45

Table 6: Patients with simultaneous colonization of $\geq 2$ species 48

Table 7: Median CD4 T cell count for $C$. albicans and non- $C$. albicans yeast species 52

Table 8: Distribution of $C$. albicans and non- $C$. albicans yeast species. 52

Table 9: Effect of treatment in patients with oral candidiasis 60 


\subsection{List of abbreviations}

AIDS

AILS

API

ATCC

C.

C. a; C. albicans

CBS

CCUG

CD4

CDC

CFU

CIA

CLSI

CNLS

DE

DNA

EC

ECC

ECG

et al.

HAART

HCCA

HFB
Acquired immunodeficiency syndrome

Association Interdiocesaine de Lutte contre le SIDA

Analytical profile index

American Type Culture Collection

Candida

Candida albicans

Center for Biological Sequence analysis

Culture Collection University of Göteborg (Sweden)

Cluster of differentiation 4

Center of Disease Control

Colony-forming units

Central Intelligence Agency

Clinical and Laboratory Standards Institute

Conseil National de Lutte contre le SIDA

Deutschland (Germany)

Deoxyribonucleic acid

Erythematous candidiasis

EC-Clearinghouse

Electrocardiogramm

et alia (latin: and others)

Highly active antiretroviral therapy

Alpha-cyano-4-hydroxy cinamic acid

High fungal burden 


\begin{tabular}{|c|c|}
\hline HIV & Human immunodeficiency virus \\
\hline $\mathrm{Hz}$ & Hertz \\
\hline IL & Israel \\
\hline I. orientalis & Issatchenkia orientalis (=C. krusei) \\
\hline IT & Italy \\
\hline ITS2 & Internal transcribed spacer region 2 \\
\hline $\mathrm{kDa}$ & kilo Dalton \\
\hline LCBC & Lake Chad Bassin Commission \\
\hline LFB & Low fungal burden \\
\hline MALDI-TOF & Matrix assisted laser desorption/ionization in time of flight \\
\hline MIC & Minimal inhibiting concentration \\
\hline MRG & Median rhomboid glossitis \\
\hline NAM & National AIDS Manual \\
\hline NCCLS & National Committee for Clinical Laboratory Standards \\
\hline $\mathrm{nm}$ & nanometer \\
\hline NRTI & Nucleosid reverse transcriptase inhibitor \\
\hline OC & Oral candidiasis \\
\hline$P$. & Pichia \\
\hline PC & Pseudomembranous candidiasis \\
\hline PCR & Polymerase chain reaction \\
\hline PI & Protease inhibitor \\
\hline rDNA & Ribosomal deoxyribonucleic acid \\
\hline RPMI & Roswell Park Memorial Institute \\
\hline SARAMIS & Spectral Archive and Microbial Identification System \\
\hline Spp. & Species \\
\hline
\end{tabular}


UNAIDS

UNDP

UNGASS

UK

US

WHO

WHOPAR

WMA

Ynos

YmS

YsS
United Nations Programme on HIV/AIDS

United Nations Development Programme

United Nations General Assembly

United Kingdom

United States

World Health Organization

World Health Organization Public Assessment Report

World Medical Association

Yeast carriers without symptoms

Yeast-carriers with mild symptoms

Yeast-carriers with severe symptoms 


\section{References}

AAOMP (2005): Lychen planus. Retrieved 15.06.14, from http://www.aaomp.org/ public/docs/lichen-planus.pdf.

Agwu E, Ihongbe JC, McManus BA, Moran GP, Coleman DC, Sullivan DJ (2011): Distribution of yeast species associated with oral lesions in HIV-infected

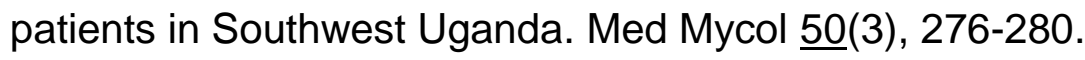

Ahmadou Ahidjo B, Veale R, Duse AG, Becker P, Marais E (2008): The nucleoside reverse transcriptase inhibitors didanosine, lamivudine, stavudine and zidovudine show little effect on the virulence of Candida albicans in vitro. Int $\mathrm{J}$ Antimicrob Agents 32(2), 186-191.

Akpan A, Morgan R (2002): Oral candidiasis. Postgrad Med J 표(922), 455-459.

Ally R, Schurmann D, Kreisel W, Carosi G, Aguirrebengoa K, Dupont B, Hodges M, Troke P, Romero AJ (2001): A randomized, double-blind, double-dummy, multicenter trial of voriconazole and fluconazole in the treatment of esophageal candidiasis in immunocompromised patients. Clin Infect Dis $\underline{33}(9)$, 1447-1454.

Angebault C, Djossou F, Abelanet S, Permal E, Ben Soltana M, Diancourt L, Bouchier C, Woerther PL, Catzeflis F, Andremont A et al. (2013): Candida albicans is not always the preferential yeast colonizing humans: A study in Wayampi Amerindians. J Infect Dis 208(10), 1705-1716.

Anwar Khan P, Malik A, Subhan Khan H (2012): Profile of candidiasis in HIV infected patients. Iran J Microbiol 4(4), 204-209.

Ascher MS, Sheppard HW (1988): AIDS as immune system activation: a model for pathogenesis. Clin Exp Immunol 73(2), 165-167.

Axell T, Samaranayake LP, Reichart PA, Olsen I (1997): A proposal for reclassification of oral candidosis. Oral Surg Oral Med Oral Pathol Oral Radiol Endod 84(2), 111-112.

Back-Brito GN, Mota AJ, Vasconcellos TC, Querido SM, Jorge AO, Reis AS, Balducci I, Koga-Ito CY (2009): Frequency of Candida spp. in the oral cavity of Brazilian HIV-positive patients and correlation with CD4 cell counts and viral load. Mycopathologia 167(2), 81-87. 
Bader O, Weig M, Taverne-Ghadwal L, Lugert R, Groß U, Kuhns M (2011): Improved clinical laboratory identification of human pathogenic yeasts by matrix-assisted laser desorption ionization time-of-flight mass spectrometry. Clin Microbiol Infect 17(9), 1359-1365.

Badiee P, Alborzi A, Davarpanah MA, Shakiba E (2010): Distributions and antifungal susceptibility of Candida species from mucosal sites in HIV positive patients. Arch Iran Med 13 $(4)$, 282-287.

Bagg J, Sweeney MP, Lewis MA, Jackson MS, Coleman D, Al MA, Baxter W, McEndrick S, McHugh S (2003): High prevalence of non-albicans yeasts and detection of anti-fungal resistance in the oral flora of patients with advanced cancer. Palliat Med 17(6), 477-481.

Baixench MT, Viguie C, Paugam A (2008): Isolation of Candida dubliniensis in a French hospital mycology laboratory. J Med Microbiol 57(Pt 2), 258-259.

Barasch A, Safford MM, Catalanotto FA, Fine DH, Katz RV (2000): Oral soft tissue manifestations in HIV-positive vs. HIV-negative children from an inner city population: a two-year observational study. Pediatr Dent 22(3), 215-220.

Barre-Sinoussi F, Chermann JC, Rey F, Nugeyre MT, Chamaret S, Gruest J, Dauguet C, Axler-Blin C, Vezinet-Brun F, Rouzioux C et al. (1983): Isolation of a T-lymphotropic retrovirus from a patient at risk for acquired immune deficiency syndrome (AIDS). Science 220(4599), 868-871.

Bassetti M, Ansaldi F, Nicolini L, Malfatto E, Molinari MP, Mussap M, Rebesco B, Bobbio Pallavicini F, Icardi G, Viscoli C (2009): Incidence of candidaemia and relationship with fluconazole use in an intensive care unit. J Antimicrob Chemother 64(3), 625-629.

BBC (2015): News Africa_Chad Profile. Retrieved 20.03.15, from http://www.bbc.com Inews/world-africa-13164686.

Binolfi A, Biasoli MS, Luque AG, Tosello ME, Magaro HM (2005): High prevalence of oral colonization by Candida dubliniensis in HIV-positive patients in Argentina. Med Mycol $\underline{43}(5)$, 431-437.

Blignaut E (2007): Oral candidiasis and oral yeast carriage among institutionalised South African paediatric HIV/AIDS patients. Mycopathologia 163(2), 67-73.

Blignaut E, Pujol C, Joly S, Soll DR (2003): Racial distribution of Candida dubliniensis colonization among South Africans. Journal of clinical microbiology 411(5), 1838-1842. 
Bodhade AS, Ganvir SM, Hazarey VK (2011): Oral manifestations of HIV infection and their correlation with CD4 count. J Oral Sci $\underline{53}(2), 203-211$.

Borg-von Zepelin M, Meyer I, Thomssen R, Wurzner R, Sanglard D, Telenti A, Monod M (1999): HIV-Protease inhibitors reduce cell adherence of Candida albicans strains by inhibition of yeast secreted aspartic proteases. J Invest Dermatol 113(5), 747-751.

Cannon RD, Holmes AR, Mason AB, Monk BC (1995): Oral Candida: clearance, colonization, or candidiasis? J Dent Res 74(5), 1152-1161.

Cartledge JD, Midgley J, Gazzard BG (1999): Non-albicans oral candidosis in HIVpositive patients. J Antimicrob Chemother $\underline{43}(3), 419-422$.

Cassone A, Cauda R (2012): Candida and candidiasis in HIV-infected patients: where commensalism, opportunistic behavior and frank pathogenicity lose their borders. AIDS 26 6 (12), 1457-1472.

Cassone A, De Bernardis F, Torosantucci A, Tacconelli E, Tumbarello M, Cauda R (1999): In vitro and in vivo anticandidal activity of human immunodeficiency virus protease inhibitors. J Infect Dis $\underline{180}(2), 448-453$.

Cauda R, Tacconelli E, Tumbarello M, Morace G, De Bernardis F, Torosantucci A, Cassone A (1999): Role of protease inhibitors in preventing recurrent oral candidosis in patients with HIV infection: a prospective case-control study. J Acquir Immune Defic Syndr 21 (1), 20-25.

CDC (1985): Update: prospective evaluation of health-care workers exposed via the parenteral or mucous-membrane route to blood or body fluids from patients with acquired immunodeficiency syndrome--United States. MMWR Morb Mortal Wkly Rep 34(7), 101-103.

CDC (1992): Revised Classification System for HIV Infection and Expanded Surveillance Case Definition for AIDS Among Adolescents and Adults. MMWR Morb Mortal Wkly Rep $\underline{41}$ (no.RR-17).

Chen YC, Eisner JD, Kattar MM, Rassoulian-Barrett SL, LaFe K, Yarfitz SL, Limaye AP, Cookson BT (2000): Identification of medically important yeasts using PCR-based detection of DNA sequence polymorphisms in the internal transcribed spacer 2 region of the rRNA genes. Journal of clinical microbiology $\underline{38}(6), 2302-2310$.

CIA (2014): The world Factbook_Chad. Retrieved 20.06.2014, from https://www.cia .gov/library/publications/the-world-factbook/geos/cd.html. 
CNLS (2012): Rapport d'activités sur la riposte au SIDA au Tchad 2010-2011. Retrieved 15.06.2014, from http://www.unaids.org/en/dataanalysis/knowyour response/countryprogressreports/2012countries/ce TD Narrative Report[1].p df.

Coleman DC, Sullivan DJ, Bennett DE, Moran GP, Barry HJ, Shanley DB (1997): Candidiasis: the emergence of a novel species, Candida dubliniensis. AIDS 11(5), 557-567.

Coogan MM, Greenspan J, Challacombe SJ (2005): Oral lesions in infection with human immunodeficiency virus. Bull World Health Organ $\underline{\text { 83}}(9), 700-706$.

Coronado-Castellote L, Jimenez-Soriano Y (2013): Clinical and microbiological diagnosis of oral candidiasis. J Clin Exp Dent $\underline{5}(5)$, e279-e286.

Curran JW (1985): The epidemiology and prevention of the acquired immunodeficiency syndrome. Ann Intern Med 103(5), 657-662.

Curtis AJ, Marshall CS, Spelman T, Greig J, Elliot JH, Shanks L, Du Cros P, Casas EC, Da Fonseca MS, O'Brien DP (2012): Incidence of WHO stage 3 and 4 conditions following initiation of anti-retroviral therapy in resource limited settings. PLoS One $\underline{7}(12)$, e52019.

Dabas PS (2013): An approach to etiology, diagnosis and management of different types of candidiasis. J Yeast Fungal Res $\underline{4}(6), 63-74$.

Damtie D, Yismaw G, Woldeyohannes D, Anagaw B (2013): Common opportunistic infections and their CD4 cell correlates among HIV-infected patients attending at antiretroviral therapy clinic of Gondar University Hospital, Northwest Ethiopia. BMC Res Notes $\underline{6}, 534$.

De Beaudrap P, Boulle C, Lewden C, Gabillard D, Nacro B, Diagbouga S, Fassinou P, Hien H, Laurent C, Msellati P (2013): Morbidity after antiretroviral therapy initiation in HIV-1-infected children in West Africa: temporal trends and relation to CD4 count. Pediatr Infect Dis J 32(4), 354-360.

De Bernardis F, Chiani P, Ciccozzi M, Pellegrini G, Ceddia T, D'Offizzi G, Quinti I, Sullivan PA, Cassone A (1996): Elevated aspartic proteinase secretion and experimental pathogenicity of Candida albicans isolates from oral cavities of subjects infected with human immunodeficiency virus. Infect Immun $\underline{64}(2)$, 466-471. 
Dongari-Bagtzoglou A, Dwivedi P, loannidou E, Shaqman M, Hull D, Burleson J (2009): Oral Candida infection and colonization in solid organ transplant recipients. Oral Microbiol Immunol 24(3), 249-254.

Douek DC, Roederer M, Koup RA (2009): Emerging concepts in the immunopathogenesis of AIDS. Annu Rev Med $\underline{60}$, 471-484.

Dronda F, Alonso-Sanz M, Laguna F, Chaves F, Martinez-Suarez JV, RodriguezTudela JL, Gonzalez-Lopez A, Valencia E (1996): Mixed oropharyngeal candidiasis due to Candida albicans and non-albicans Candida strains in HIVinfected patients. Eur J Clin Microbiol Infect Dis 15(6), 446-452.

EC-Clearinghouse (1993): Classification and diagnostic criteria for oral lesions in HIV infection. J Oral Pathol Med 22 (7), 289-291.

Enwonwu CO (1994): Cellular and molecular effects of malnutrition and their relevance to periodontal diseases. J Clin Periodontol 21 (10), 643-657.

Enwuru CA, Ogunledun A, Idika N, Enwuru NV, Ogbonna F, Aniedobe M, Adeiga A (2008): Fluconazole resistant opportunistic oro-pharyngeal Candida and nonCandida yeast-like isolates from HIV infected patients attending ARV clinics in Lagos, Nigeria. Afr Health Sci $\underline{8}(3), 142-148$.

Epstein JB, Pearsall NN, Truelove EL (1980): Quantitative relationships between Candida albicans in saliva and the clinical status of human subjects. Journal of clinical microbiology 12(3), 475-476.

Fethi T, Asma J, Amine SM, Amel EB, Taoufik BC, Mohamed C, Amel LO, Mounira G (2005): Effects on immunological and virological outcome of patients using one protease inhibitor or one non-nucleoside reverse transcriptase inhibitor in a triple antiretroviral therapy: normal clinical practice versus clinical trial findings. Curr HIV Res $\underline{3}(3)$, 271-276.

Fetter A, Partisani M, Koenig H, Kremer M, Lang JM (1993): Asymptomatic oral Candida albicans carriage in HIV-infection: frequency and predisposing factors. J Oral Pathol Med 22 (2), 57-59.

Fidel PL Jr (2006): Candida-host interactions in HIV disease: relationships in oropharyngeal candidiasis. Adv Dent Res 19 (1), 80-84.

Fidel PL Jr (2011): Candida-host interactions in HIV disease: implications for oropharyngeal candidiasis. Adv Dent Res $\underline{23}(1), 45-49$. 
Fidel PL Jr, Vazquez JA, Sobel JD (1999): Candida glabrata: review of epidemiology, pathogenesis, and clinical disease with comparison to C. albicans. Clin Microbiol Rev 12(1), 80-96.

Fisher-Hoch SP, Hutwagner L (1995): Opportunistic candidiasis: an epidemic of the 1980s. Clin Infect Dis 21 (4), 897-904.

Flaitz CM, Hicks MJ (1999): Oral candidiasis in children with immune suppression: clinical appearance and therapeutic considerations. ASDC J Dent Child $\underline{66}(3)$, 161-166, 154.

Gallo RC, Salahuddin SZ, Popovic M, Shearer GM, Kaplan M, Haynes BF, Palker TJ, Redfield R, Oleske J, Safai B et al. (1984): Frequent detection and isolation of cytopathic retroviruses (HTLV-III) from patients with AIDS and at risk for AIDS. Science 224(4648), 500-503.

Gautam H, Kaur R, Goyal R, Bhalla P, Dewan R (2010): Oral thrush to candidemia: a morbid outcome. J Int Assoc Physicians AIDS Care (Chic) $\underline{9}(5), 325-327$.

Gazzard BG, Smith D (1990): Oral candidosis in HIV-infected patients. Br J Clin Pract Suppl 1ㅡ, 103-108.

Goodwin TJ, Ormandy JE, Poulter RT (2001): L1-like non-LTR retrotransposons in the yeast Candida albicans. Curr Genet 39(2), 83-91.

Gottfredsson M, Cox GM, Indridason OS, de Almeida GM, Heald AE, Perfect JR (1999): Association of plasma levels of human immunodeficiency virus type 1 RNA and oropharyngeal Candida colonization. J Infect Dis 180(2), 534-537.

Gottlieb MS, Schroff R, Schanker HM, Weisman JD, Fan PT, Wolf RA, Saxon A (1981): Pneumocystis carinii pneumonia and mucosal candidiasis in previously healthy homosexual men: evidence of a new acquired cellular

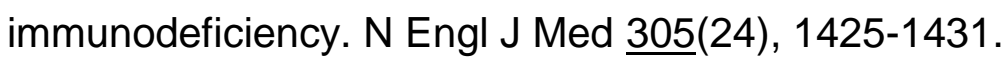

Greenspan JS (1997): Sentinels and signposts: the epidemiology and significance of the oral manifestations of HIV disease. Oral Dis 3 Suppl 1, S13-17.

Greenspan D, Gange SJ, Phelan JA, Navazesh M, Alves ME, MacPhail LA, Mulligan R, Greenspan JS (2004): Incidence of oral lesions in HIV-1-infected women: reduction with HAART. J Dent Res 83(2), 145-150.

Grimoud AM, Marty N, Bocquet H, Andrieu S, Lodter JP, Chabanon G (2003): Colonization of the oral cavity by Candida species: risk factors in long-term geriatric care. J Oral Sci $\underline{45}(1), 51-55$. 
Gudlaugsson O, Gillespie S, Lee K, Vande Berg J, Hu J, Messer S, Herwaldt L, Pfaller M, Diekema D (2003): Attributable mortality of nosocomial candidemia, revisited. Clin Infect Dis $\underline{37}(9), 1172-1177$.

Gupta KL, Ghosh AK, Kochhar R, Jha V, Chakrabarti A, Sakhuja V (1994): Esophageal candidiasis after renal transplantation: comparative study in patients on different immunosuppressive protocols. Am J Gastroenterol $\underline{89}(7)$, 1062-1065.

Hamza OJ, Matee MI, Simon EN, Kikwilu E, Moshi MJ, Mugusi F, Mikx FH, Verweij PE, van der Ven AJ (2006): Oral manifestations of HIV infection in children and adults receiving highly active anti-retroviral therapy [HAART] in Dar es Salaam, Tanzania. BMC Oral Health $\underline{6}, 12$.

Hamza OJ, Matee MI, Moshi MJ, Simon EN, Mugusi F, Mikx FH, Helderman WH, Rijs AJ, van der Ven AJ, Verweij PE (2008): Species distribution and in vitro antifungal susceptibility of oral yeast isolates from Tanzanian HIV-infected patients with primary and recurrent oropharyngeal candidiasis. BMC Microbiol $\underline{8}, 135$.

Hauman CH, Thompson IO, Theunissen F, Wolfaardt P (1993): Oral carriage of Candida in healthy and HIV-seropositive persons. Oral Surg Oral Med Oral Pathol $\underline{76}(5), 570-572$.

Hodgson TA (1997): HIV-associated oral lesions: prevalence in Zambia. Oral Dis $\underline{3}$ Suppl 1, S46-50.

Hodgson TA, Rachanis CC (2002): Oral fungal and bacterial infections in HIVinfected individuals: an overview in Africa. Oral Dis 8 Suppl 2, 80-87.

Hodgson TA, Greenspan D, Greenspan JS (2006): Oral lesions of HIV disease and HAART in industrialized countries. Adv Dent Res 19(1), 57-62.

Hood S, Bonington A, Evans J, Denning D (1998): Reduction in oropharyngeal candidiasis following introduction of protease inhibitors. AIDS 12(4), 447-448.

Hope W, Morton A, Eisen DP (2002): Increase in prevalence of nosocomial nonCandida albicans candidaemia and the association of Candida krusei with fluconazole use. J Hosp Infect 50 (1), 56-65.

Jabra-Rizk MA, Falkler WA Jr, Enwonwu CO, Onwujekwe DI Jr, Merz WG, Meiller TF (2001): Prevalence of yeast among children in Nigeria and the United States. Oral Microbiol Immunol 16 (6), 383-385. 
Jordan RA (2007): Prävalenz oraler Manifestationen bei HIV-seropositiven Patienten unter dem Einfluss der hochaktiven antiretroviralen Therapie. Dtsch Zahnarztl Z $\underline{62}$ (6), 376-385.

Kamiru HN, Naidoo S (2002): Oral HIV lesions and oral health behaviour of HIVpositive patients attending the Queen Elizabeth II Hospital, Maseru, Lesotho. SADJ $\underline{57}(11), 479-482$.

Khlif M, Sellami H, Sellami A, Chelly H, Makni F, Bouaziz M, Ayadi A (2009): Candida dubliniensis: first identification in Sfax Hospital, Tunisia. Mycoses $\underline{52(2), 171-}$ 175.

Klein RS, Harris CA, Small CB, Moll B, Lesser M, Friedland GH (1984): Oral candidiasis in high-risk patients as the initial manifestation of the acquired immunodeficiency syndrome. N Engl J Med 311(6), 354-358.

Kolokotronis A, Kioses V, Antoniades D, Mandraveli K, Doutsos I, Papanayotou P (1994): Median rhomboid glossitis. An oral manifestation in patients infected with HIV. Oral Surg Oral Med Oral Pathol 78 (1), 36-40.

Krcmery V, Barnes AJ (2002): Non-albicans Candida spp. causing fungaemia: pathogenicity and antifungal resistance. J Hosp Infect $\underline{50}$ (4), 243-260.

Kumar RK, Mohan G, Reddy NV, Rao VA, Shameer M, Christopher A (2013): Associated oral lesions in human immunodefeciency virus infected children of age 1 to 14 years in anti retroviral therapy centers in Tamil Nadu. Contemp Clin Dent 4 (4), 467-471.

Kwamin F, Nartey NO, Codjoe FS, Newman MJ (2013): Distribution of Candida species among HIV-positive patients with oropharyngeal candidiasis in Accra, Ghana. J Infect Dev Ctries $\underline{7}(1), 41-45$.

Lalla RV, Latortue MC, Hong $\mathrm{CH}$, Ariyawardana A, D'Amato-Palumbo S, Fischer DJ, Martof A, Nicolatou-Galitis O, Patton LL, Elting LS et al. (2010): A systematic review of oral fungal infections in patients receiving cancer therapy. Support Care Cancer 18(8), 985-992.

Lalla RV, Patton LL, Dongari-Bagtzoglou A (2013): Oral candidiasis: pathogenesis, clinical presentation, diagnosis and treatment strategies. J Calif Dent Assoc 41(4), 263-268.

Lattif AA, Banerjee U, Prasad R, Biswas A, Wig N, Sharma N, Haque A, Gupta N, Baquer NZ, Mukhopadhyay G (2004): Susceptibility pattern and molecular type of species-specific Candida in oropharyngeal lesions of Indian human 
immunodeficiency virus-positive patients. Journal of clinical microbiology 42(3), 1260-1262.

LCBC (2013): Climate_Chad. Retrieved 15.06.14, from http://www.cblt.org/en/ climate.

Leao JC, Ribeiro CM, Carvalho AA, Frezzini C, Porter S (2009): Oral complications of HIV disease. Clinics (Sao Paulo) 64(5), 459-470.

Lehner T (1964): Oral Thrush, or Acute Pseudomembranous Candidiasis; a Clinicopathologic Study of Forty-Four Cases. Oral Surg Oral Med Oral Pathol 18, 27-37.

Levy JA (1993): Pathogenesis of human immunodeficiency virus infection. Microbiol Rev $\underline{57}(1), 183-289$.

Lindan CP, Allen S, Serufilira A, Lifson AR, Van de Perre P, Chen-Rundle A, Batungwanayo J, Nsengumuremyi F, Bogaerts J, Hulley S (1992): Predictors of mortality among HIV-infected women in Kigali, Rwanda. Ann Intern Med $\underline{116}(4), 320-328$.

Lohoue Petmy J, Lando AJ, Kaptue L, Tchinda V, Folefack M (2004): Superficial mycoses and HIV infection in Yaounde. J Eur Acad Dermatol Venereol 18(3), 301-304.

Lopez-Pintor RM, Hernandez G, de Arriba L, de Andres A (2013): Oral candidiasis in patients with renal transplants. Med Oral Patol Oral Cir Bucal 18(3), e381-387.

Loreto ES, Scheid LA, Nogueira CW, Zeni G, Santurio JM, Alves SH (2010): Candida dubliniensis: epidemiology and phenotypic methods for identification. Mycopathologia 169(6), 431-443.

Lourenco AG, Motta AC, Figueiredo LT, Machado AA, Komesu MC (2011): Oral lesions associated with HIV infection before and during the antiretroviral therapy era in Ribeirao Preto, Brazil. J Oral Sci $\underline{53}(3), 379-385$.

Macher AM (1988): The pathology of AIDS. Public Health Rep 103(3), 246-254.

Madhu PM (2013): Oral Candidiasis Int J Pharm Sci Invent 2(12), 03-06.

Mane A, Panchvalli S, Bembalkar S, Risbud A (2010): Species distribution \& antifungal susceptibility of oral Candida colonising or infecting HIV infected individuals. Indian J Med Res 131, 836-838.

Maoura N (2005): Identification and typing of the yeast strains isolated from bili bili, a traditional sorghum beer of Chad. Afr J Biotechnol 4(7), 646-656. 
Martinez M, Lopez-Ribot JL, Kirkpatrick WR, Coco BJ, Bachmann SP, Patterson TF (2002): Replacement of Candida albicans with C. dubliniensis in human immunodeficiency virus-infected patients with oropharyngeal candidiasis treated with fluconazole. Journal of clinical microbiology $\underline{40}$ (9), 3135-3139.

Marzouk B, Marzouk Z, Decor R, Edziri H, Haloui E, Fenina N, Aouni M (2009): Antibacterial and anticandidal screening of Tunisian Citrullus colocynthis Schrad. from Medenine. J Ethnopharmacol 125(2), 344-349.

Masur H, Michelis MA, Greene JB, Onorato I, Stouwe RA, Holzman RS, Wormser G, Brettman L, Lange M, Murray HW et al. (1981): An outbreak of communityacquired Pneumocystis carinii pneumonia: initial manifestation of cellular immune dysfunction. N Engl J Med 305(24), 1431-1438.

Mataftsi M, Skoura L, Sakellari D (2011): HIV infection and periodontal diseases: an overview of the post-HAART era. Oral Dis $\underline{17}(1), 13-25$.

Matee MI, Scheutz F, Moshy J (2000): Occurrence of oral lesions in relation to clinical and immunological status among HIV-infected adult Tanzanians. Oral Dis $\underline{6}(2), 106-111$.

McCullough MJ, Waugh AC, Hodgson TA, Jorge J Jr, Molyneux EM, Porter SR (2001): Susceptibility of oral yeast isolated from patients in Blantyre, Malawi to fluconazole and gentian violet. Clin Infect Dis $\underline{33}(7), 1198-1198$.

Meless D, Ba B, Faye M, Diby JS, N'Zore S, Datte S, Diecket L, N'Diaye C, Aka EA, Kouakou $\mathrm{K}$ et al. (2014): Oral lesions among HIV-infected children on antiretroviral treatment in West Africa. Trop Med Int Health 19 (3), 246-255.

Melo NR, Taguchi H, Jorge J, Pedro RJ, Almeida OP, Fukushima K, Nishimura K, Miyaji M (2004): Oral Candida flora from Brazilian human immunodeficiency virus-infected patients in the highly active antiretroviral therapy era. Mem Inst Oswaldo Cruz 99(4), 425-431.

Mercante DE, Leigh JE, Lilly EA, McNulty K, Fidel PL Jr (2006): Assessment of the association between HIV viral load and CD4 cell count on the occurrence of oropharyngeal candidiasis in HIV-infected patients. J Acquir Immune Defic Syndr $\underline{42}(5), 578-583$.

Moran GP, Sullivan DJ, Henman MC, McCreary CE, Harrington BJ, Shanley DB, Coleman DC (1997): Antifungal drug susceptibilities of oral Candida dubliniensis isolates from human immunodeficiency virus (HIV)-infected and 
non-HIV-infected subjects and generation of stable fluconazole-resistant derivatives in vitro. Antimicrob Agents Chemother 41(3), 617-623.

Nadagir SD, Chunchanur SK, Halesh LH, Yasmeen K, Chandrasekhar MR, Patil BS (2008): Significance of isolation and drug susceptibility testing of non-Candida albicans species causing oropharyngeal candidiasis in HIV patients. Southeast Asian J Trop Med Public Health 39(3), 492-495.

Naidu GS, Thakur R, Singh AK, Rajbhandary S, Mishra RK, Sagtani A (2013): Oral lesions and immune status of HIV infected adults from eastern Nepal. J Clin Exp Dent $\underline{5}(1)$, e1-7.

NAM (2014): HIV treatment directory_Triomune 30. Retrieved 15.06.2014, from http: //www.aidsmap.com/resources/treatmentsdirectory/drugs/iTriomunei/page/173 1254/.

NCCLS (2002): Reference method for broth dilution antifungal susceptibility testing of yeasts; approved standard. $2^{\text {nd }}$ edition; NCCLS, Wayne 2002.

Nishimura S, Nagata N, Shimbo T, Asayama N, Akiyama J, Ohmagari N, Yazaki H, Oka S, Uemura N (2013): Factors Associated with Esophageal Candidiasis and Its Endoscopic Severity in the Era of Antiretroviral Therapy. PLoS One $\underline{8}(3)$.

Nittayananta W, Chanowanna N, Sripatanakul S, Winn T (2001): Risk factors associated with oral lesions in HIV-infected heterosexual people and intravenous drug users in Thailand. J Oral Pathol Med 30(4), 224-230.

Njunda A (2011): Candidiasis in HIV and AIDS Patients Attending the Nylon Health District Hospital in Douala, Cameroon. TAF Prev Med Bull 10(6), 701-706.

Nkuize M, De Wit S, Muls V, Arvanitakis M, Buset M (2010): Upper gastrointestinal endoscopic findings in the era of highly active antiretroviral therapy. HIV Med 11(6), 412-417.

Nweze El, Ogbonnaya UL (2011): Oral Candida isolates among HIV-infected subjects in Nigeria. J Microbiol Immunol Infect 44(3), 172-177.

Okoje VN, Oladokun RE, Osinusi K, Obimakinde OS (2013): Oral Lesions and their Association with CD4 Count and Viral Load in HIV Positive Nigerian Children. Oral Health Dent Manag 12(4), 200-204.

Okunseri C, Badner V, Wiznia A, Rosenberg M (2003): Prevalence of oral lesions and percent CD4+ T-lymphocytes in HIV-infected children on antiretroviral therapy. AIDS Patient Care STDS 17(1), 5-11. 
Ortega KL, Vale DA, Magalhaes MH (2009): Impact of PI and NNRTI HAART-based therapy on oral lesions of Brazilian HIV-infected patients. J Oral Pathol Med $\underline{38}(6), 489-494$.

Owotade FJ, Shiboski CH, Poole L, Ramstead CA, Malvin K, Hecht FM, Greenspan JS (2008): Prevalence of oral disease among adults with primary HIV infection. Oral Dis 14(6), 497-499.

Owotade FJ, Patel M, Ralephenya TR, Vergotine G (2013): Oral Candida colonization in HIV-positive women: associated factors and changes following antiretroviral therapy. J Med Microbiol $\underline{62}$ (Pt 1), 126-132.

Pappas PG, Kauffman CA, Andes D, Benjamin DK Jr, Calandra TF, Edwards JE Jr, Filler SG, Fisher JF, Kullberg BJ, Ostrosky-Zeichner L et al. (2009): Clinical practice guidelines for the management of candidiasis: 2009 update by the Infectious Diseases Society of America. Clin Infect Dis 48 (5), 503-535.

Parihar S (2011): Oral Candidiasis- A Review. WebmedCentral DENTISTRY $\underline{2}$ (11).

Patel M, Shackleton JT, Coogan MM (2006): Effect of antifungal treatment on the prevalence of yeasts in HIV-infected subjects. J Med Microbiol $\underline{55}(\mathrm{Pt} 9), 1279$ 1284.

Patterson JE (1999): Epidemiology of fungal infections in solid organ transplant patients. Transpl Infect Dis 1 (4), 229-236.

Patton LL (2000): Sensitivity, specificity, and positive predictive value of oral opportunistic infections in adults with HIV/AIDS as markers of immune suppression and viral burden. Oral Surg Oral Med Oral Pathol Oral Radiol Endod 90(2), 182-188.

Patton LL, Ramirez-Amador V, Anaya-Saavedra G, Nittayananta W, Carrozzo M, Ranganathan K (2013): Urban legends series: oral manifestations of HIV infection. Oral Dis $\underline{19}(6), 533-550$.

Paugam A, Baixench MT, Viguie C (2008): An update on Candida dubliniensis. Med Mal Infect $\underline{38}(1), 1-7$.

Petruzzi MN, Cherubini K, Salum FG, Figueiredo MA (2013): Risk factors of HIVrelated oral lesions in adults. Rev Saude Publica $\underline{47}(1), 52-59$.

Pfaller MA (1995): Epidemiology of candidiasis. J Hosp Infect 30 Suppl, 329-338.

Pfaller MA, Diekema DJ (2007): Epidemiology of invasive candidiasis: a persistent public health problem. Clin Microbiol Rev $\underline{20}(1), 133-163$. 
Pfaller MA, Diekema DJ, Rex JH, Espinel-Ingroff A, Johnson EM, Andes D, Chaturvedi V, Ghannoum MA, Odds FC, Rinaldi MG et al. (2006): Correlation of MIC with outcome for Candida species tested against voriconazole: analysis and proposal for interpretive breakpoints. Journal of clinical microbiology $\underline{44}(3), 819-826$.

Pfaller MA, Diekema DJ, Gibbs DL, Newell VA, Meis JF, Gould IM, Fu W, Colombo AL, Rodriguez-Noriega E (2007): Results from the ARTEMIS DISK Global Antifungal Surveillance study, 1997 to 2005: an 8.5-year analysis of susceptibilities of Candida species and other yeast species to fluconazole and voriconazole determined by CLSI standardized disk diffusion testing. Journal of clinical microbiology $\underline{45}(6), 1735-1745$.

Pomarico L, Cerqueira DF, de Araujo Soares RM, de Souza IP, de Araujo Castro GF, Socransky S, Haffajee A, Teles RP (2009): Associations among the use of highly active antiretroviral therapy, oral candidiasis, oral Candida species and salivary immunoglobulin A in HIV-infected children. Oral Surg Oral Med Oral Pathol Oral Radiol Endod 108(2), 203-210.

Powderly WG, Landay A, Lederman MM (1998): Recovery of the immune system with antiretroviral therapy: the end of opportunism? JAMA 280(1), 72-77.

Premanathan M (2011): Treatment of oral candidiasis (thrush) by saccharomyces cerevisiae. Int J Med Med Sci $\underline{3}(3), 83-86$.

Prunier G (2008): Patt im Tschad_Das Epizentrum der zentralafrikanischen Krise liegt in Khartum. Le Monde diplomatique Nr. 8530.

Ranganathan K, Umadevi M, Saraswathi TR, Kumarasamy N, Solomon S, Johnson $N$ (2004): Oral lesions and conditions associated with human immunodeficiency virus infection in 1000 South Indian patients. Ann Acad Med Singapore $\underline{33}$ (4 Suppl), 37-42.

Rawashdeh MA, Ayesh JA, Darwazeh AM (2011): Oral candidal colonization in cleft patients as a function of age, gender, surgery, type of cleft, and oral health. $J$ Oral Maxillofac Surg 69(4), 1207-1213.

Redding SW (2001): The role of yeasts other than Candida albicans in oropharyngeal candidiasis. Curr Opin Infect Dis 14(6), 673-677.

Redding SW, Zellars RC, Kirkpatrick WR, McAtee RK, Caceres MA, Fothergill AW, Lopez-Ribot JL, Bailey CW, Rinaldi MG, Patterson TF (1999): Epidemiology of oropharyngeal Candida colonization and infection in patients receiving 
radiation for head and neck cancer. Journal of clinical microbiology $\underline{37}(12)$, 3896-3900.

Room A (2008): African Placenames, Origins and meanings of the names for natural features, towns, cities, provinces, and countries. $2^{\text {nd }}$ ed.; McFarland $\&$ co., Jefferson 2008.

Rukayadi Y, Shim JS, Hwang JK (2008): Screening of Thai medicinal plants for anticandidal activity. Mycoses 51(4), 308-312.

Samaranayake LP, Fidel PL, Naglik JR, Sweet SP, Teanpaisan R, Coogan MM, Blignaut E, Wanzala P (2002): Fungal infections associated with HIV infection. Oral Dis 8 Suppl 2, 151-160.

Sanchez-Vargas LO, Ortiz-Lopez NG, Villar M, Moragues MD, Aguirre JM, CashatCruz M, Lopez-Ribot JL, Gaitan-Cepeda LA, Quindos G (2005a): Point prevalence, microbiology and antifungal susceptibility patterns of oral Candida isolates colonizing or infecting Mexican HIV/AIDS patients and healthy persons. Rev Iberoam Micol 22(2), 83-92.

Sanchez-Vargas LO, Ortiz-Lopez NG, Villar M, Moragues MD, Aguirre JM, CashatCruz M, Lopez-Ribot JL, Gaitan-Cepeda LA, Quindos G (2005b): Oral Candida isolates colonizing or infecting human immunodeficiency virusinfected and healthy persons in Mexico. Journal of clinical microbiology $\underline{43}(8)$, 4159-4162.

Scheid LA, Mario DA, Kubica TF, Santurio JM, Alves SH (2012): In vitro activities of antifungal agents alone and in combination against fluconazole-susceptible and -resistant strains of Candida dubliniensis. Braz J Infect Dis 16 (1), 78-81.

Schliep TC, Yarrish RL (1999): Pneumocystis carinii pneumonia. Semin Respir Infect 14(4), 333-343.

Schmidt-Westhausen AM, Priepke F, Bergmann FJ, Reichart PA (2000): Decline in the rate of oral opportunistic infections following introduction of highly active antiretroviral therapy. J Oral Pathol Med $\underline{29}$ (7), 336-341.

Schoofs AG, Odds FC, Colebunders R, leven M, Goossens H (1998): Crosssectional study of oral Candida carriage in a human immunodeficiency virus (HIV)-seropositive population: predisposing factors, epidemiology and antifungal susceptibility. Mycoses $\underline{41}(5-6), 203-211$.

Schuman P, Sobel JD, Ohmit SE, Mayer KH, Carpenter CC, Rompalo A, Duerr A, Smith DK, Warren D, Klein RS (1998): Mucosal candidal colonization and 
candidiasis in women with or at risk for human immunodeficiency virus infection. HIV Epidemiology Research Study (HERS) Group. Clin Infect Dis 27(5), 1161-1167.

Schüpbach J: Human Immunodeficiency Viruses. In: Manual of clinical microbiology.

Eds.: B. E. Murray PR, Pfaller MA, Tenover FC, Yolken RH. 7th edition edn; American Society for Microbiology (ASM) press, Washington 1999, 847-870.

Scully C, Laskaris G, Pindborg J, Porter SR, Reichart P (1991): Oral manifestations of HIV infection and their management. I. More common lesions. Oral Surg Oral Med Oral Pathol 71(2), 158-166.

Sedgley CM, Samaranayake LP (1994): The oral prevalence of aerobic and facultatively anaerobic gram-negative rods and yeasts in Hong Kong Chinese. Arch Oral Biol $\underline{39}(6)$, 459-466.

Snydman DR (2003): Shifting patterns in the epidemiology of nosocomial Candida infections. Chest $\underline{123}(5 \mathrm{Suppl}), 500 \mathrm{~S}-503 \mathrm{~S}$.

Staib P, Morschhauser J (1999): Chlamydospore formation on Staib agar as a species-specific characteristic of Candida dubliniensis. Mycoses $\underline{42}(9-10)$, 521-524.

Sturtevant J (2000): Applications of differential-display reverse transcription-PCR to molecular pathogenesis and medical mycology. Clin Microbiol Rev $\underline{13}(3), 408-$ 427.

Sullivan DJ, Westerneng TJ, Haynes KA, Bennett DE, Coleman DC (1995): Candida dubliniensis sp. nov.: phenotypic and molecular characterization of a novel species associated with oral candidosis in HIV-infected individuals. Microbiology 141 ( Pt 7), 1507-1521.

Symmers WS (1965): Opportunistic Infections. The Concept of 'Opportunistic Infections'. Proc R Soc Med 58, 341-346.

Tarcin BG (2011): Oral candidosis: Aetiology, Clinical Manifestations, Diagnosis and Management. J Marmara Univ Inst of Health Sci 1 (2), 140-148.

Tavitian A, Raufman JP, Rosenthal LE (1986): Oral candidiasis as a marker for esophageal candidiasis in the acquired immunodeficiency syndrome. Ann Intern Med 104(1), 54-55.

Thompson GR 3rd, Patel PK, Kirkpatrick WR, Westbrook SD, Berg D, Erlandsen J, Redding SW, Patterson TF (2010): Oropharyngeal candidiasis in the era of 
antiretroviral therapy. Oral Surg Oral Med Oral Pathol Oral Radiol Endod 109(4), 488-495.

Tirwomwe JF, Rwenyonyi CM, Muwazi LM, Besigye B, Mboli F (2007): Oral manifestations of HIV/AIDS in clients attending TASO clinics in Uganda. Clin Oral Investig 11(3), 289-292.

Umadevi KM, Ranganathan K, Pavithra S, Hemalatha R, Saraswathi TR, Kumarasamy N, Solomon S, Greenspan JS (2007): Oral lesions among persons with HIV disease with and without highly active antiretroviral therapy in southern India. J Oral Pathol Med $\underline{36}(3), 136-141$.

UNAIDS (2006): overview on the global AIDS epidemic 2006. Retrieved 15.06.14, from http://data.unaids.org/pub/globalreport/2006/2006 gr ch02 en.pdf

UNAIDS (2007): AIDS epidemic update. Retrieved 15.06.14, from http://data.unaids .org/pub/epislides/2007/2007 epiupdate en.pdf

UNAIDS (2009): AIDS epidemic update. Retrieved 15.06.14, from http://data.unaids .org/pub/report/2009/jc1700 epi update 2009 en.pdf.

UNAIDS (2010): report on the global AIDs epidemic 2010. Retrieved 15.06.14, from http://www.unaids.org/documents/20101123 GlobalReport em.pdf.

UNAIDS (2013): UNAIDS Report on the Global AIDS epidemic. Retrieved 20.03.2015, from http://www.unaids.org/en/resources/campaigns/globalreport 2013/globalreport.

UNDP (2013): Human development report. Retrieved 15.06.14, from http://hdr.undp .org/sites/default/files/reports/14/hdr2013 en complete.pdf.

UNESCO (2012): Adult and youth literacy 1999-2015. Analysis of data for 41 selected countries. Retrieved 20.03.15, from http://www.uis.unesco.org/Fact Sheets/Pages/ Literacy.aspx.

UNGASS (2008): UNGASS 2008: Country progress reports. Retrieved 15.06.14, from http://www.unaids.org/en/Resources/PressCentre/Featurestories/2008/ January/20080204UNGASS2008CPR/.

Vargas KG, Joly S (2002): Carriage frequency, intensity of carriage, and strains of oral yeast species vary in the progression to oral candidiasis in human immunodeficiency virus-positive individuals. Journal of clinical microbiology $\underline{40}(2), 341-350$. 
Wanzala P, Manji F, Pindborg JJ, Plummer F (1989): Low prevalence of oral mucosal lesions in HIV-1 seropositive African women. J Oral Pathol Med 18(7), 416418.

WHO (2006): Antiretroviral therapy for HIV infection in adults and adolescents: Recommendations for a public health approach. Retrieved 20.06.14, from http://www.who.int/hiv/pub/guidelines/artadultguidelines.pdf?ua=1.

WHO (2007): WHO Case Definitions of HIV for Surveillance and Revised Clinical Staging and Immunological Classification of HIV-Related Disease in Adults and Children. Retrieved 20.06.14, from http://www.who.int/hiv/pub/guidelines/ HIVstaging150307.pdf

WHO (2010): World health statistics. Retrieved 20.06.14, from http://www.who.int/ whosis/whostat/EN WHS10 Full.pdf.

WHOPAR (2011): Patient Information leaflet: Triomune 30. Retrieved 20.06.14, from http://apps.who.int/prequal/whopar/whoparproducts/HA267part3v1.pdf.

Williams AB (1997): New horizons: antiretroviral therapy in 1997. J Assoc Nurses AIDS Care $\underline{8}(4), 26-38$.

Williams D and Lewis M (2011): Pathogenesis and treatment of oral candidosis. J Oral Microbiol $\underline{3}$.

Witzel AL, Silveira FR, Pires Mde F, Lotufo MA (2008): Oral candidiasis in HIV+ patients under treatment with protease inhibitors. Braz Oral Res 22(4), 371377.

WMA (2013): WMA Declaration of Helsinki - Ethical Principles for Medical Research Involving Human Subjects. Retrieved 20.06.14, from www.wma.net/en/ 30publications/10policies/b3/index.html.

Wu CJ, Lee HC, Yang YL, Chang CM, Chen HT, Lin CC, Lee NY, Chu WL, Hsieh LY, Wang YL et al. (2011): Oropharyngeal yeast colonization in HIV-infected outpatients in southern Taiwan: CD4 count, efavirenz therapy and intravenous drug use matter. Clin Microbiol Infect.

Wu T, Samaranayake LP, Cao BY, Wang J (1996): In-vitro proteinase production by oral Candida albicans isolates from individuals with and without HIV infection and its attenuation by antimycotic agents. J Med Microbiol 44(4), 311-316.

Xu J and Mitchell TG (2003): Geographical differences in human oral yeast flora. Clin Infect Dis $\underline{36}(2), 221-224$. 
Yang YL, Lo HJ, Hung CC, Li Y (2006): Effect of prolonged HAART on oral colonization with Candida and candidiasis. BMC Infect Dis $\underline{6}, 8$.

Yang YL, Leaw SN, Wang AH, Chen HT, Cheng WT, Lo HJ (2011): Characterization of yeasts colonizing in healthy individuals. Med Mycol $\underline{49}(1), 103-106$. 


\section{Acknowledgments}

I would like to thank to all those who have accompanied me during the time from the beginning until the successful completion of this work:

Professor Dr. Uwe Groß for the proposal of the subject, the providing of the contact in Chad and the opportunity to perform this work in the Department of Medical Microbiology of the University Medical Center Göttingen. Special thanks to him for his constant presence and availability for questions and constructive discussions.

Dr. Oliver Bader for his excellent assistance and supervision of the different steps of work towards the fulfillment of this scientific work.

Miss Kellner with coworkers, who have shown and taught me the practice of species differentiation and Mister Schaldt, wo has taught me how to produce the Sabouraud agar plates.

Misses Hanne Fleischmann from the Missionsärztliches Institut Würzburg, Germany, for helping in organizing the trip and the transportation of working material to make the work in Maingara, Chad possible.

Dr. Lydia Kersch for her great constant moral and professional medical support and accompaniment during the data collection in Maingara, Sarh, Chad.

All the patients who have given their consent to participate in this study and all the translators and nurses for their great commitment that has enormously helped in succeeding with the uptake of the data and history of the patients. 